\title{
Guía de aprendizaje Dreamweaver CS4
}

Autor: Carlos Casado Martínez

Coordinación: César Pablo Córcoles Briongos 


\section{Índice de tutoriales}

0. Introducción

1. Crear una página web para alquilar un apartamento

2. Mejorando la presentación

3. Crear un sitio

4. Añadir fotografías y enlaces a lugares de interés

5. Catálogo de apartamentos

6. Temporadas y precios

7. Crear una página de contacto 


\section{Introducción}

Adobe ${ }^{\circledR}$ Dreamweaver ${ }^{\circledR}$ es una potente aplicación de creación y edición de páginas web. Su interfaz permite trabajar tanto con una visión WYSIWYG (vista de diseño) como editar directamente el código HTML (vista de código) y facilita su uso tanto a personas que no tienen conocimientos de HTML como a expertos diseñadores web.

$$
\checkmark \text { Código } \triangle \text { Dividir } \leftrightarrows \text { Diseño }
$$

En esta guía vamos a ver cómo se realiza una página web; empezaremos desde el principio y añadiremos poco a poco diferentes elementos. Usaremos Dreamweaver como un editor completo, aprovechando sus opciones de edición, aunque dejaremos de lado algunas potentes herramientas que incorpora, como la de gestión de bases de datos. Veremos cómo, a pesar de que el editor WYSIWYG es muy potente, nos irá bien usar la vista de código para algunas opciones. También veremos cómo usar CSS en nuestras páginas sin necesidad de recordar los nombres de los diferentes atributos que podemos modificar.

Dreamweaver nos ayudará a crear páginas web válidas y accesibles. Además, desde la vista de diseño podremos disponer capas, aplicar estilos, cambiar propiedades,... Sin embargo, en muchos casos será necesario revisar lo que hagamos desde la vista de código (¡no todo se puede hacer desde la vista de diseño!).

A pesar de que esta es una guía de Dreamweaver (o precisamente por ello) vamos a incidir mucho en la necesidad de validar el código y en que las páginas sean accesibles. A lo largo de esta guía usaremos a menudo las herramientas que Dreamweaver pone a nuestra disposición para esta labor. 


\section{Introducción}

Para avanzar por la guía vamos a crear un sitio web sencillo: empezaremos por una página para alquilar un apartamento en un lugar de veraneo y acabaremos con todo un sitio pensado para alquilar varios apartamentos. Daremos todos los pasos necesarios para, empezando desde cero, crear toda la web usando los diferentes recursos que nos permiten utilizar XHTML y CSS

Como codificación, usaremos XHTML 1.0 Transitional.

Esta guía presupone que el usuario tiene buenos conocimientos de estándares web. Es un "detalle" importante, pues aquí no se explicarán, y, en algunos casos, podría quedar coja la explicación si no se tienen los conocimientos necesarios. 


\section{Créditos}

Grado y Máster en Multimedia (GMMD)

http://multimedia.uoc.edu/guias

\section{Coordinación}

César Pablo Córcoles Briongos

\section{Autoría}

Carlos Casado Martínez

Fecha de publicación

13.09.2009

PID_00147023 www.uoc.edu
Estudios de Informática, Multimedia y Telecomunicación 
Tutorial 1. Crear una página web para alquilar un apartamento

\section{Desarrollo del tutorial: paso 1 de 17}

Vamos a crear una sencilla página web con un poco de texto y algunas imágenes, pensada para alquilar un apartamento en Menorca. Es un primer ejercicio donde veremos cómo empezar a usar Dreamweaver. Normalmente, no haremos webs de una sola página, pero ahora nos servirá para familiarizarnos con el entorno y empezar a ver cómo se usa el programa.

Una vez abrimos Dreamweaver, en la barra de título y a la izquierda de la caja de búsqueda, encontramos un desplegable que nos permitirá seleccionar un estilo de espacio de trabajo predeterminado.

Para seguir esta guía, lo más útil será seleccionar la vista de Diseñador, que nos muestra una barra lateral, con los estilos y los archivos del sitio, y una inferior, con las propiedades del elemento que tenemos seleccionado.

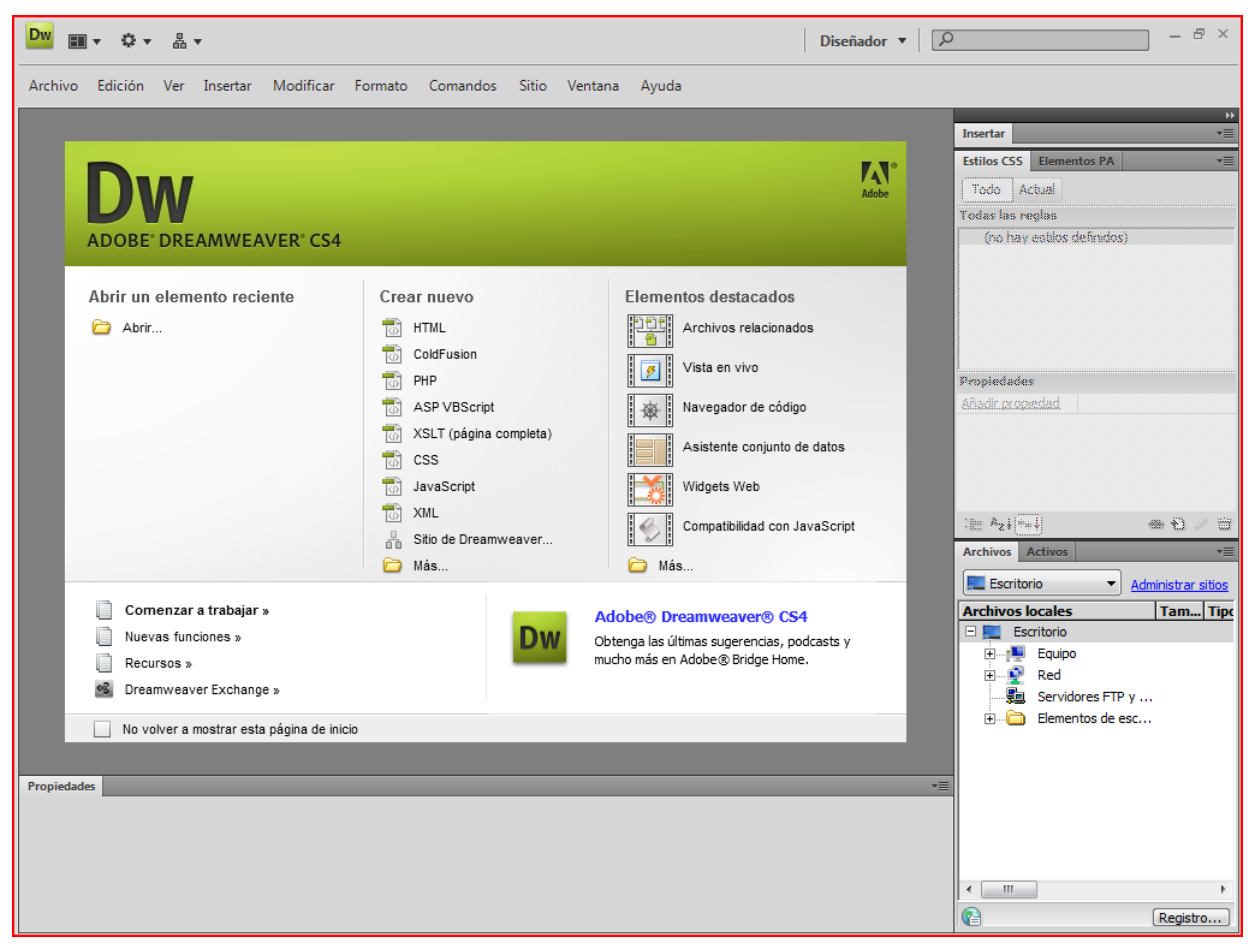

Diseñador 
Tutorial 1. Crear una página web para alquilar un apartamento

\section{Desarrollo del tutorial: paso 2 de 17}

\begin{tabular}{|c|c|}
\hline $\begin{array}{l}\text { Abrir un elemento reciente } \\
\square \text { Abrir... }\end{array}$ & 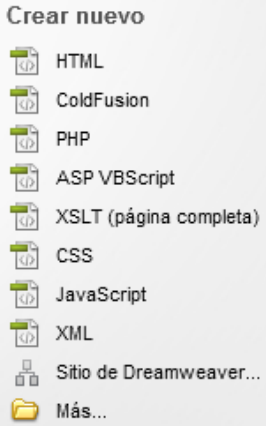 \\
\hline
\end{tabular}

Vamos a crear un nuevo documento donde haremos nuestra primera página. Para ello, en el menú seleccionamos Archivo - Nuevo... y en la ventana que aparece seleccionamos HTML.

También podemos hacer clic en Crear nuevo HTML de la ventana de presentación de Dreamweaver.

Por defecto, Dreamweaver presenta la vista de diseño, con lo que se nos presentará una pantalla en blanco. Sin embargo, es interesante ver qué ha puesto Dreamweaver en esta página inicial.

Para ello seleccionaremos la vista de Código y veremos lo que aparece en la imagen de la derecha.

En total, Dreamweaver ha escrito nueve líneas de código (nótese que hay una partida en dos).

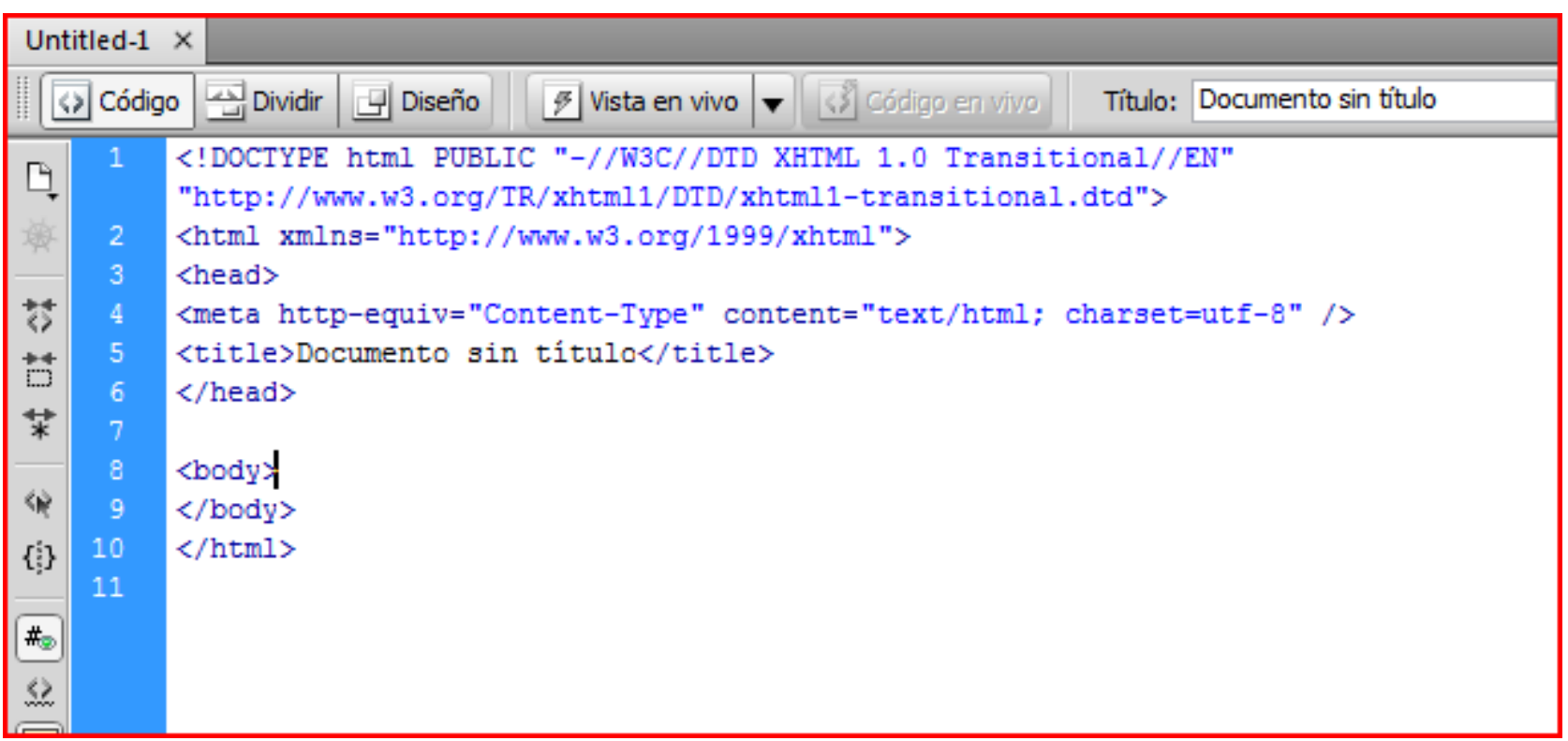


Tutorial 1. Crear una página web para alquilar un apartamento

Desarrollo del tutorial: paso 3 de 17

A pesar de que ya deberíamos saber qué significa lo que aparece en la vista de código, conviene repasarlo brevemente.
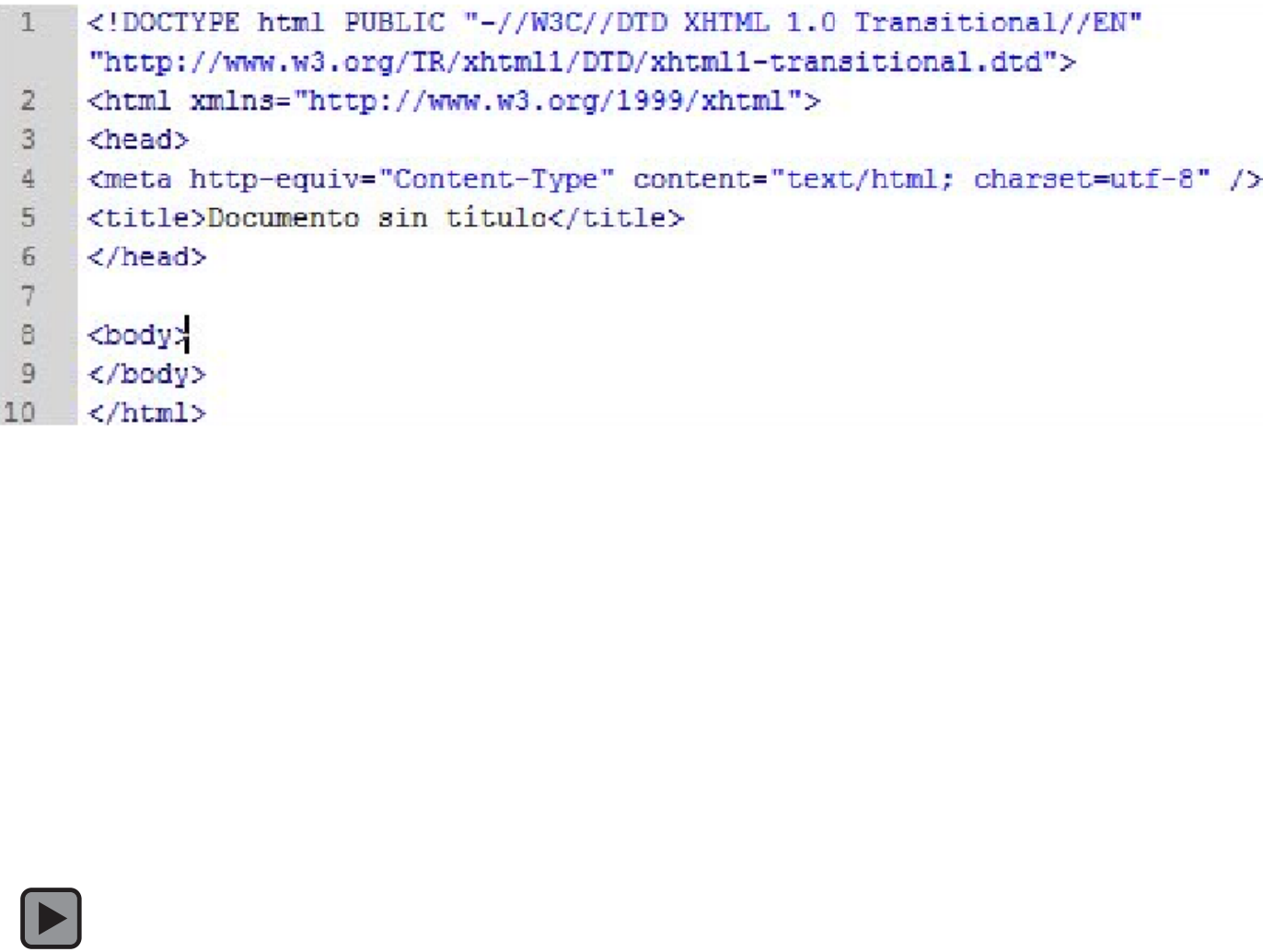


\section{Tutorial 1. Crear una página web para alquilar un apartamento}

\section{Desarrollo del tutorial: paso 4 de 17}

Una vez hemos creado el nuevo documento, podemos configurar unos parámetros que afectarán al conjunto de la página. Esos parámetros los podemos modificar en el menú Modificar-Propiedades de la página.

Las cuatro categorías iniciales nos permiten modificar el aspecto general de la página. Como especificaremos el diseño de la página desde un archivo CSS, nos saltamos esas categorías para centrarnos en la de Título-Codificación.

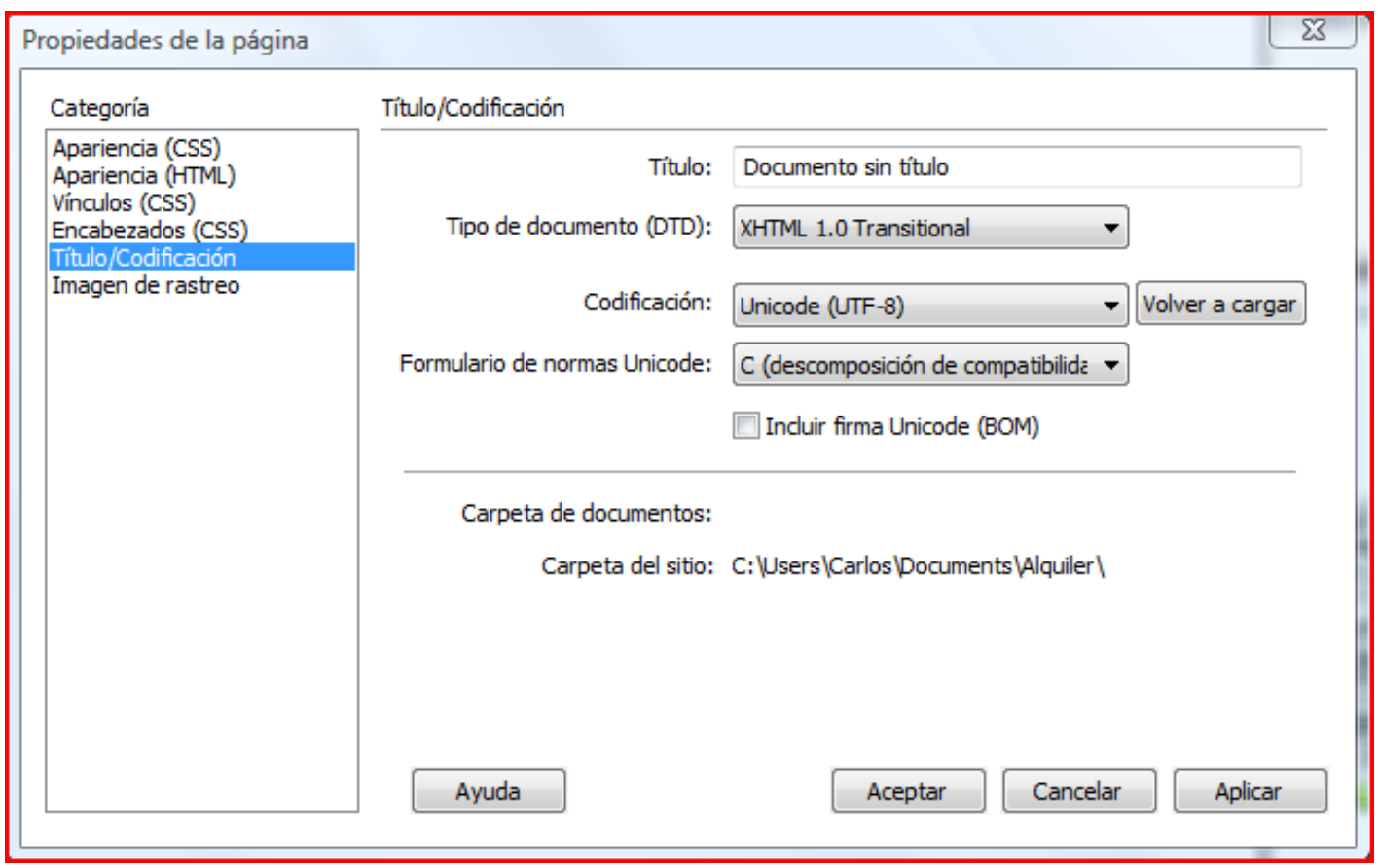

Fijémonos en las diferentes opciones:

Título: Es el texto que aparece en la pestaña donde está abierta la página.

DTD: Indica qué versión del lenguaje de etiquetado usaremos. Dreamweaver selecciona por defecto XHTML 1.0 transicional, que como hemos dicho ya nos irá bien. Podría interesarnos, también, HTML 4.01 o, en un futuro, HTML5. Sea cual sea la versión que queramos usar, este es el lugar para indicarlo.

Codificación: Indica de qué manera se codifican los caracteres. UTF-8 suele ser una buena opción porque permite la codificación de cualquier carácter. Sin embargo, dependiendo del servidor, podría ser necesario usar la codificación "Europeo occidental" (ISO-8859-1).

Finalmente, en la categoría Imagen de rastreo podemos seleccionar una imagen, que se pondría como fondo, para que nos sirva de muestra a la hora de montar nuestra página. Esa imagen no aparecerá cuando publiquemos la página. 
Tutorial 1. Crear una página web para alquilar un apartamento

\section{Desarrollo del tutorial: paso 5 de 17}

Hay un paso que Dreamweaver no hace de forma automática pero es imprescindible: indicar el idioma principal de nuestra página web. Debemos hacerlo en la vista de código y ponerlo en la etiqueta $<\mathrm{html}>$.

Afortunadamente, Dreamweaver nos ayuda a hacerlo.

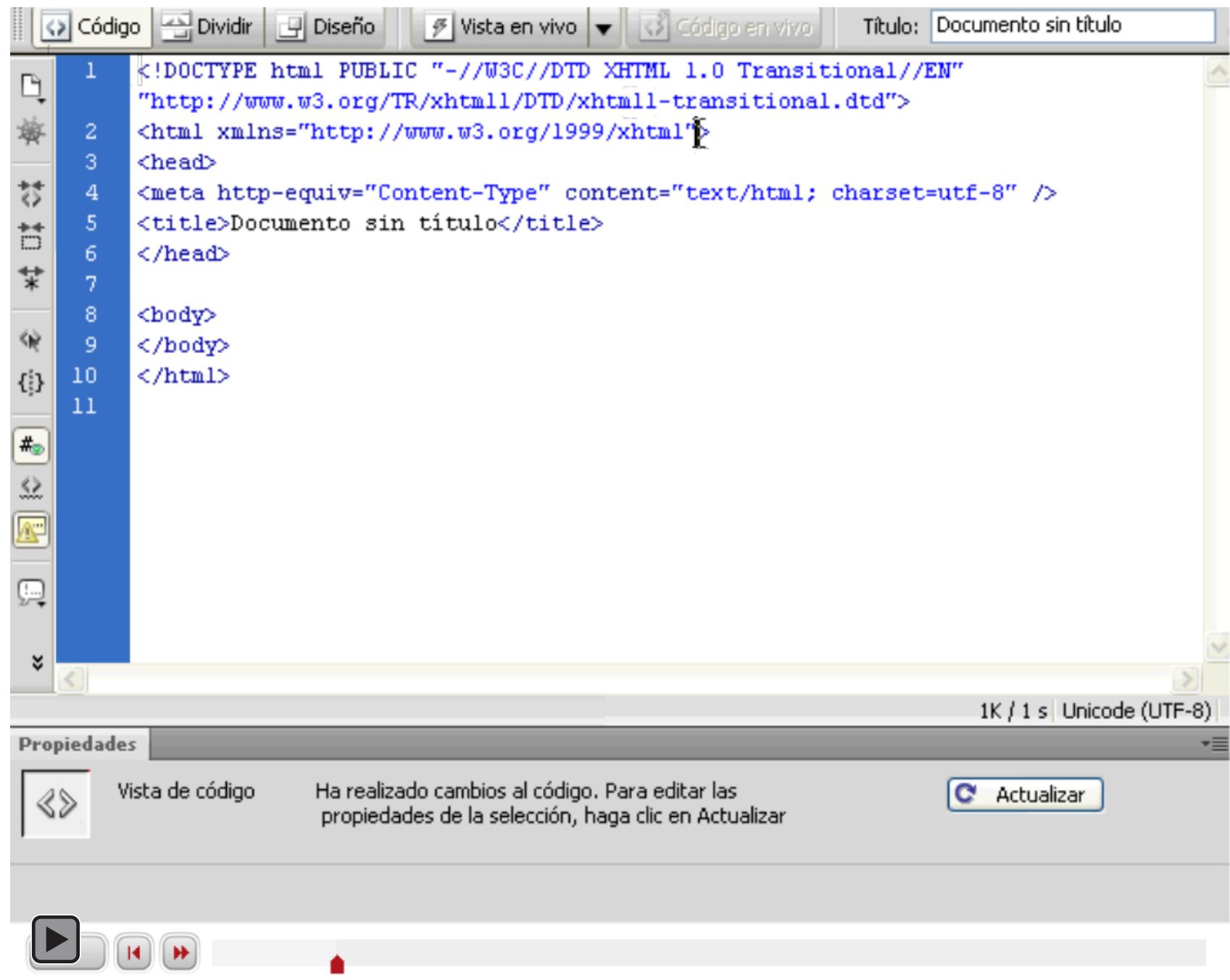


Tutorial 1. Crear una página web para alquilar un apartamento

\section{Desarrollo del tutorial: paso 6 de 17}

Vamos a acabar la preparación de nuestra página poniéndole el título a la misma. Esto lo podemos realizar en tres sitios diferentes:

- Directamente en el código, modificando el texto Documento sin título. Vimos cómo acceder al código de la página en un paso anterior.

- En el menú, en Modificar-Propiedades de la página, en la categoría Título-Codificación tenemos un campo llamado Título donde podemos modificar ese dato.

- Finalmente, en la barra de herramientas que aparece bajo el menú, tenemos también un cuadro de texto donde podemos modificar el título de nuestra página. Vamos a hacerlo aquí; vamos a poner "Alquiler de apartamento en Menorca".
Ahora ya estamos a punto de poder incluir contenido en nuestra página. Nos queda tan solo grabar la página con el nombre index.html.

¿Por qué index.html? index.html es el archivo que la mayoría de servidores carga por defecto cuando se accede a un sitio web.

\begin{tabular}{|c|c|c|c|c|c|c|c|c|}
\hline Archivo $\mathrm{E}$ & idición Ver & Insertar & Modificar & Formato & Comandos & Ventana & Ayuda & \\
\hline \multicolumn{9}{|c|}{ Untitled $-1^{*} \times$} \\
\hline (5) Código & Dividir & Diseño & 3) Vista e & n vivo $\mid \nabla$ & \$Y) Código en vivo & Título: $\cdot c$ & apartamento en Menorca ภิษ. & C 国、 \\
\hline
\end{tabular}


Tutorial 1. Crear una página web para alquilar un apartamento

\section{Desarrollo del tutorial: paso 7 de 17}

Ha llegado el momento de empezar a añadir contenido a nuestra página. Vamos a escribir un breve texto con la siguiente estructura:

Título principal: "Alquiler de apartamento en Menorca" Subtítulo: "Ubicación"

Subtítulo: "Características"

Además, bajo cada uno de los subtítulos pondremos un párrafo explicativo.
En "Ubicación": En Cala'n Bosch, a 100 metros de la playa de Son Xoriguer. Conjunto de apartamentos en bloques de 2 pisos de altura (planta baja más piso), con zona comunitaria con piscina.

En "Características": Apartamento en primer piso de 65 metros cuadrados totalmente equipado. Un cuarto de baño completo, cocina americana equipada con horno,

microondas, nevera y lavavajillas. Tres habitaciones, una de matrimonio y dos dobles.

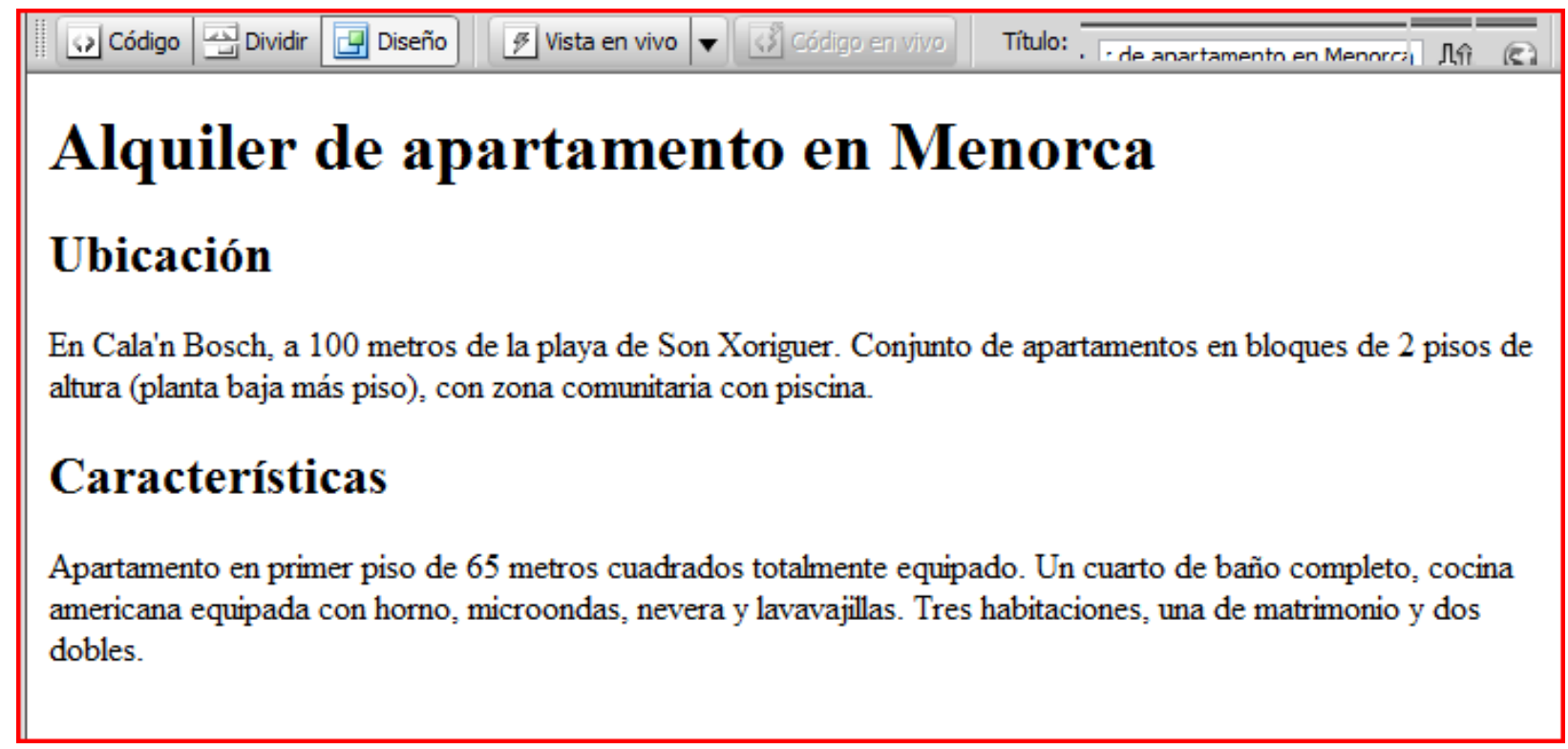


Tutorial 1. Crear una página web para alquilar un apartamento

Desarrollo del tutorial: paso 8 de 17

En Dreamweaver introduciremos

texto como si estuviésemos

trabajando con un procesador de

textos.

En la parte inferior de la pantalla tendremos la barra de herramientas de propiedades que nos facilitará la entrada de texto.

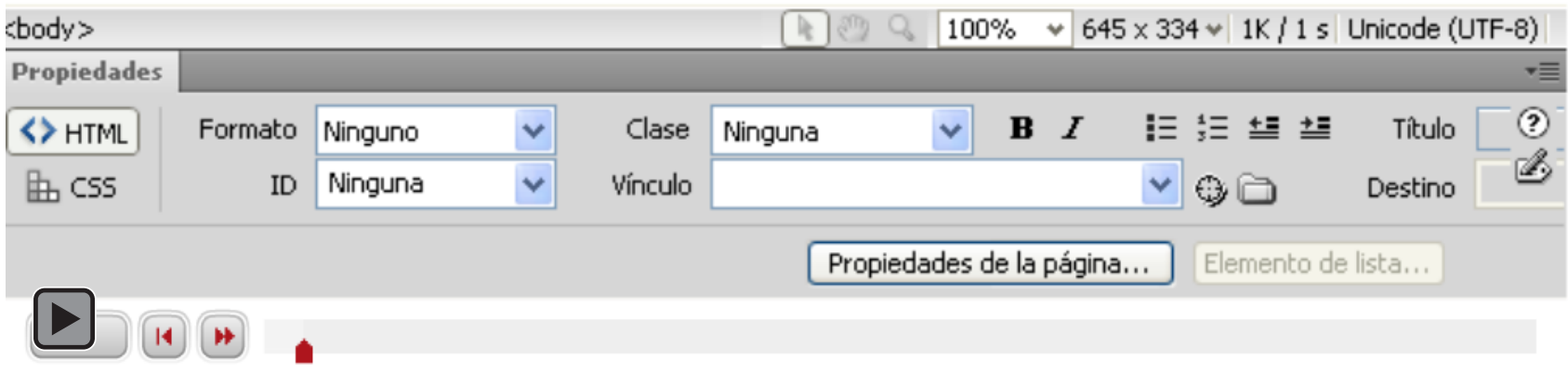


Tutorial 1. Crear una página web para alquilar un apartamento

\section{Desarrollo del tutorial: paso 9 de 17}

Antes de continuar, guardaremos de nuevo. Veamos cómo ha quedado el código (será necesario hacer clic en el botón Código):

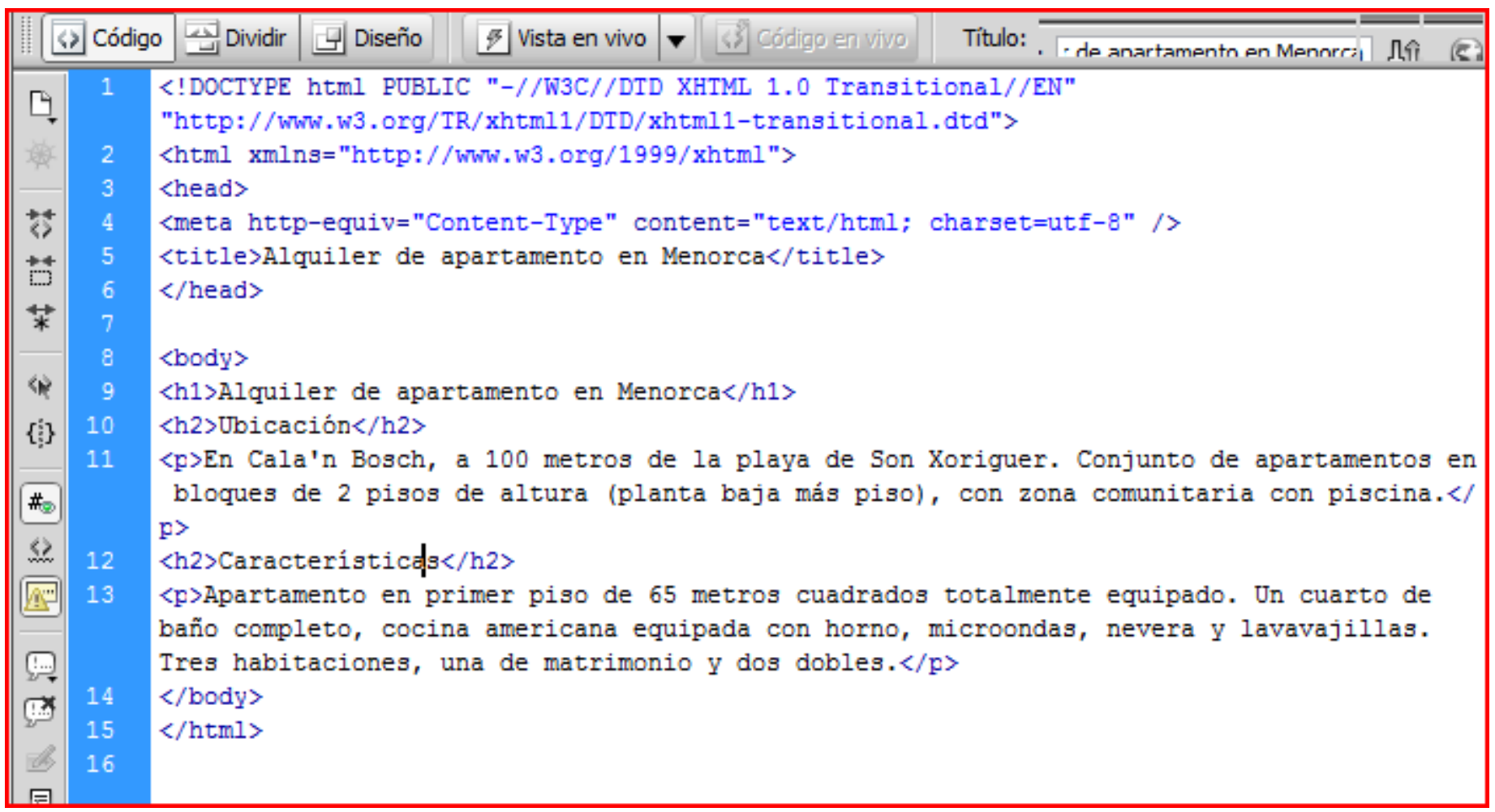

Aquí podemos ver cómo el Encabezado 1 se corresponde con la etiqueta $<$ h1 $>$, y el Encabezado 2 con la etiqueta $<$ h2 $>$. Además, aunque no lo habíamos especificado, todo el texto que no es encabezado ha quedado marcado dentro de etiquetas $\langle p\rangle$. 
Tutorial 1. Crear una página web para alquilar un apartamento

\section{Desarrollo del tutorial: paso 10 de 16}

Ahora que hemos escrito el texto, vamos a marcar aquellas palabras que sean más relevantes. Vamos a usar dos etiquetas, <strong $>\mathrm{y}<\mathrm{em}>$, que, por defecto, en pantalla aparecerán con negrita y cursiva respectivamente, pero cuyo significado vendría a ser "resaltado" y "enfatizado".

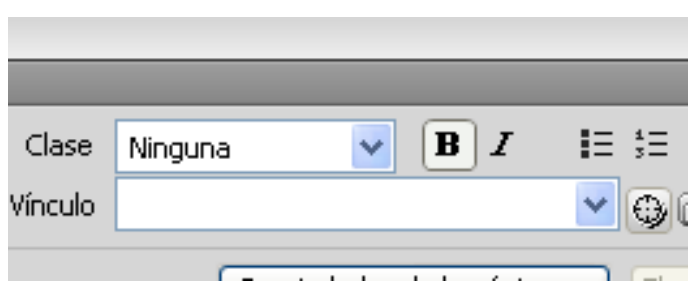

En el primer párrafo seleccionamos "playa de Son Xoriguer" y en la barra de propiedades apretamos el botón $\mathbf{b}$ (de bold, negrita).

En la pantalla (en la vista de diseño) veremos esto:

100 metros de la playa de Son Xoriguer. Conjunto d

Y si seleccionamos la vista de código, lo que veremos será esto:

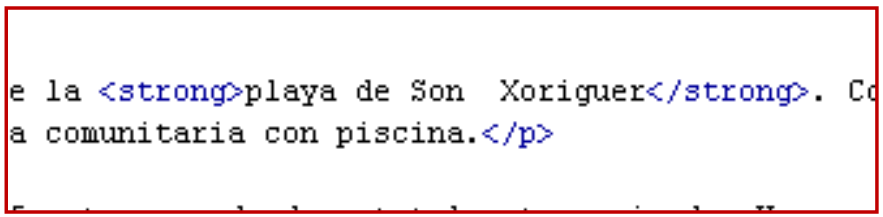

A pesar de la utilización de la inicial $\mathbf{b}$ como indicador de <strong > y de que la presentación en pantalla de esta etiqueta es un texto en negrita, esto no es obligatorio; lo importante es la carga semántica de la etiqueta. 
Tutorial 1. Crear una página web para alquilar un apartamento

Desarrollo del tutorial: paso 11 de 17

Hacemos lo mismo con la etiqueta $<$ em $>$.

\begin{tabular}{|c|c|c|c|c|c|}
\hline (a) Código & $\triangle$ Dividir & Diseño & 3 Vista en vivo & $\mathbf{\nabla}$ (3) Código en vivo & Título: de apartamento en Menorca \\
\hline
\end{tabular}

\section{Alquiler de apartamento en Menorca}

\section{Ubicación}

En Cala'n Bosch, a 100 metros de la playa de Son Xoriguer. Conjunto de apartamentos en bloques de 2 pisos de altura (planta baja más piso), contzona comunitaria con piscina.

\section{Características}

Apartamento en primer piso de 65 metros cuadrados totalmente equipado. Un cuarto de baño completo, cocina americana equipada con horno, microondas, nevera y lavavajillas. Tres habitaciones, una de matrimonio y dos dobles.

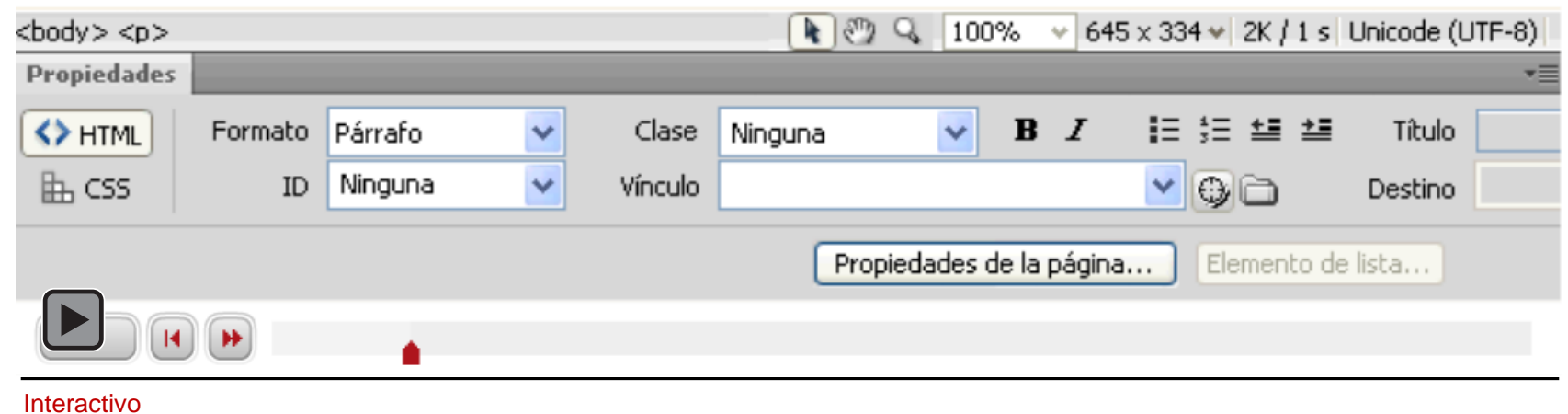


Tutorial 1. Crear una página web para alquilar un apartamento

Desarrollo del tutorial: paso 12 de 17

Dreamweaver nos indica al pie de la ventana las

características del contenido sobre el que se encuentra el cursor.

En la vista de diseño, puede ser muy útil ver qué etiquetas se encuentran activas en un punto dado.

\begin{tabular}{|c|c|c|c|c|c|c|c|}
\hline$\checkmark\rangle \mid$ Código & $\triangle$ Dividir & $\square$ Diseño & 3 Vista en vivo & $\nabla$ & इ3) Codigo en vivol & Título: & Alquiler de apartamento en $\mathrm{M}_{\mathrm{r}}$ \\
\hline
\end{tabular}

\section{Alquiler de apartamento en Menorca}

\section{Ubicación}

En Cala'n Bosch, a 100 metros de la playa de Son Xoriguer. Conjunto de apartamentos en bloques de 2 pisos de altura (planta baja más piso), con zona comunitaria con piscina.

\section{Características}

Apartamento en primer piso de 65 metros cuadrados totalmente equipado. Un cuarto de baño completo, cocina americana equipada con horno, microondas, nevera y lavavajillas. Tres habitaciones, una de matrimonio y dos dobles.

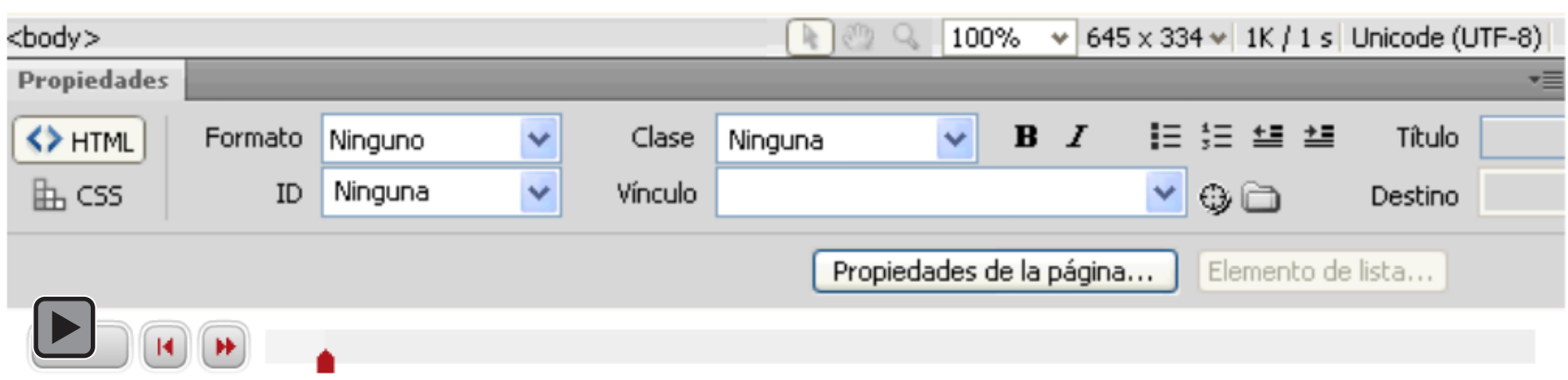


Tutorial 1. Crear una página web para alquilar un apartamento

\section{Desarrollo del tutorial: paso 13 de 17}

Tenemos en la página dos contenidos diferenciados: la ubicación y las características. Vamos a separarlos usando la etiqueta $<$ div $>$.

Para que la diferencia sea clara, a cada uno de ellos le asignaremos un identificador, ubicacion a uno y caracteristicas al otro (la falta de los acentos es intencionada).

El resultado es éste (vista código): <meta http-equiv="Content-Type" content="text/html; charset=utf- ${ }^{r r} />$ $\langle$ title>Alquiler de apartamento en Menorca</title>

$</$ heads

$\langle$ body $>$

$\langle$ hl $>$ Alquiler de apartamento en Menorca< $/ \mathrm{hl}\rangle$

$\langle$ div id="ubicacion">

$<$ h2> Jbicación</h2>

$<$ p $\gg$ En Cala'n Bosch, a 100 metros de la <strong $>$ playa de son Xoriguer $</ s t r o 1$ altura (planta baja más piso), con $\langle e m\rangle$ zona comunitaria con piscina $</ e m\rangle .</]$ $</$ div $>$

$\langle$ div id="caracteristicas">

$<$ h $2>$ Características $</ \mathrm{h} 2>$

<p>Apartamento en primer piso de 65 metros cuadrados totalmente equipado. 1 horno, microondas, nevera y lavavajillas. Tres habitaciones, una de matrim $</$ div $\rangle$

$</$ body $s$ 
Tutorial 1. Crear una página web para alquilar un apartamento

Desarrollo del tutorial: paso 14 de 17

Y éste en vista de diseño:

\begin{tabular}{|c|c|c|c|c|c|c|}
\hline ( ) Código & $\triangle$ Dividir & $\square$ Diseño & 3 Vista en vivo & $\nabla$ & 43) Código en vivo & Título: Alquiler de apartamento en $\mathrm{M}$ \\
\hline
\end{tabular}

\section{Alquiler de apartamento en Menorca}

\section{Ubicación}

En Cala'n Bosch, a 100 metros de la playa de SonlXoriguer. Conjunto de apartamentos en bloques de 2 pisos de altura (planta baja más piso), con zona comunitaria con piscina.

\section{Características}

Apartamento en primer piso de 65 metros cuadrados totalmente equipado. Un cuarto de baño completo, cocina americana equipada con homo, microondas, nevera y lavavajllas. Tres habitaciones, una de matrimonio y dos dobles. 
Tutorial 1. Crear una página web para alquilar un apartamento

\section{Desarrollo del tutorial: paso 15 de 17}

Ahora estamos en condiciones de ver nuestra página en un navegador.

En la pestaña donde aparece el nombre del archivo, podemos ver que tiene un asterisco a su derecha.

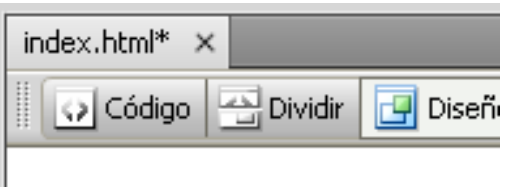

El asterisco en el nombre del archivo indica que el archivo ha sido modificado desde la última vez que se guardó.

\section{Guardamos (<Ctrl>+s) y} pulsamos la tecla F12. Al hacer esto, se abrirá nuestro navegador principal y mostrará la página.

\begin{tabular}{|c|c|c|}
\hline \multicolumn{2}{|c|}{ (3) Alquiler de apartamento en Menorca - Mozilla Firefox } & $-\square \times$ \\
\hline \multicolumn{3}{|c|}{ Archivo Editar Ver Historial Marcadores Herramientas Ayunda } \\
\hline$(<)>$ C $>$ B & 'C:/Documents and Settings/UOC/Mis documentos/Älquiler/index.h th & $\rho$ \\
\hline \multicolumn{3}{|c|}{ D. Más visitados $\square$ Comenzar a usar Firef... Siltimas noticias } \\
\hline Alquiler de apartamento en Menorca & + & 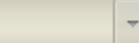 \\
\hline
\end{tabular}

\section{Alquiler de apartamento en Menorca}

\section{Ubicación}

En Cala'n Bosch, a 100 metros de la playa de Son Xoriguer. Conjunto de apartamentos en bloques de 2 pisos de altura (planta baja más piso), con zona comunitaria con piscina.

\section{Características}

Apartamento en primer piso de 65 metros cuadrados totalmente equipado. Un cuarto de baño completo, cocina americana equipada con horno, microondas, nevera y lavavajillas. Tres habitaciones, una de matrimonio y dos dobles.

Terminado 
Tutorial 1. Crear una página web para alquilar un apartamento

\section{Desarrollo del tutorial: paso 16 de 17}

Como hemos visto en el paso anterior, en este caso el navegador

predeterminado es Firefox. Con Dreamweaver podemos definir dos navegadores para ver una presentación preliminar de nuestras páginas. El principal es accesible con F12, y el secundario, con CTRL+F12.

Podemos definir qué navegadores queremos usar para la presentación preliminar en el menú, Edición-Preferencias, categoría Vista previa en el navegador.

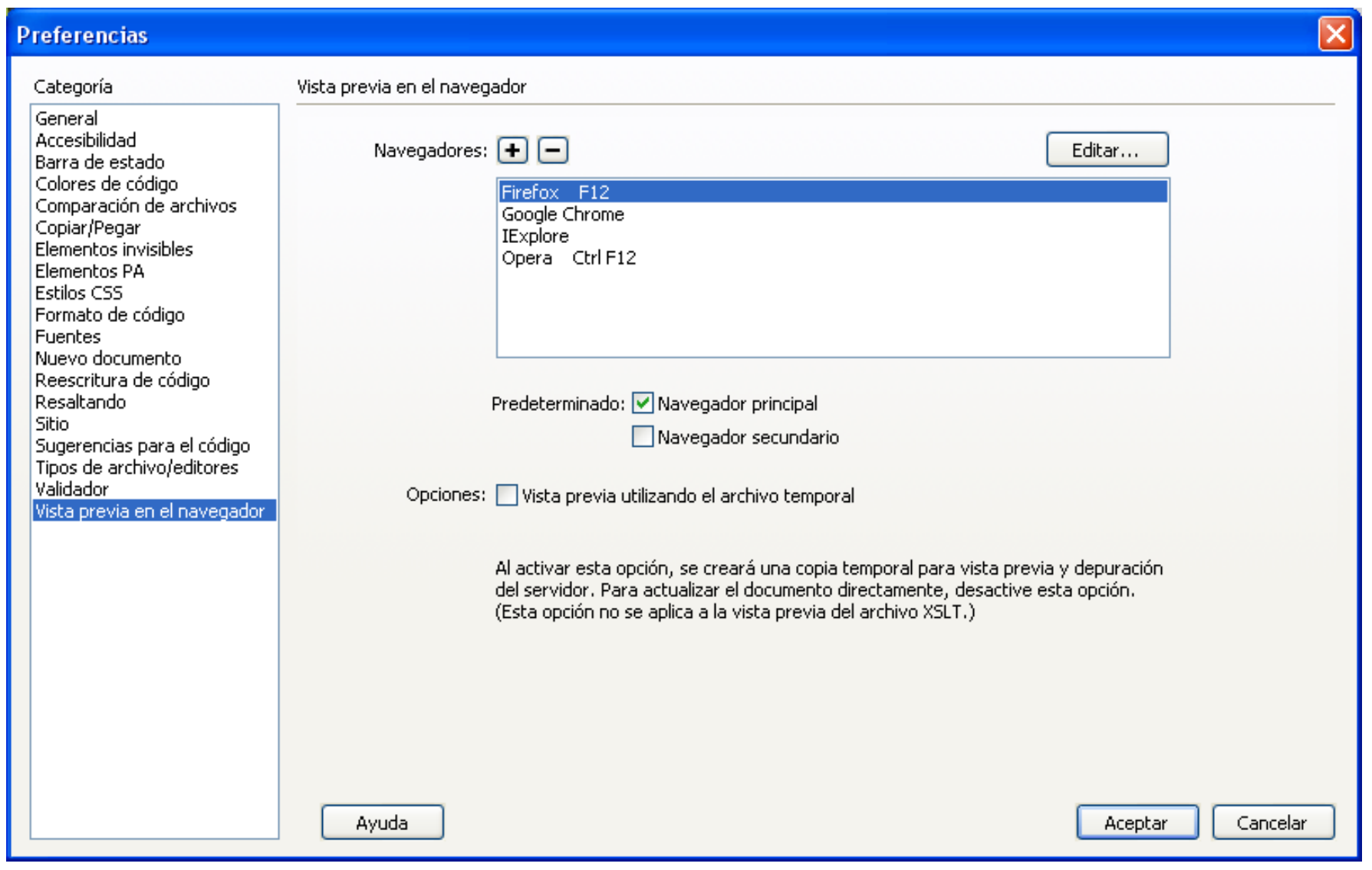


Tutorial 1. Crear una página web para alquilar un apartamento

Desarrollo del tutorial: paso 17 de 17

Para asentar los conceptos desarrollados en este tutorial, se recomienda hacer la siguiente actividad.

Cread una nueva página web, cuyo título será "Crear y mantener una página web", que tendrá el siguiente texto:

\section{Introducción}

A mediados de los años 90, para crear una página web necesitábamos tener algunos conocimientos de HTML, un espacio donde alojarla, un cliente ftp y mucho tiempo para mantenerla. Y, sin embargo, GeoCities, un servicio gratuito de alojamiento, albergaba innumerables webs. Muchas personas tenían cuestiones que explicar y GeoCities ofrecía un espacio donde hacerlo.

\section{Creando una web sencilla}

Así, cuando la página no pretende más que ofrecer una información puntual que no debe cambiar, puede ser interesante usar opciones sencillas, y a priori menos costosas que los sistemas de gestión de contenidos. 


\section{Tutorial 2. Mejorando la presentación}

\section{Desarrollo del tutorial: paso 1 de 18}

Nuestra página no tiene un gran aspecto. Las características por defecto de HTML no son muy vistosas, por lo que, seguramente, nos convendrá cambiarlas.

Para mejorar la presentación usaremos CSS. Podemos hacerlo de tres maneras diferentes:

- directamente sobre un elemento determinado (estilo en línea), - definiendo reglas CSS en la página que estamos editando, - definiendo las reglas CSS en un archivo aparte.

Para empezar vamos a ver la opción menos recomendable: la definición de un estilo en línea.

En este ejemplo, hemos puesto un texto de color rojo y en negrita. ¿Qué diferencia hay entre esta negrita y la que usamos en el tutorial anterior?

\section{Alquiler de apartamento en Menorca}

\section{Ubicación}

En Cala'n Bosch, a 100 metros de la playa de Son Xoriguer. Conjunto de apartamentos en bloques ide 2 pisos de altura (planta baja más piso), con zona comunitaria con piscina.

\section{Características}

Apartamento en primer piso de 5 metros cuadrados totalmente equipado. Un cuarto de baño completo, cocina americana equipada con horno, microondas, nevera y lavavajillas. Tres habitaciones, una de matrimonio y dos dobles.

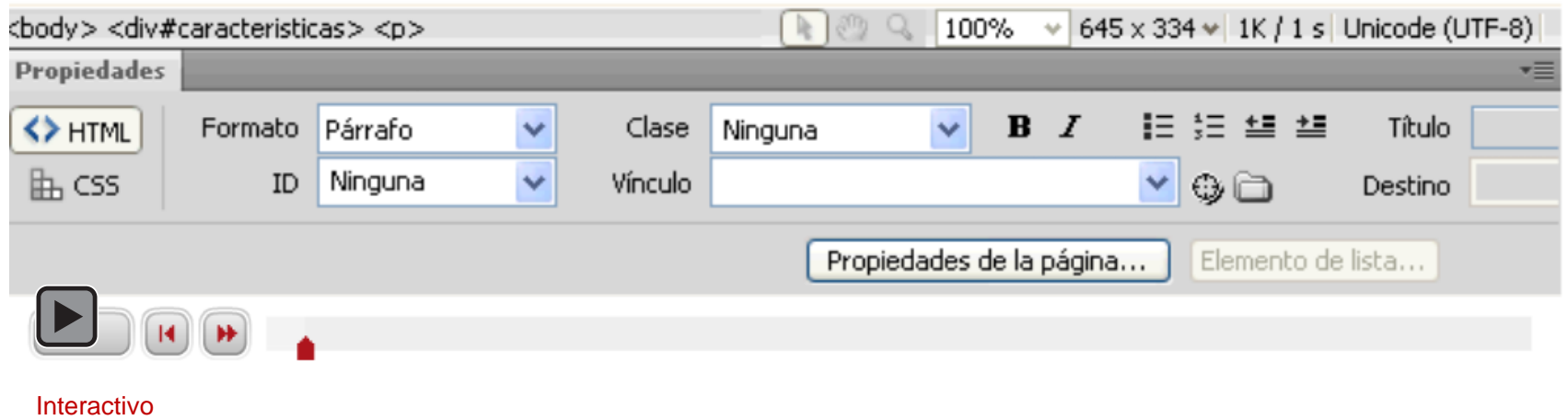




\section{Tutorial 2. Mejorando la presentación}

\section{Desarrollo del tutorial: paso 2 de 18}

Hemos visto cómo crear un estilo en línea, pero también hemos comentado que es la peor opción posible. ¿Por qué? Porque si necesitamos hacer cambios en la página tendremos que revisar todas las páginas de nuestro sitio buscando los estilos en línea.

En el paso anterior hemos seleccionado un estilo en línea. En el siguiente paso veremos la opción habitualmente más recomendable: guardar los estilos en un archivo CSS.

Existe un paso intermedio que nos puede ser útil cuando estamos haciendo una sola página: Crear los estilos en la página. En Dreamweaver, al crear una nueva regla CSS, se nos pregunta dónde se va a definir la regla (en la parte inferior del cuadro de diálogo). Tal como está seleccionado en la imagen de la derecha, la regla se crearía en el documento HTML. En el siguiente paso veremos que, seleccionando Nuevo archivo de hoja de estilos, las reglas CSS se guardan en un archivo aparte, con extensión .css.

\section{Definición de regla:}

Elija dónde se va a definir la regla.

$$
\text { (Nuevo archivo de hoja de estilos) }
$$

\section{Nueva regla CSS}

Tipo de selector:

Elija un tipo de selector contextual para la regla CSS.

$$
\text { Clase (puede ser aplicable a cualquier elemento HTMI } \checkmark
$$

Nombre del selector:

Elija o introduzca un nombre para el selector.

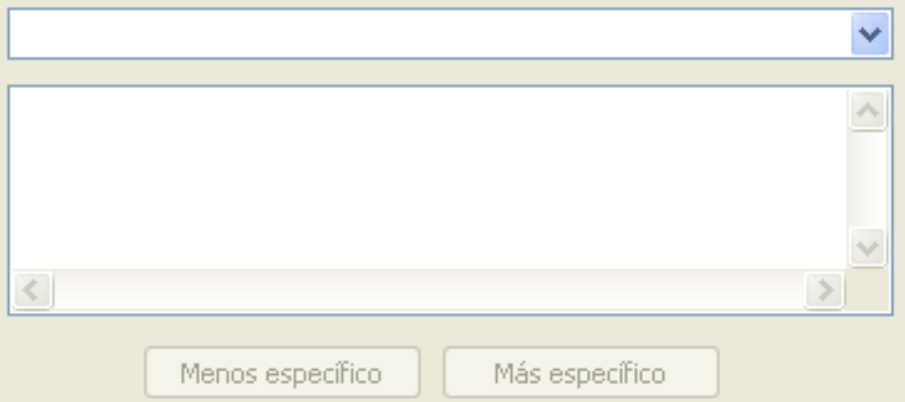

Definición de regla:

Elija dónde se va a definir la regla.

$$
\text { (Sólo este documento) }
$$


Tutorial 2. Mejorando la presentación

\title{
Desarrollo del tutorial: paso 3 de 18
}

Tal y como hemos visto en el paso a código lavidr anterior, la mejor opción para trabajar con estilos es guardar un conjunto de reglas CSS en un archivo externo que nos servirá para todas las páginas de nuestro sitio. De esta manera, si necesitamos realizar algún cambio, basta con modificar el archivo de las reglas CSS (o archivo CSS) para transformar todas nuestras páginas.

Vamos a eliminar el estilo en línea que habíamos creado en el paso 1 y a crear un archivo CSS donde guardar una regla que nos permita poner un texto en rojo y negrita.

\section{Alquiler de apartamento en Menorca}

\author{
Ubicación \\ En Cala'n Bosch, a 1 Seleccionamos la visión de código para eliminar el tamentos en bloques \\ ide 2 pisos de altura l código que habiamos introducido antes.

\section{Características} \\ Apartamento en primer piso de 65 metros cuadrados totalmente equipado. Un cuarto de baño \\ completo, cocina americana equipatida con horno, microondas, nevera y lavavajillas. Tres habitaciones, \\ una de matrimonio y dos dobles.
}






\section{Tutorial 2. Mejorando la presentación}

\section{Desarrollo del tutorial: paso 4 de 18}

Vamos a cambiar ahora los estilos de los diferentes elementos de la página para mejorar su presentación. Teniendo en pantalla la vista de diseño de nuestra página web, pulsamos $<$ May $>+F 11$ para visualizar la barra de Estilos CSS, seleccionamos Todo para ver los estilos que tenemos definidos.

\begin{tabular}{|c|}
\hline \multicolumn{2}{|c|}{ Estilos CSS Elementos PA } \\
\hline Todo Actual \\
\hline Todas las reglas \\
\hline estilos.css \\
-resaltado \\
\hline
\end{tabular}

Para crear un nuevo estilo, hacemos clic con el botón derecho del ratón en la barra de herramientas de Estilos CSS y seleccionamos Nuevo. Nos aparecerá el cuadro de diálogo de nueva regla CSS, y allí seleccionaremos crear una regla para una etiqueta, que será <body $>$, que se definirá en el archivo estilos.css.

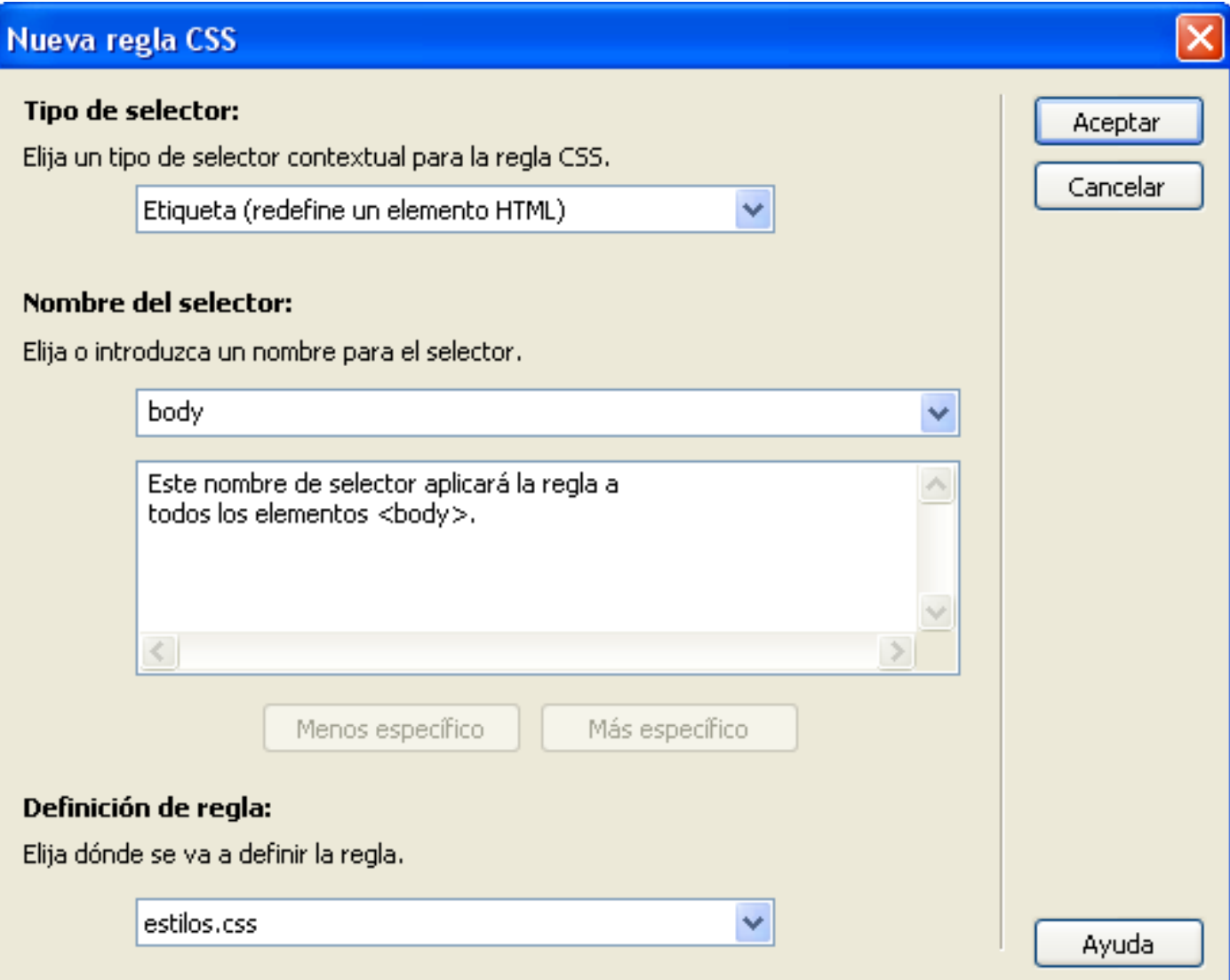




\section{Tutorial 2. Mejorando la presentación}

\section{Desarrollo del tutorial: paso 5 de 18}

En la etiqueta $<$ body $>$ vamos a definir las características generales del texto, el tipo de letra, y el tamaño y color que tendrá por defecto, y el color del fondo:

- En la categoría Tipo seleccionamos la Font-family que será Verdana, Geneva, sans-serif y el color \#333.

- En la categoría Fondo cambiamos el Background-color a \#D6E1E2.

Aceptamos, y el archivo estilos.css se actualizará automáticamente (y aparecerá un asterisco junto a su nombre, puesto que estará pendiente de ser guardado). Si miramos qué hay en ese archivo, veremos lo siguiente:

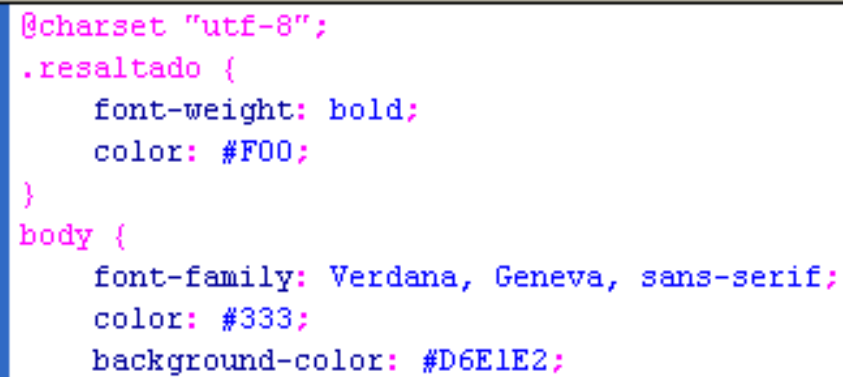

Alquiler de apartamento en Menorca

\section{Alquiler de apartamento en Menorca}

\section{Ubicación}

En Cala'n Bosch, a 100 metros de la playa de Son Xoriguer. Conjunto de apartamentos en bloques de 2 pisos de altura (planta baja más piso), con zona comunitaria con piscina.

\section{Características}

Apartamento en primer piso de 65 metros cuadrados totalmente equipado. Un cuarto de baño completo, cocina americana equipada con horno, microondas, nevera y lavavajillas. Tres habitaciones, una de matrimonio y dos dobles.

Si con F12 hacemos una vista previa en nuestro navegador, podremos apreciar las diferencia con lo que teníamos antes. El texto resaltado no ha cambiado, a pesar de que la manera de indicarle el estilo ha variado considerablemente. Por otra parte, al haber cambiado las características del texto en la etiqueta <body>, todo el texto de la página ha cambiado, modificándose el color (aunque al ser un gris oscuro apenas se aprecia) y la tipografía (antes era una tipografía tipo serif y ahora es sin serif).

Un detalle a tener en cuenta: en la captura de pantalla que hay sobre estas líneas, puede dar la sensación de que varía el color del texto entre los títulos y los párrafos, pero no es así. El cambio se debe al grosor del texto, ya que el color es el mismo para todo el texto (¡menos para el resaltado!). Se puede comprobar cambiando el color del texto a azul, por ejemplo. 


\section{Tutorial 2. Mejorando la presentación}

\section{Desarrollo del tutorial: paso 6 de 18}

Ahora vamos a mejorar la presentación de los encabezados 1 y $2(<\mathrm{h} 1>$ y $<\mathrm{h} 2>)$.

Nos situamos en el archivo index.html (jojo!, si Dreamweaver nos está mostrando el archivo estilos.css, no podremos crear una nueva regla, por lo que es necesario que estemos visualizando nuestra página web).

Hacemos clic en con el botón derecho del ratón en la barra de herramientas de Estilos CSS y seleccionamos Nuevo. A continuación seleccionamos la etiqueta, $<\mathrm{h} 1>$ y estilos.css

En la categoría Tipo, en font-size, ponemos 1.8 em:

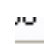

\begin{tabular}{|c|c|c|c|c|c|}
\hline Font-family: & | & & & & \\
\hline Font-size: & 1.8 & $\checkmark$ & em & $v$ & \\
\hline Font-style: & & $\checkmark$ & & & Fo \\
\hline
\end{tabular}

Para el encabezado h2 hacemos algo similar, poniendo el tamaño a 1.2 em.

Si miramos el archivo estilos.css aparecerán las nuevas reglas:

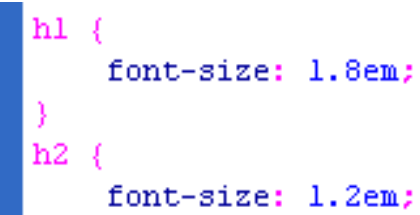

Cuando tenemos abierto un archivo HTML Dreamweaver muestra todos los archivos CSS asociados. Podemos verlo en la parte superior derecha de la ventana de código:

index.html $\times$
Código fuente estilos.css

Además, si seleccionamos estilos.css y Dividir podemos ver en la parte superior las reglas css y en la parte inferior la presentación preliminar de la página. 
Tutorial 2. Mejorando la presentación

Desarrollo del tutorial: paso 7 de 18

Nuestra página web tiene ahora este aspecto:

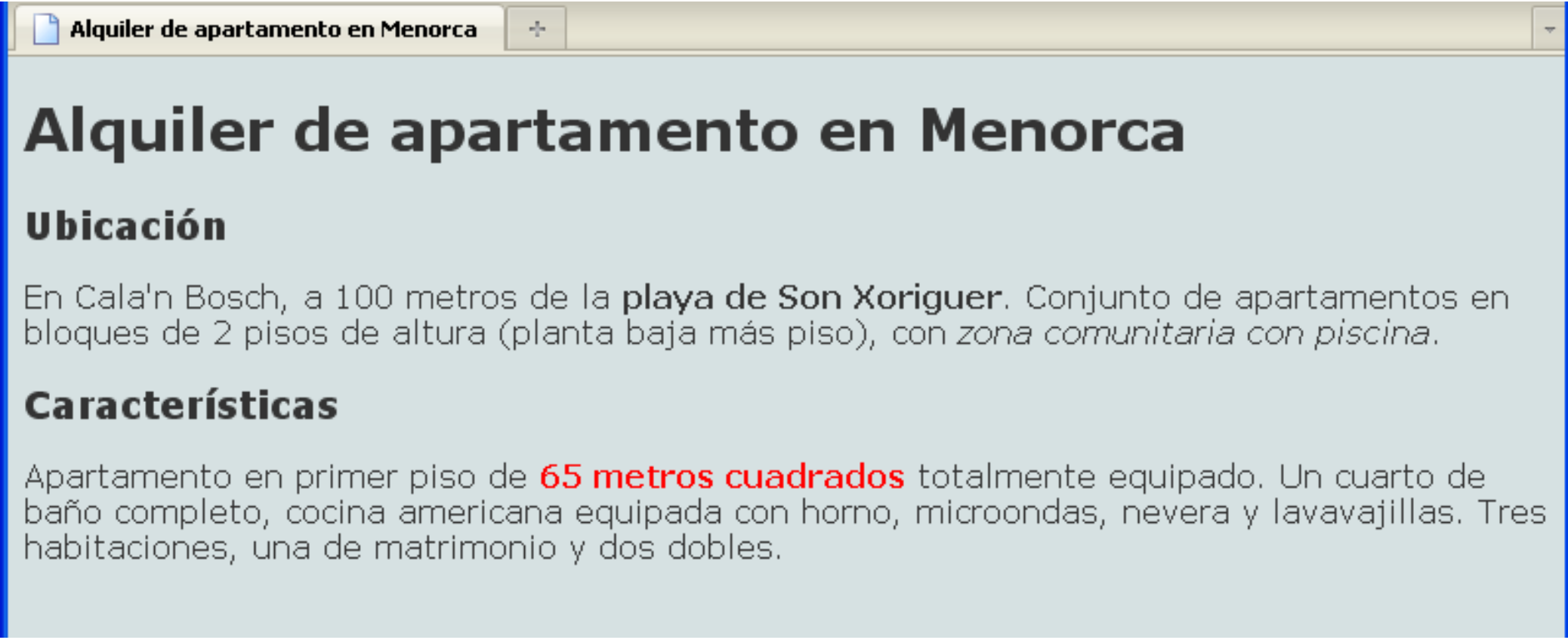

Ha mejorado considerablemente, pero aún será difícil que atraiga a nadie: ocupa toda la ventana, con lo que en pantallas grandes no quedará bien; además, le falta algún dato importante (como una manera de contactar) y algunas fotos...
Vamos a empezar por determinar un tamaño para el contenido para que no ocupe la totalidad de la pantalla y mejorar así la presentación de nuestra página. 


\section{Tutorial 2. Mejorando la presentación}

\section{Desarrollo del tutorial: paso 8 de 18}

Para determinar un tamaño para la presentación de nuestro texto y centrarlo en pantalla, lo primero que debemos hacer es crear una capa que contenga todo nuestro contenido.

Lo más rápido será hacerlo en vista de diseño:

- Seleccionamos todo el contenido.

- En la barra de la derecha hacemos doble clic en el título de la barra Insertar.

- Seleccionamos Insertar etiqueta Div.

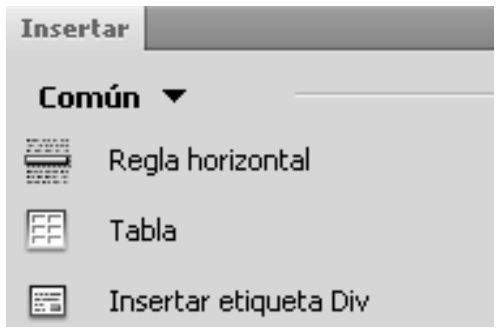

- En el cuadro de diálogo Insertar etiqueta Div seleccionamos Ajustar alrededor de la selección y lo ponemos como ID contenedor.

- A continuación, hacemos clic sobre el botón Nueva regla CSS y en la categoría Cuadro modificamos los ajustes según la imagen de la derecha (Width 800px, Margin 0px en Top y Bottom, y auto en Right y Left)

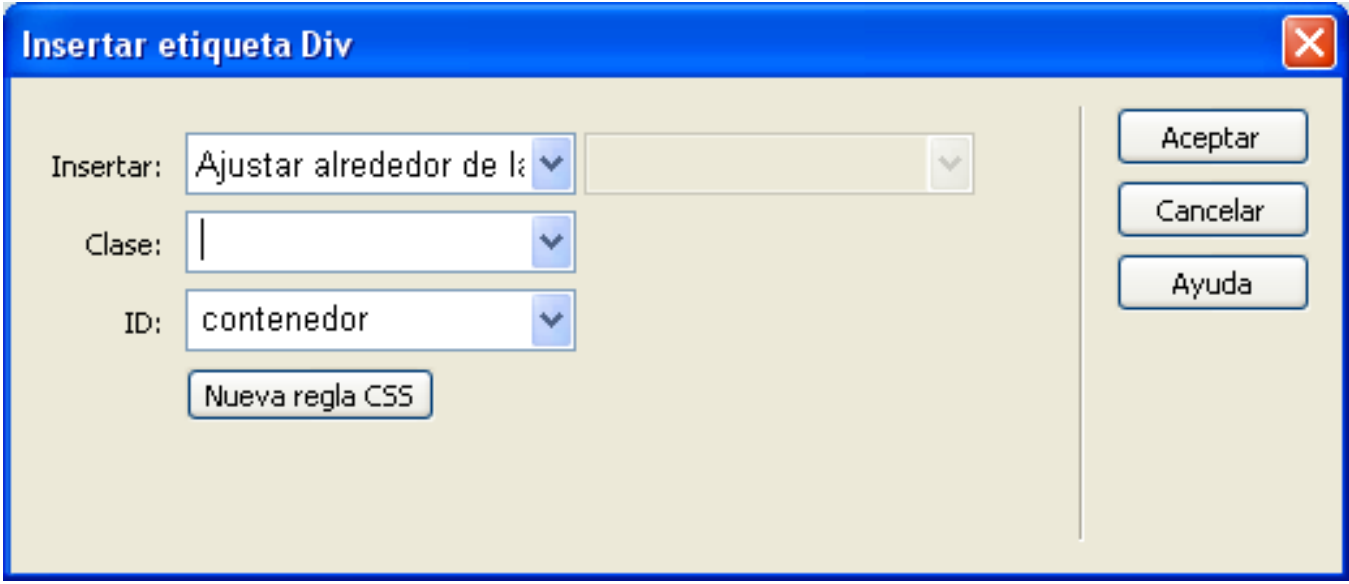

\section{Cuadro}

Width: $300 \quad v$ px $\quad \checkmark$
Height:
Padding
Top: $\square$ Igual para todo
Right:
Bottom:
Left:

Float:

Clear: Margin

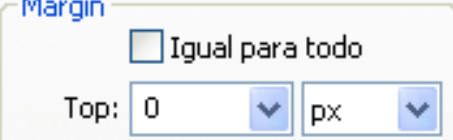

Right: auto

Bottom: 0

Left: auto 


\section{Tutorial 2. Mejorando la presentación}

\section{Desarrollo del tutorial: paso 9 de 18}

Pulsar F12 (después de haber guardado el archivo CSS) nos mostrará cómo queda el documento.

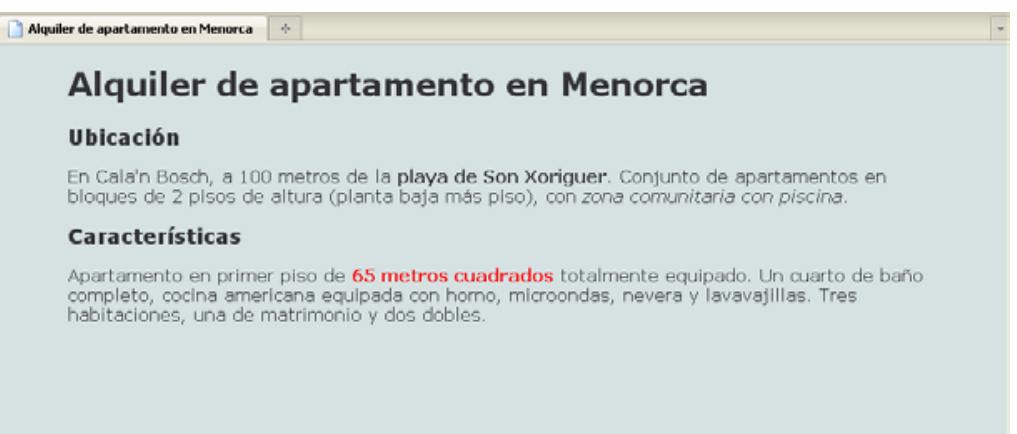

Vamos a mejorar un poco el aspecto cambiando el fondo de la ventana, añadiendo una imagen de fondo. Para ello seleccionamos la etiqueta <body $>$ en la barra de CSS y, con el botón derecho del ratón, seleccionamos Edición...

En el cuadro de diálogo seleccionamos la categoría Fondo y, tras hacer clic en el botón Examinar..., seleccionamos la imagen llamada fondo.png, que habremos guardado en una carpeta a la que llamaremos img.

\begin{tabular}{c|l|l|} 
Background-color: & & \#D6E1E2 \\
Background-image: & img/fondo.png & $\checkmark$ Examinar...
\end{tabular}

Guardamos el archivo CSS y con F12 podemos ver cómo queda ahora el documento.

\section{Alquiler de apartamento en Menorca}

Ubicación

En Cala'n Bosch, a 100 metros de la playa de Son Xoriguer. Conjunto de apartamentos en bloques de 2 pisos de altura (planta baja más píso), con zona comunitaria con piscina.

\section{Características}

Apartamento en primer piso de 65 metros cuadrados totalmente equipado. Un cuarto de baño completo, cocina americana equipada con horno, microondas, nevera y lavavajillas. Tres habitaciones, una de matrimonio y dos dobles.

Pero con ese fondo el texto no queda suficientemente legible. Vamos a cambiar el fondo del contenedor para que tenga un color plano y facilite la lectura.

Para hacerlo, cambiamos la regla CSS del identificador \#contenedor de manera que tenga como color de fondo el \#EEE
Background-color: 
Tutorial 2. Mejorando la presentación

\section{Desarrollo del tutorial: paso 10 de 18}

Alquiler de apartamento en Menorca

\section{Alquiler de apartamento en Menorca}

\section{Ubicación}

En Cala'n Bosch, a 100 metros de la playa de Son Xoriguer. Conjunto de apartamentos en bloques de 2 pisos de altura (planta baja más piso), con zona comunitaria con piscina.

\section{Características}

Apartamento en primer piso de 65 metros cuadrados totalmente equipado. Un cuarto de baño completo, cocina americana equipada con horno, microondas, nevera y lavavajillas. Tres habitaciones, una de matrimonio y dos dobles.

Alquiler de apartamento en Menorca

\section{Alquiler de apartamento en Menorca}

\section{Ubicación}

En Cala'n Bosch, a 100 metros de la playa de Son Xoriguer. Conjunto de apartamentos en bloques de 2 pisos de altura (planta baja más piso), con zona comunitaria con piscina.

\section{Características}

Apartamento en primer piso de 65 metros cuadrados totalmente equipado. Un cuarto de baño completo, cocina americana equipada con horno, microondas, nevera y lavavajillas. Tres

habitaciones, una de matrimonio y dos dobles.
Hemos ganado en legibilidad, pero el texto queda demasiado pegado al borde de la capa. Vamos a añadirle un padding para modificar los márgenes interiores.

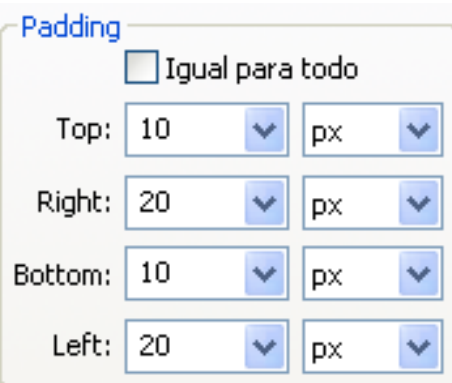

Una vez mejorado el fondo, deberíamos añadir alguna imagen que facilite al visitante hacerse una idea de cómo es el apartamento 
Tutorial 2. Mejorando la presentación

Desarrollo del tutorial: paso 11 de 18

Vamos a añadir la primera foto, una fotografía de la zona

comunitaria con piscina.

El primer paso es guardar en la carpeta img la imagen con el tamaño que vayamos a usar.

Para este tutorial, esta primera imagen la hemos guardado a 300x225 píxeles.

Para poner la imagen en la página web iremos al menú, Insertar-Imagen.

Veamos cómo hacerlo.

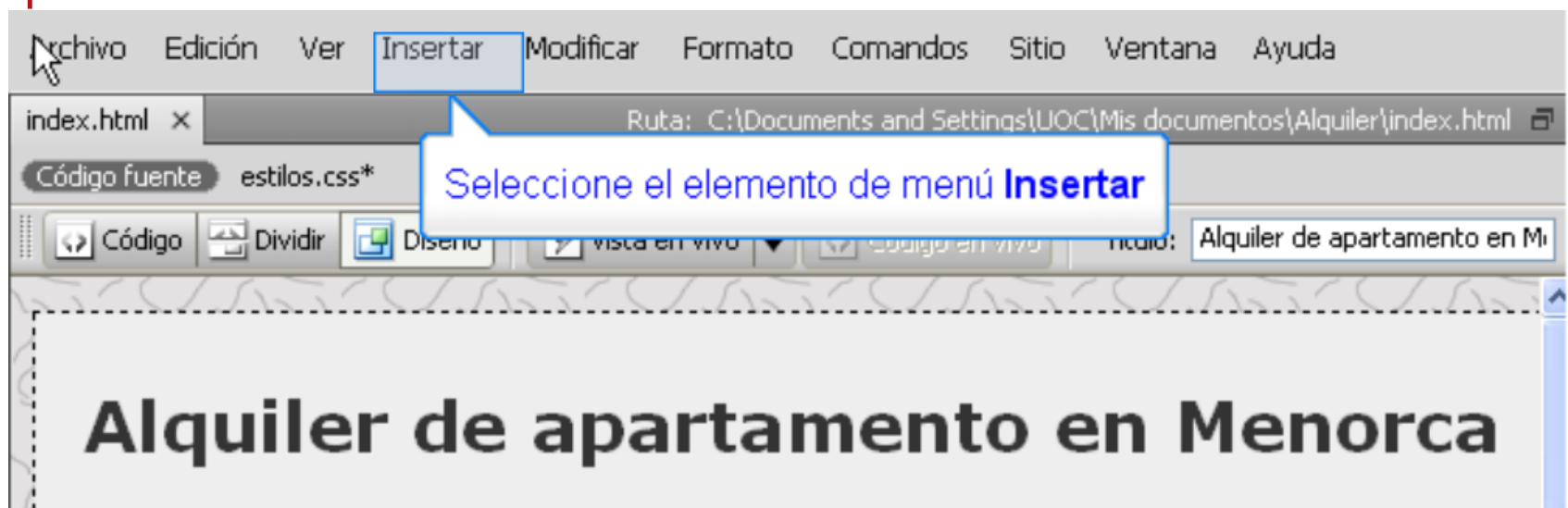

\section{Ubicación}

:En Cala'n Bosch, a 100 metros de la playa de Son Xoriguer. Conjunto d bloques de 2 pisos de altura (planta baja más piso) con zona comunitar

\section{Características}

Apartamento en primer piso de 65 metros cuadrados totalmente equip. completo, cocina americana equipada con horno, microondas, nevera y lz habitaciones, una de matrimonio y dos dobles.

A. $100 \% \vee 645 \times 310 \vee 2 \mathrm{~K} / 1 \mathrm{~s}$ Unicode (UTF-8)

Propiedades

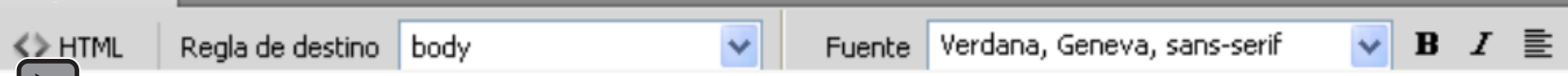




\section{Tutorial 2. Mejorando la presentación}

\section{Desarrollo del tutorial: paso 12 de 18}

Ya hemos puesto la foto, pero no queda en un sitio demasiado adecuado. La situaremos al final del documento, después de los textos. Para hacerlo, aunque podemos arrastrar la imagen con el ratón en la vista de diseño, vamos a seleccionar la vista de código y a cortar y copiar la etiqueta <img>, de manera que la pondremos justo antes del último $</$ div $>$.

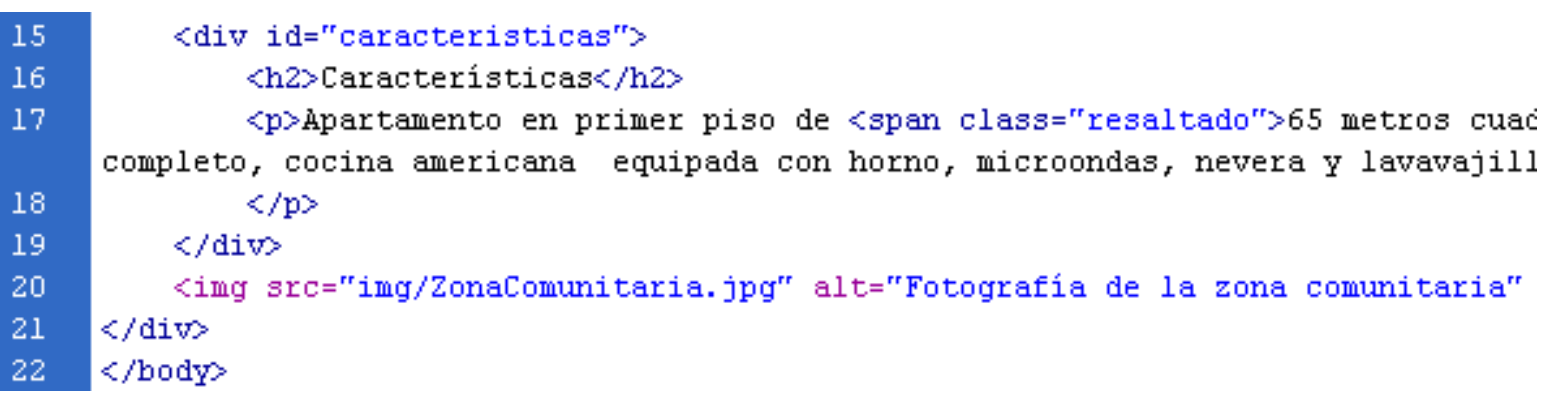

A continuación añadimos una nueva foto, en este caso del interior del apartamento. La ubicaremos justo a continuación de la otra.

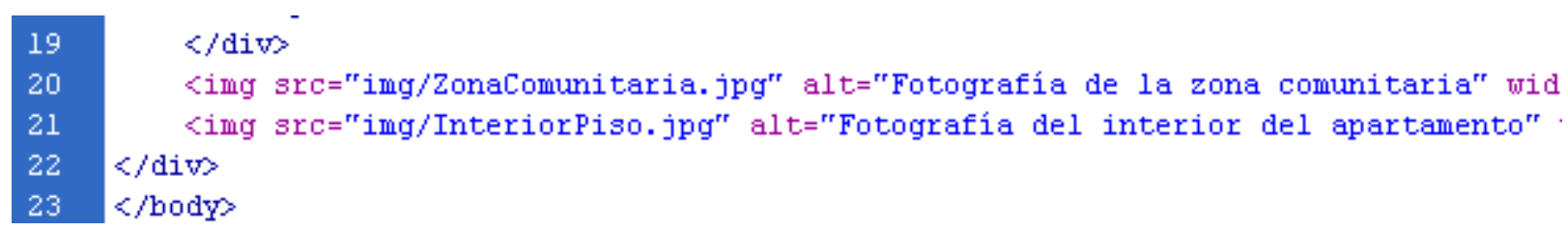

Ahora las imágenes aparecen una al lado de la otra después del texto y a la izquierda. 


\section{Tutorial 2. Mejorando la presentación}

\section{Desarrollo del tutorial: paso 13 de 18}

Así se ve ahora nuestra página web.

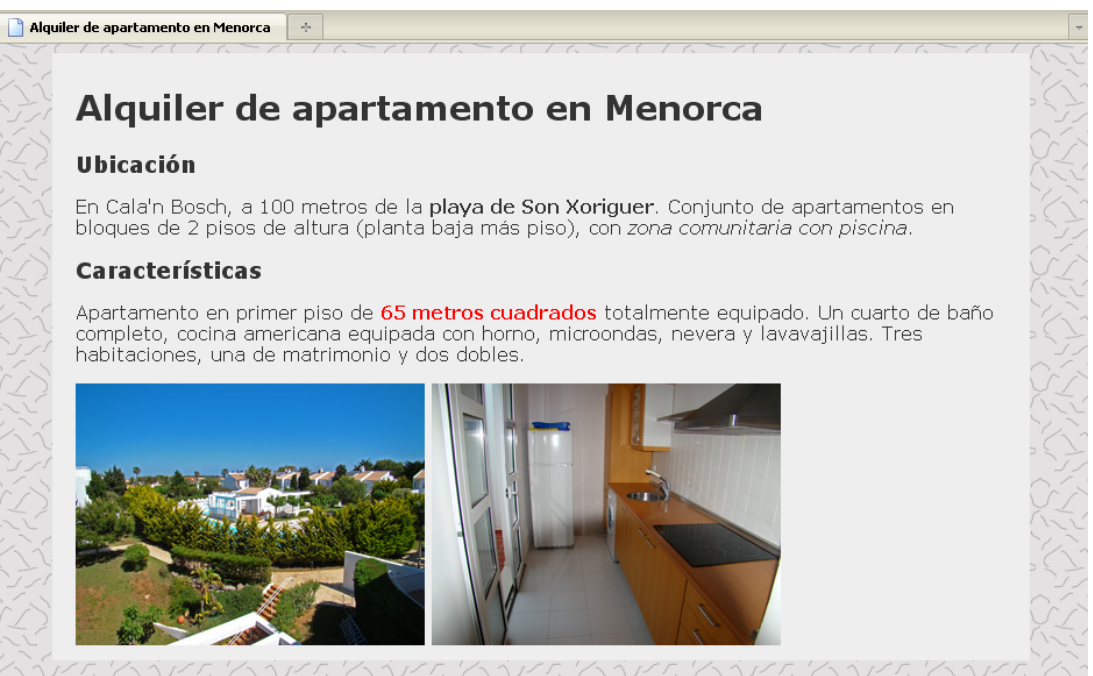

Vamos a poner la imagen del apartamento alineado a la derecha para que quede cada imagen a un lado de la página. Para hacerlo, pondremos un identificador a la imagen de la derecha.
Para poner el identificador podemos hacerlo en la vista de código o en la vista de diseño.

<img src="img/ZonaComunitaria.jpg" alt="Fotografía de la <img id="fotoInt" src="img/InteriorPiso.jpg" alt="Fotogr liv>

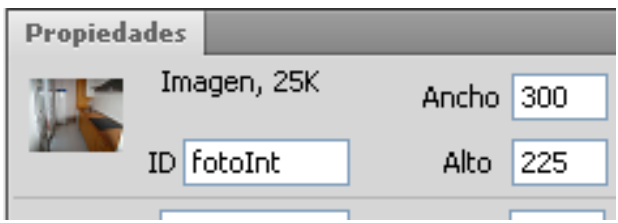




\section{Tutorial 2. Mejorando la presentación}

\section{Desarrollo del tutorial: paso 14 de 18}

Ahora creamos un nuevo CSS para el identificador fotolnt

\section{Tipo de selector:}

Elija un tipo de selector contextual para la regla CSS.

$$
\text { ID (sólo es aplicable a un elemento HTML) }
$$

\section{Nombre del selector:}

Elija o introduzca un nombre para el selector.

$$
\text { \#fotoInt }
$$
todos los elementos HTML con id "fotoInt".

Y en la categoría Cuadro ponemos en Float la opción Right

$$
\text { Cuadro }
$$

Width: $1 \quad v$ px
Height:

$\begin{array}{ll}\text { Float: } & \text { right } \quad \checkmark \\ \text { Clear: } & \checkmark\end{array}$

Paddina

- Marain
Una vez guardado todo (será necesario guardar tanto el archivo HTML como el CSS) actualizamos el navegador y comprobamos que ambas imágenes quedan cada una a cada lado del contenedor respectivamente.

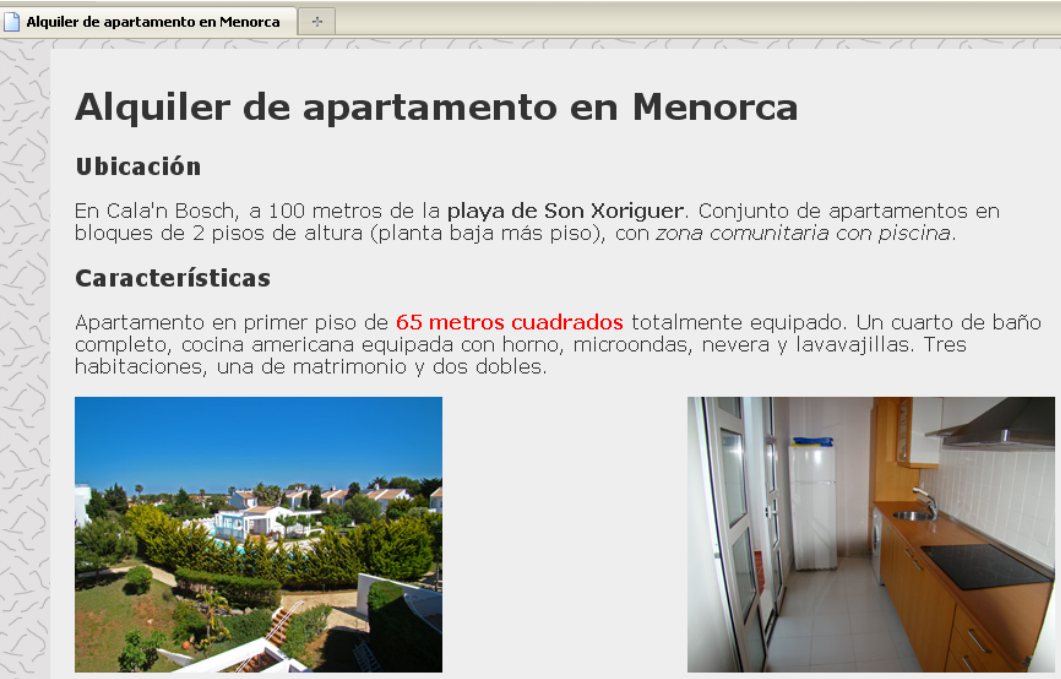




\section{Tutorial 2. Mejorando la presentación}

\section{Desarrollo del tutorial: paso 15 de 18}

Nos queda una cosa por hacer: poner los datos de contacto. Vamos a indicar un teléfono y una dirección de correo electrónico al pie de la página.

Para ello, crearemos una nueva capa, a la que llamaremos contacto, dentro del contenedor y debajo de las imágenes. Y en esa capa será donde, en un párrafo, pondremos la información de contacto.

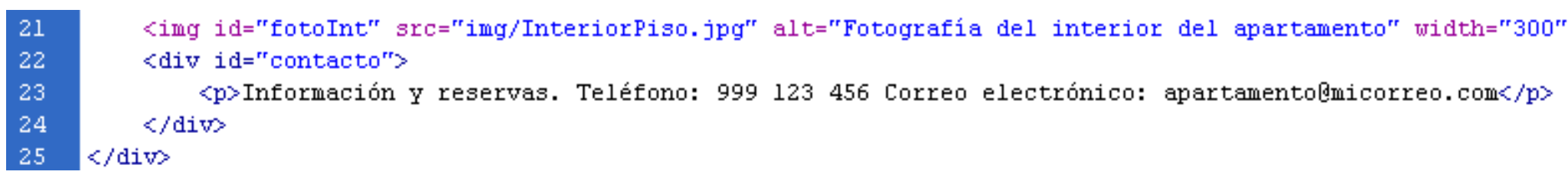

\section{Pero el resultado no es demasiado vistoso:}

Apartamento en primer piso de 65 metros cuadrados totalmente equipado. Un cuarto de baño completo, cocina americana equipada con horno, microondas, nevera y lavavajillas. Tres habitaciones, una de matrimonio y dos dobles.
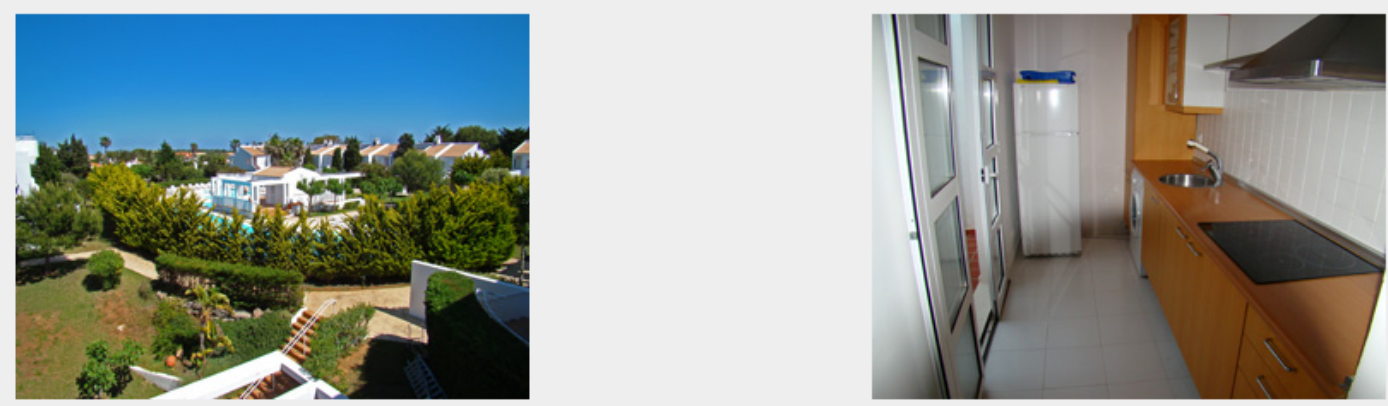

Información y reservas. Teléfono: 999123456 Correo electrónico: apartamento@micorreo.com 


\section{Tutorial 2. Mejorando la presentación}

\section{Desarrollo del tutorial: paso 16 de 18}

Vamos a sacar la información del contenedor para darle más relevancia. Además, cambiaremos el color de fondo y del texto y también alguna de las características del texto. Vamos a hacerlo por pasos.

En primer lugar sacaremos la capa contacto del contenedor:

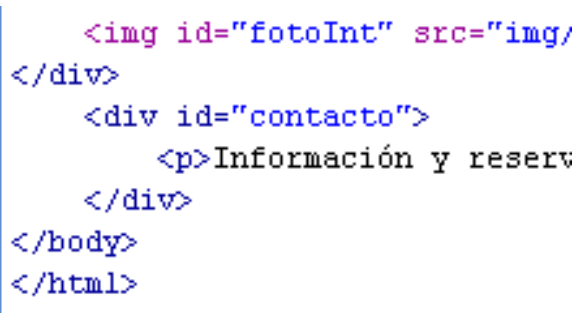

Después crearemos un nuevo estilo de ID para la capa contacto, donde haremos los cambios que afectarán a la forma de presentar esa capa en la página.
En el cuadro de diálogo de Definición de regla de Dreamweaver, haremos los siguientes cambios:

- En la categoría Tipo, en Font-weight, pondremos bold.

- En esa misma categoría, en Color, pondremos \#FFF.

- En la categoría Fondo, en Background-color, pondremos \#009.

- En la categoría Cuadro, en Margin, pondremos, en Top y Bottom, un 0 y en Right y Left, pondremos auto. En Padding, pondremos, en Top y Bottom, un 0 y en Right y Left, 20 px.

- En esta misma categoría, en Width, pondremos 800 px y en Height, 20 px.

En el archivo .css debería quedarnos algo similar a esto:

$\left.\begin{array}{l}12 \\ 13 \\ 14 \\ 15 \\ 16 \\ 17 \\ 18 \\ 19 \\ 20 \\ 21 \\ 22 \\ 23 \\ 24 \\ 25 \\ 26 \\ 27\end{array}\right\}$

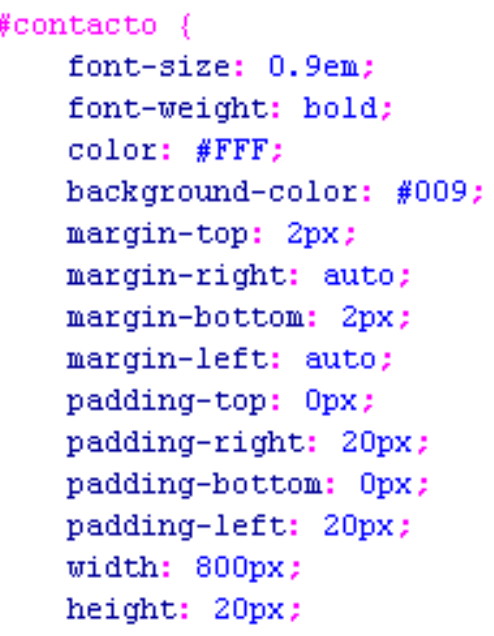


Tutorial 2. Mejorando la presentación

\section{Desarrollo del tutorial: paso 17 de 18}

Así es como queda nuestra página. No es ninguna maravilla, pero, a fin de cuentas, jtan sólo estamos empezando!

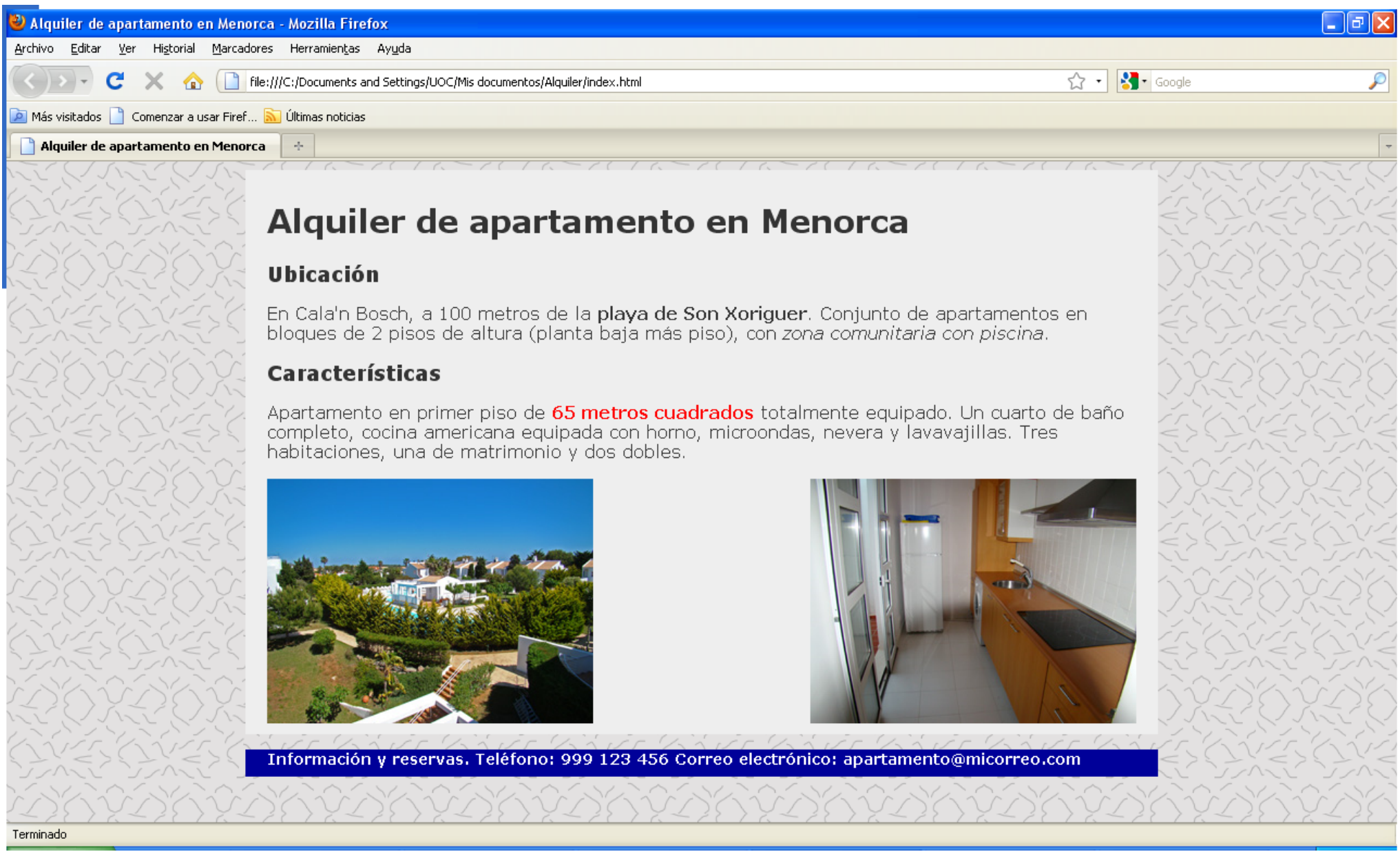




\section{Tutorial 2. Mejorando la presentación}

\section{Desarrollo del tutorial: paso 18 de 18}

Para asentar los conceptos desarrollados en este tutorial, se recomienda realizar las siguientes actividades.

- Utilizando reglas CSS :

- Haced que el título (h1) sea de color azul y los subtítulos (h2), de color verde.

- Remarcad (usando la negrita) el texto Cala'n Bosh.

- Haced que el texto playa de Son Xoriguer sea de color azul oscuro (además de mantener el remarcado).

- ¿Qué más hay que hacer, además de crear una nueva regla CSS?

- ¿Cómo se debe incluir el remarcado?

- Eliminando la etiqueta <strong $>$ y poniendo negrita con CSS.

- Tal y como está ahora, con la etiqueta <strong>.

- Utilizando la clase "resaltado", resaltad el texto "tres habitaciones".

- Cread una nueva regla CSS que añada una línea discontinua de color azul alrededor de las imágenes. 


\section{Tutorial 3. Crear un sitio}

\section{Desarrollo del tutorial: paso 1 de 18}

Nuestra sencilla página web ha llamado la atención de otro propietario de un apartamento situado en el mismo lugar que el nuestro, y, tras proponerlo a la comunidad de vecinos, hemos decido hacer una página web desde donde se puedan alquilar todos los apartamentos disponibles en nuestra comunidad.

Ya no nos sirve el esquema que teníamos de una sola página: necesitaremos una estructura que nos permita tener varias páginas enlazadas con un menú.

Aunque tenemos una parte de la página elaborada. Vamos a empezar desde el principio. Y el principio pasa por definir la estructura de la página web. Antes de comenzar con Dreamweaver, deberíamos tener claras dos cosas: qué páginas vamos a tener y cómo vamos a disponer los elementos en las páginas.

Para el sitio que vamos a crear, confeccionaremos siete páginas:

1. Página de inicio (a la que se llega cuando se escribe el nombre del dominio)

2. Ubicación (con un mapa de situación)

3. Características (características generales de los apartamentos con fotos)

4. Precios

5. Disponibilidad

6. Lugares de interés (enlaces a otros sitios de interés)

7. Formulario de contacto
Una vez hemos definido qué páginas tendremos, podemos definir la estructura de nuestro sitio, que en nuestro caso será aproximadamente esta:

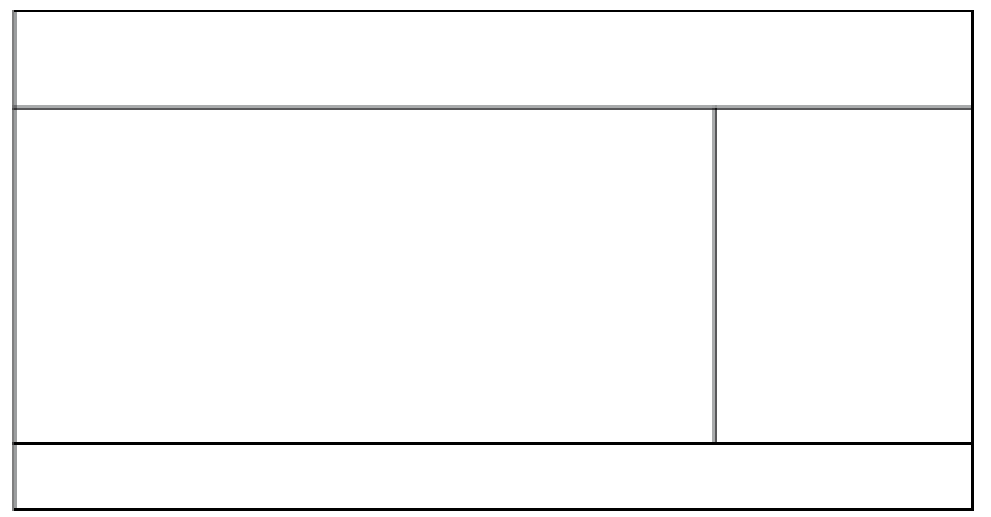

Tiene un menú a la derecha que lleva a las diferentes páginas, una cabecera y un pie. 


\section{Tutorial 3. Crear un sitio}

\section{Desarrollo del tutorial: paso 2 de 18}

El siguiente paso es crear un nuevo sitio. Al definir un nuevo sitio le indicamos a Dreamweaver dónde almacenaremos los archivos de nuestro sitio web. Es importante ser conscientes de que un sitio web no se limita a un archivo HTML; son muchos los archivos que almacenaremos (imágenes, ficheros HTML, ficheros de CSS...) y es importante que se encuentren bien ordenados.

Para crear el sitio, en el menú seleccionamos la opción Sitio, y allí, Nuevo sitio...

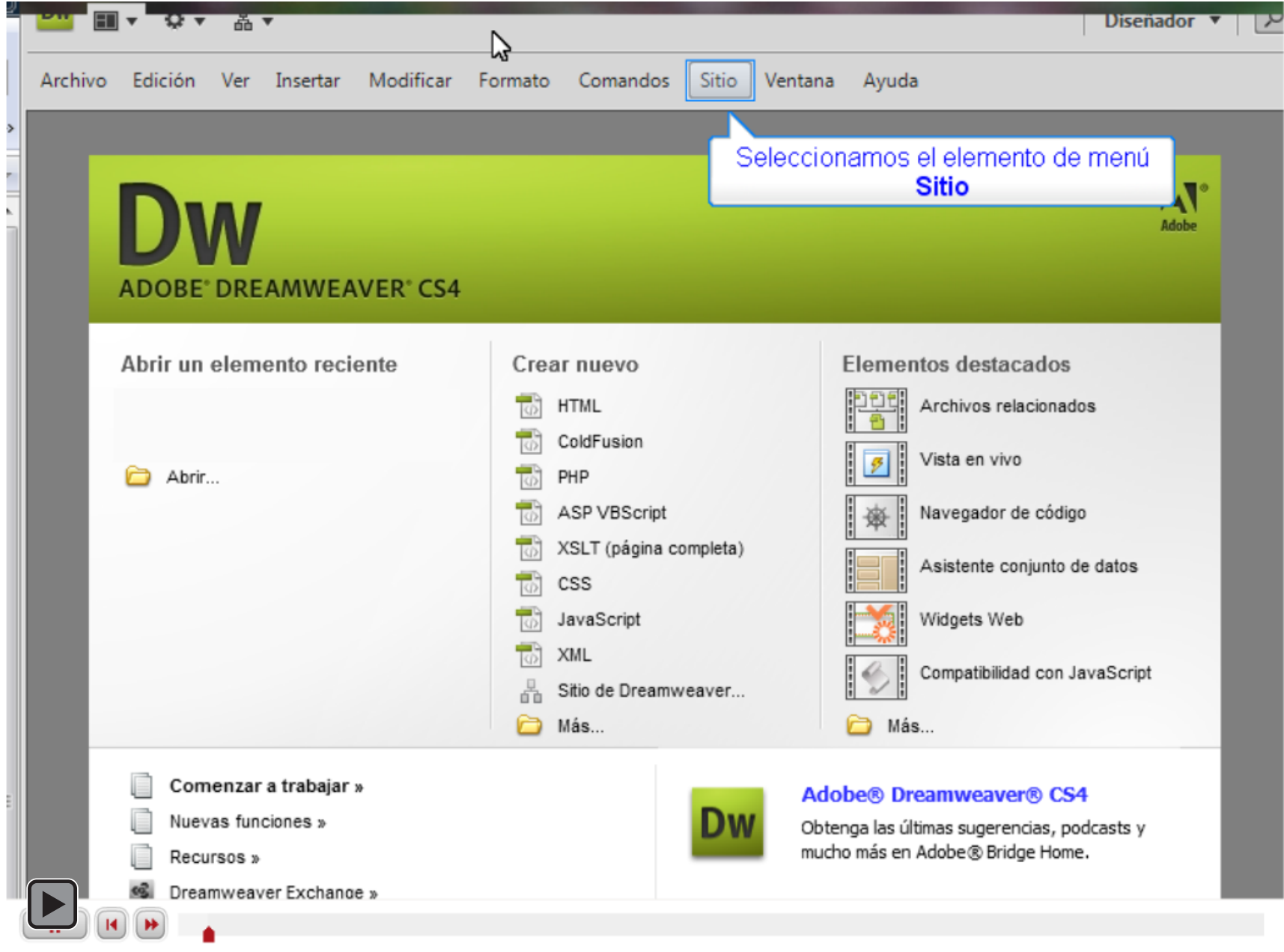




\section{Tutorial 3. Crear un sitio}

\section{Desarrollo del tutorial: paso 3 de 18}

Una vez creado el nuevo sitio, en la parte inferior de la barra de la derecha tendremos la ventana de Archivos, donde podremos ver los archivos de nuestro sitio.

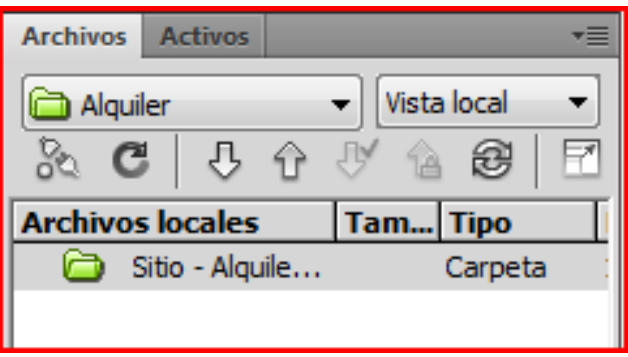

Ha llegado el momento de organizar el espacio donde guardaremos todos los archivos que formarán parte de nuestro sitio. El sitio web que vamos a crear no será demasiado complejo y sólo tendrá tres tipos de archivo:

- archivos HTML (las páginas web propiamente dichas),

- archivos CSS (los archivos donde guardaremos la parte de diseño de nuestras páginas),

- archivos de imagen (.jpg, .gif o .png serán los tipos de archivo de imagen que usaremos normalmente).
Dependiendo de la cantidad de tipos de archivos que tengamos (y también de cuantos de ellos haya), deberemos crear más o menos directorios donde almacenarlos. Es importante que tengamos nuestro sitio adecuadamente ordenado para que el mantenimiento sea sencillo. En nuestro caso, dado que tendremos pocos archivos, vamos a crear un solo subdirectorio, al que llamaremos img y donde almacenaremos las imágenes. El directorio lo crearemos directamente en la ventana de Archivos, haciendo clic con el botón derecho del ratón y seleccionando Nueva carpeta.

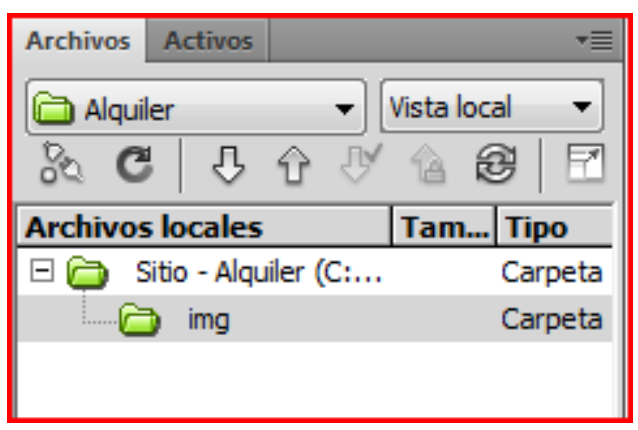


Tutorial 3. Crear un sitio

\section{Desarrollo del tutorial: paso 4 de 18}

Como hemos visto, vamos a hacer cinco páginas diferentes pero con una estructura común. Para que el trabajo sea más fácil, crearemos una plantilla en Dreamweaver. Las plantillas permiten definir elementos comunes a todas las páginas, por lo que se limitan las posibilidades de edición tan solo a unas zonas determinadas. De esta manera, una vez bien definida la plantilla, la creación de las páginas es más sencilla. Además, cuando modifiquemos la plantilla,

Dreamweaver modificará todas las páginas que hayamos hecho con ella y facilitará la modificación posterior de todo el sitio. En el tutorial 5 veremos cómo actúa Dreamweaver cuando modificamos la plantilla.

Para crear una plantilla, en la pantalla inicial de Dreamweaver seleccionamos Archivo en el menú y, a continuación, Nuevo. En la ventana que aparece, en la pestaña Página en blanco (que es la que aparece por defecto), seleccionaremos Plantilla HTML.

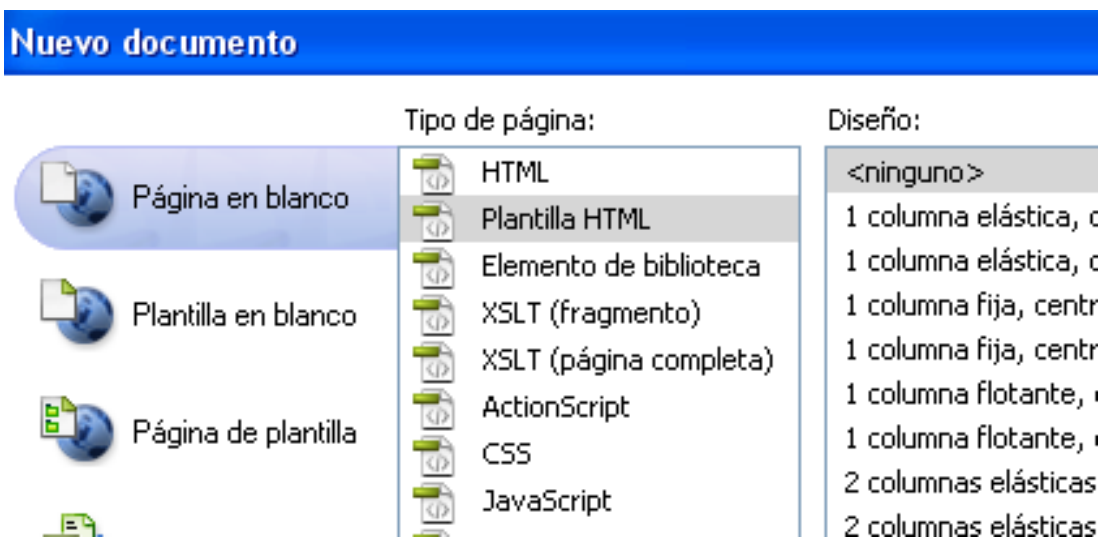


Tutorial 3. Crear un sitio

\section{Desarrollo del tutorial: paso 5 de 18}

Dreamweaver crea una nueva página y nos la presenta en vista de código.

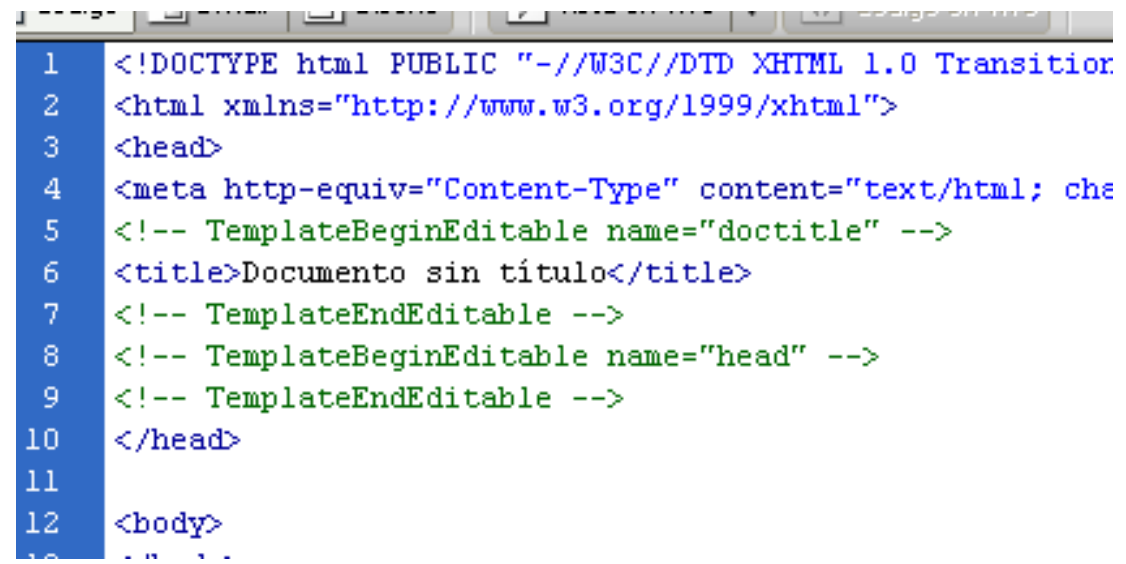

Se destacan en verde los comentarios como

TemplateBeginEditable que utiliza Dreamweaver para indicar qué partes del documento serán editables.
Una vez creada la plantilla, vamos a poner en ella el contenido común a todas las páginas. Empezaremos por la estructura de capas. Hemos visto en un paso anterior que tendremos una página dividida en tres partes: encabezado, cuerpo y pie. Además, el cuerpo lo tendremos dividido en dos partes: contenido y menú. Finalmente, tal y como vimos en los tutoriales anteriores, para centrar la página usaremos una capa que contendrá todas las demás.

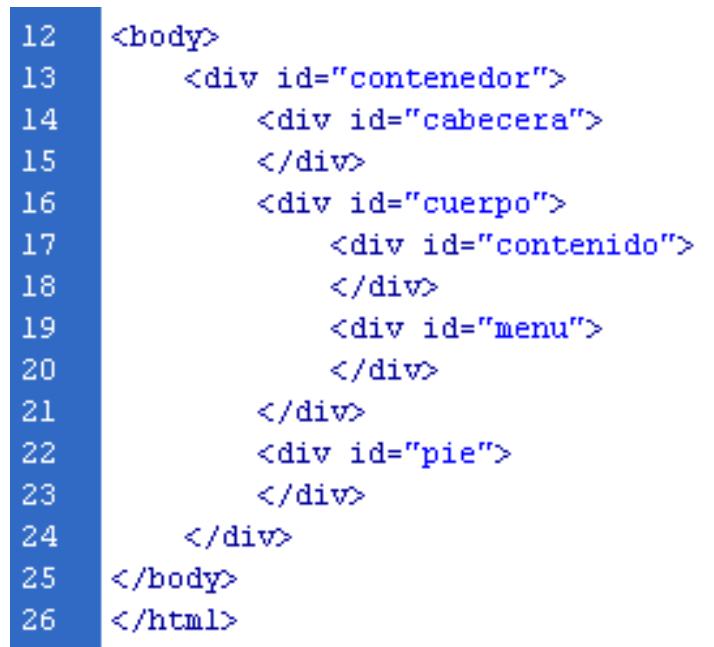

Una vez creada la estructura, vamos a crear el archivo CSS que sitúe cada capa en su sitio. 


\section{Tutorial 3. Crear un sitio}

\section{Desarrollo del tutorial: paso 6 de 18}

Posiblemente, ésta sea la parte más complicada.

Dreamweaver no ofrece ninguna utilidad para situar las capas de una forma fácil en la pantalla, así que deberemos editar directamente el fichero CSS.

Primero debemos crear el archivo y asignarlo a nuestra página (X)HTML. Para ello, haremos clic con el botón derecho del ratón en la barra de estilos CSS y seleccionaremos Nuevo...

Seleccionaremos Tipo de selector: ID, Nombre del selector: contenedor y Definición de regla: (Nuevo archivo de hoja de estilos).

Tras el clic en Aceptar, introduciremos el nombre del archivo CSS (estilos) y se abrirá el cuadro de diálogo de Definición de regla.

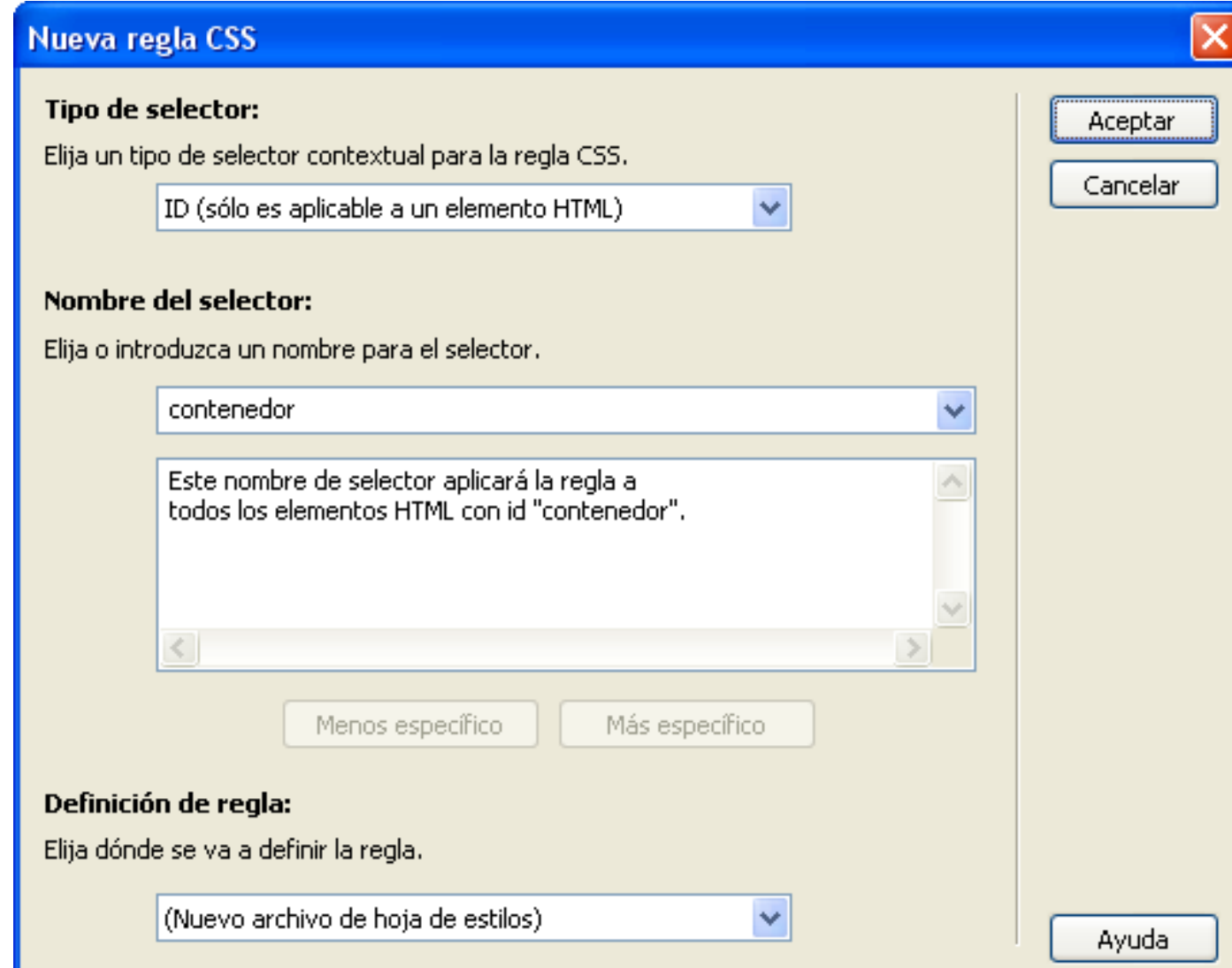




\section{Tutorial 3. Crear un sitio}

\section{Desarrollo del tutorial: paso 7 de 18}

Vamos a modificar los siguientes campos de la categoría Cuadro:

\section{Cuadro}

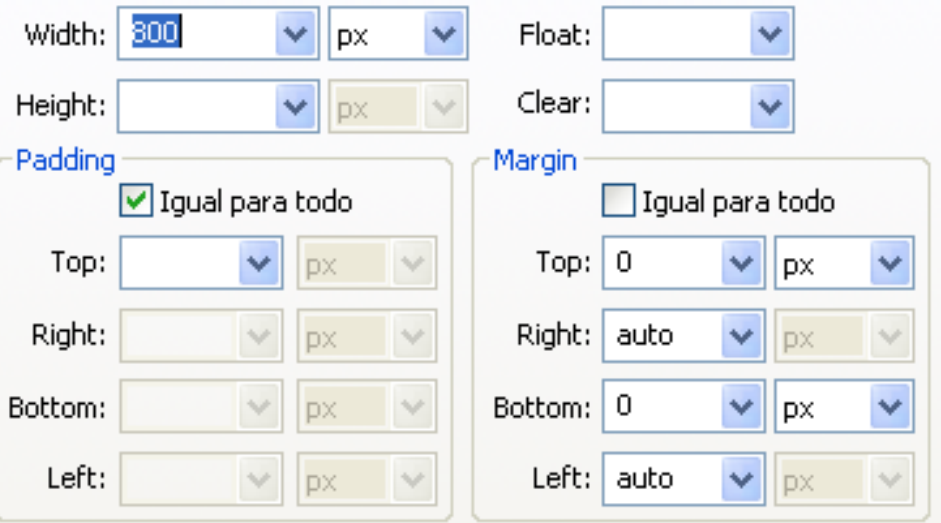

Una vez definida la regla, vamos a guardar la plantilla.

Pulsamos <ctrl>+s y aparece una ventana de advertencia:

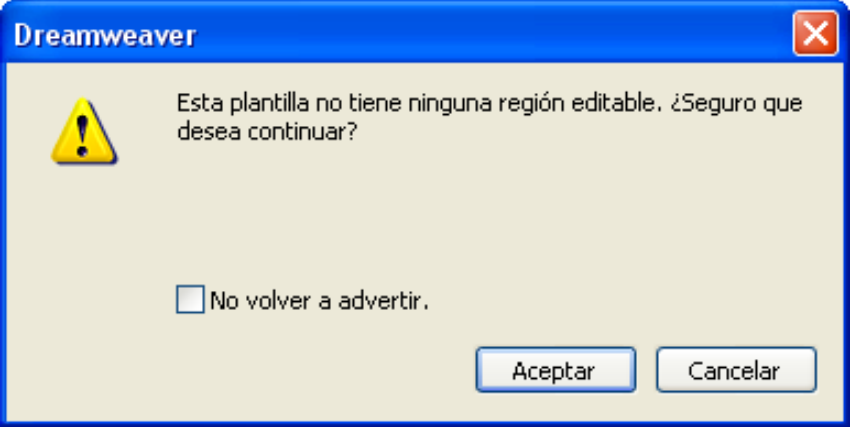

Dreamweaver nos avisa de que no hemos definido ninguna región editable. Aun así, aceptaremos, y nos pedirá el nombre del archivo y una descripción.

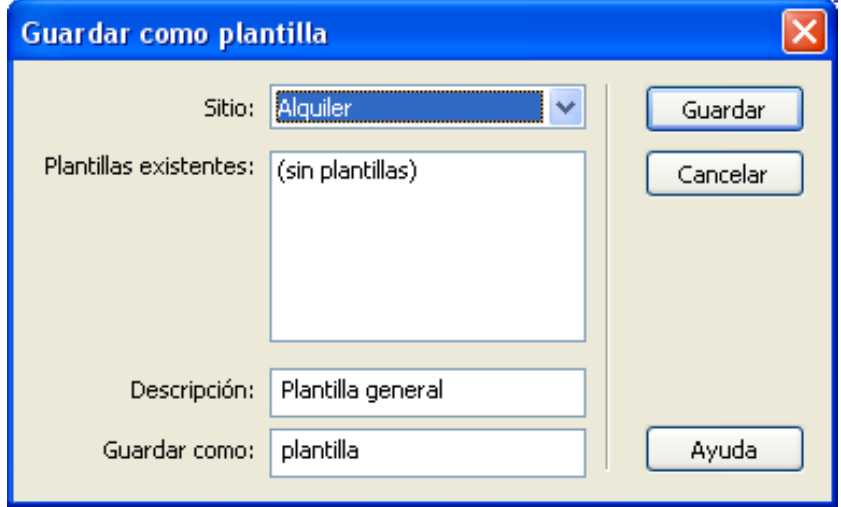

Como podemos comprobar, Dreamweaver permite guardar diferentes plantillas para un mismo sitio web. Además, guarda una descripción junto con la plantilla para que sea más fácil reusarla en un futuro. 


\section{Tutorial 3. Crear un sitio}

\section{Desarrollo del tutorial: paso 8 de 18}

Vamos ahora a añadir las reglas CSS necesarias para disponer de todas las capas en la pantalla. Como tenemos claro lo que queremos hacer, vamos a editar directamente el archivo CSS, en vez de usar la utilidad de edición de Dreamweaver.

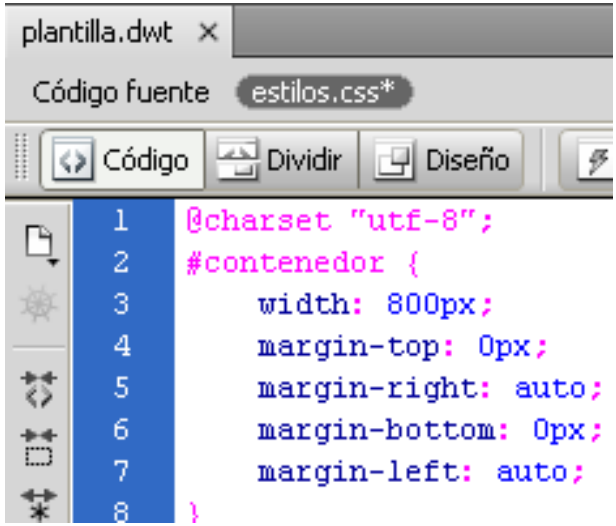

Al seleccionar el archivo estilos.css, vemos lo que Dreamweaver ha puesto en él al crear la nueva regla. Vamos a simplificar la regla existente y a añadir el resto de reglas necesarias. Así, la regla contenedor la dejaremos así:

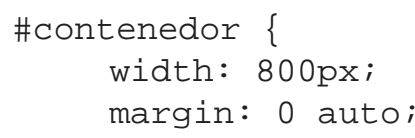

Y el resto de reglas serán las siguientes:

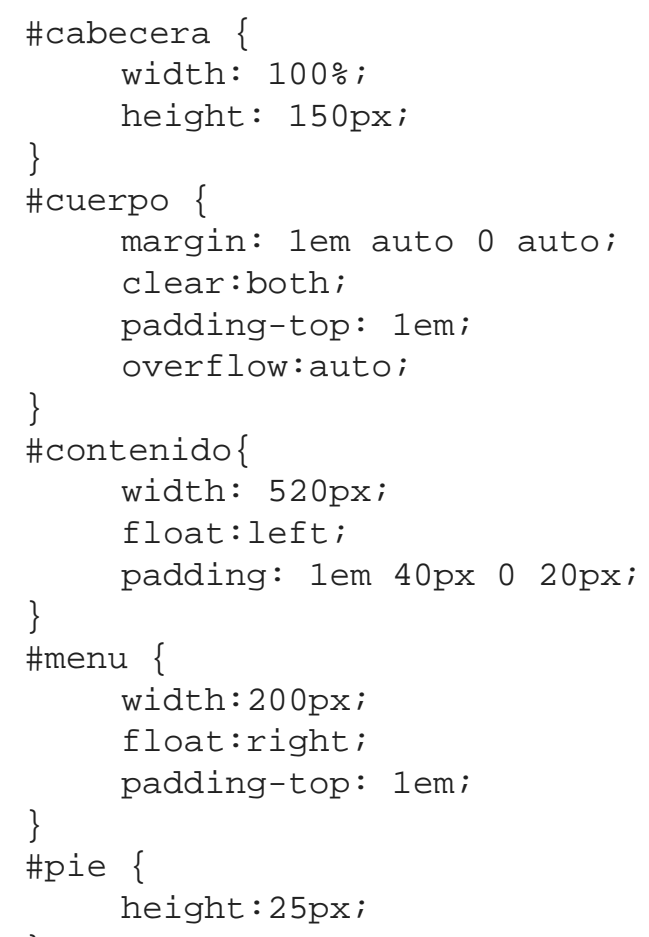




\section{Tutorial 3. Crear un sitio}

\section{Desarrollo del tutorial: paso 9 de 18}

Si hacemos una previsualización de lo que hemos hecho, veremos una página en blanco, ya que las capas no contienen nada todavía.

Completemos la plantilla. De momento tenemos la estructura, pero hay más partes de la plantilla que no cambiarán, como los fondos, o la cabecera. Vamos a empezar por establecer un tipo de letra común para todo el sitio. Para ello, definimos una regla CSS para el elemento body que indique la familia de fuentes que usaremos: Verdana, Geneva, sans-serif.

Podemos hacerlo escribiendo la regla directamente en el archivo CSS, o usando el editor de reglas de

Dreamweaver:
El siguiente paso consiste en crear la cabecera, que también es común para todas las páginas. Contendrá una imagen y dos textos. Como la imagen será de adorno, la pondremos en el CSS. El resultado será éste:

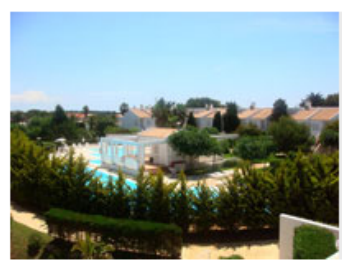

Alquiler de apartamentos en Menorca Cala'n Bosch

Definición de regla para body en estilos.css

\begin{tabular}{|c|c|c|c|c|}
\hline Categoría & Tipo & & & \\
\hline Tipo & & & & \\
\hline $\begin{array}{l}\text { Fondo } \\
\text { Bloque }\end{array}$ & Font-family: & Verdana, Gen & eva, & -ser \\
\hline Borde & Font-size: & $\checkmark$ & $\mathrm{px}$ & $v$ \\
\hline
\end{tabular}




\section{Tutorial 3. Crear un sitio}

\section{Desarrollo del tutorial: paso 10 de 18}

Los dos textos de la cabecera los colocaremos en

sendos encabezados, h1 para "Alquiler de apartamentos

en Menorca" y h2 para "Cala'n Bosh". Como están en la cabecera, los ponemos dentro de la capa correspondiente. <div id="cabecera">

$<$ hl $>$ Alquiler de apartamentos en Menorca</hl>

$\langle\mathrm{h} 2\rangle$ Cala'n Bosch $</ \mathrm{h} 2\rangle$

Y ahora modificaremos sus características en el CSS. Primero añadimos el fondo a la capa.

\section{Definición de regla para \#cabecera en estilos.css}

Categoría

Tipo

Fondo

Bloque

Cuadro

Borde

Posición

Extensiones

Desde Dreamweaver
Fondo

\begin{tabular}{rl|l|} 
Background-color: & & \#ebebeb \\
Background-image: & img/cabecera.jpg \\
Background-repeat: & no-repeal $\vee$ \\
Riarknrnı Ind-attarhment: & $\checkmark$
\end{tabular}

\#cabecera

width: 100\%:

height: 150px;

background-color: \#ebebeb;

background-image: url(img/cabecera.jpg) ;

background-repeat: no-repeat;

O directamente en el archivo CSS. 
Tutorial 3. Crear un sitio

Desarrollo del tutorial: paso 11 de 18

Y después, las características de los encabezados en CSS:

h1 \{

padding-top: 30px;

margin-left: $200 p x$;

El margen izquierdo (margin-left) es para que los

text-align: center

encabezados no queden sobre la imagen de fondo.

font-size: $1.5 \mathrm{em}$;

color:\#०७6;

\}

h2 \{

margin-left: 200px;

text-align: center;

font-size:1.2em;

\}

Ahora guardamos la plantilla y el archivo CSS y pulsamos

F12 para visualizar la plantilla. El resultado es éste:

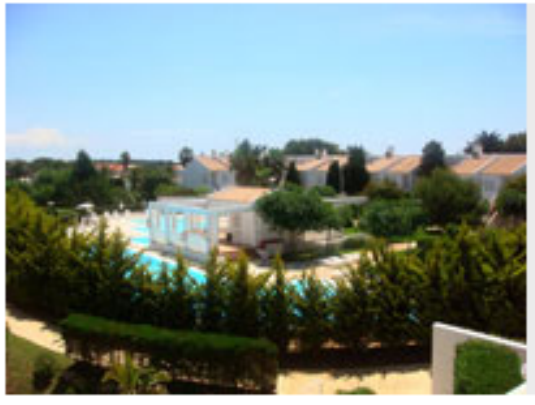

\section{Alquiler de apartamentos en Menorca}

Cala'n Bosch 


\section{Tutorial 3. Crear un sitio}

\section{Desarrollo del tutorial: paso 12 de 18}

Pasemos ahora al pie de la página. Como vamos a tener un formulario de contacto, el pie será tan solo la frase "Apartamentos familiares en Menorca":

$\langle$ div id="pier">

$<$ p Apartamentos familiares en Menorca</p> $</$ div $\rangle$

Modificamos las características de la capa.

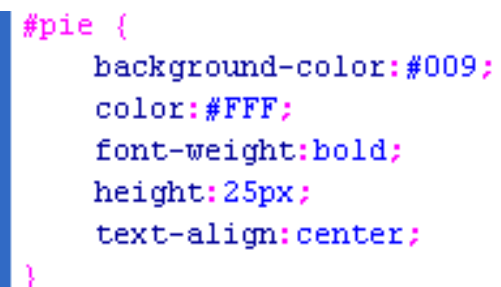

Y como el texto queda demasiado pegado al borde superior de la capa...

\section{Apartamentos familiares en Menorca}

... modificamos también las características de la etiqueta

$<p>$ de la capa pie.

\#pie p

padding-top: $2 \mathrm{px}$;

\}

Si guardamos y previsualizamos veremos esto.

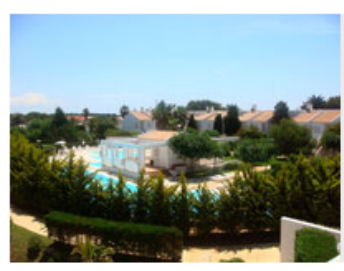

\section{Alquiler de apartamentos en Menorca}

Cala'n Bosch 


\section{Tutorial 3. Crear un sitio}

\section{Desarrollo del tutorial: paso 13 de 18}

Otra parte del sitio prácticamente idéntica en todas las páginas será el menú. El menú consiste en una lista no ordenada de ítems enlazados con las páginas correspondientes. Vamos a hacer el menú desde la vista de diseño de Dreamweaver. Antes deberemos situar el cursor en la capa menú.

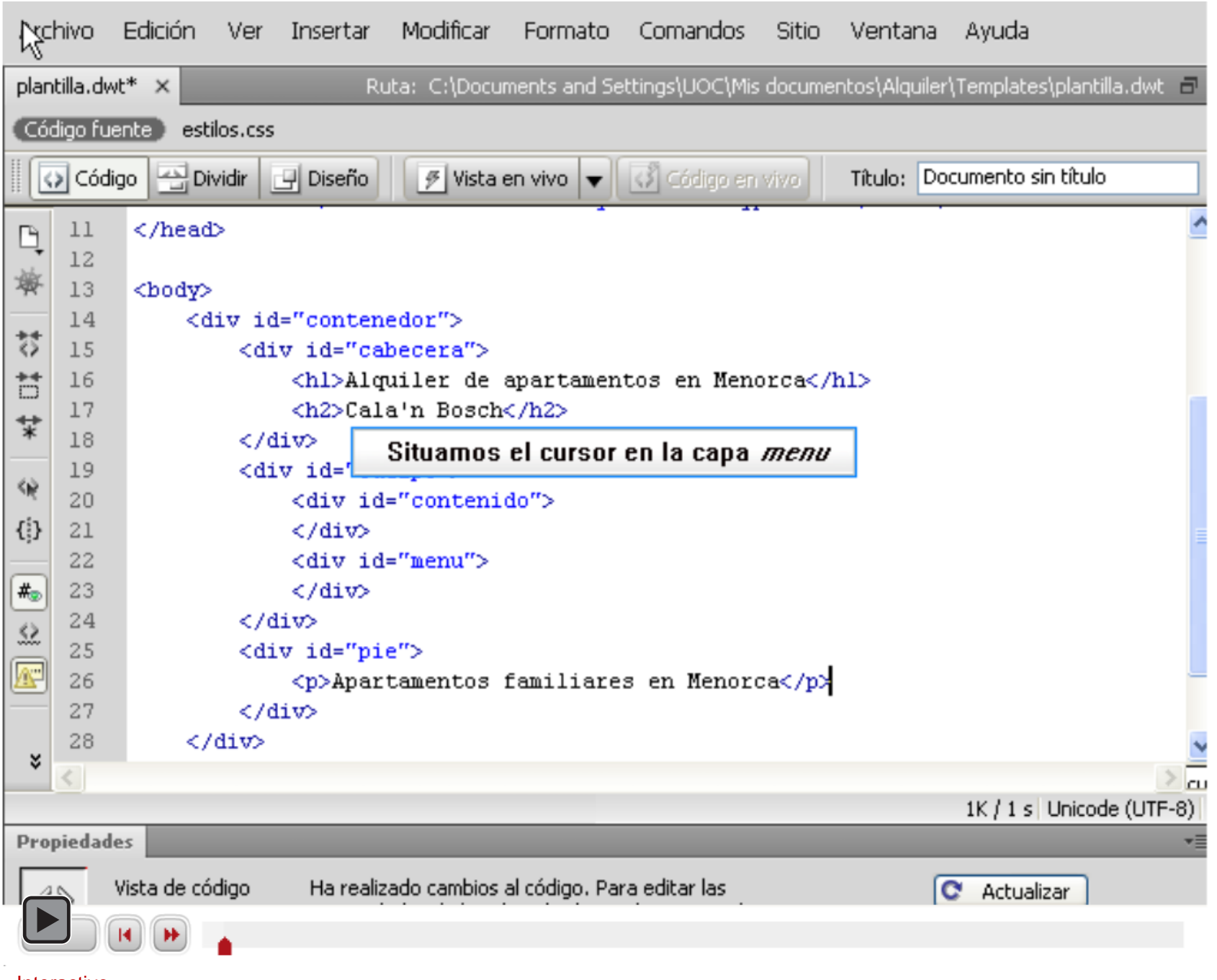

Interactivo 


\section{Tutorial 3. Crear un sitio}

\section{Desarrollo del tutorial: paso 14 de 18}

Ahora, en Dreamweaver, en vista de diseño, deberíamos ver esto:

Y en vista de código, el menú ha quedado de la siguiente

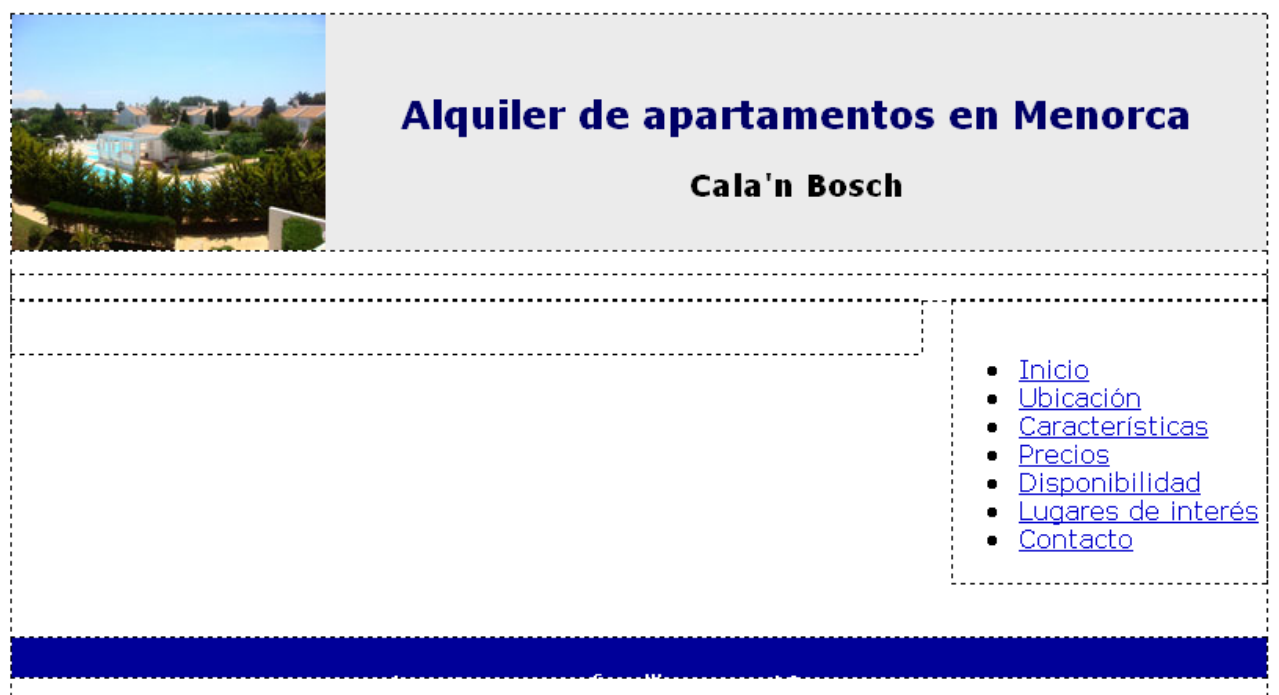
manera:

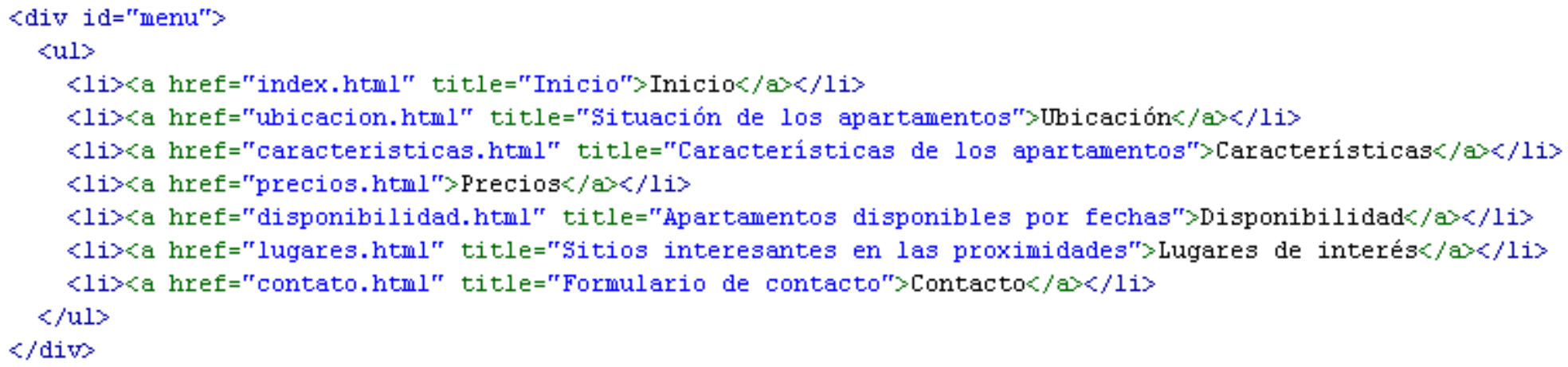


Tutorial 3. Crear un sitio

\section{Desarrollo del tutorial: paso 15 de 18}

Deberíamos ahora mejorar el aspecto del menú. Para ello añadiremos unas reglas en el archivo CSS.

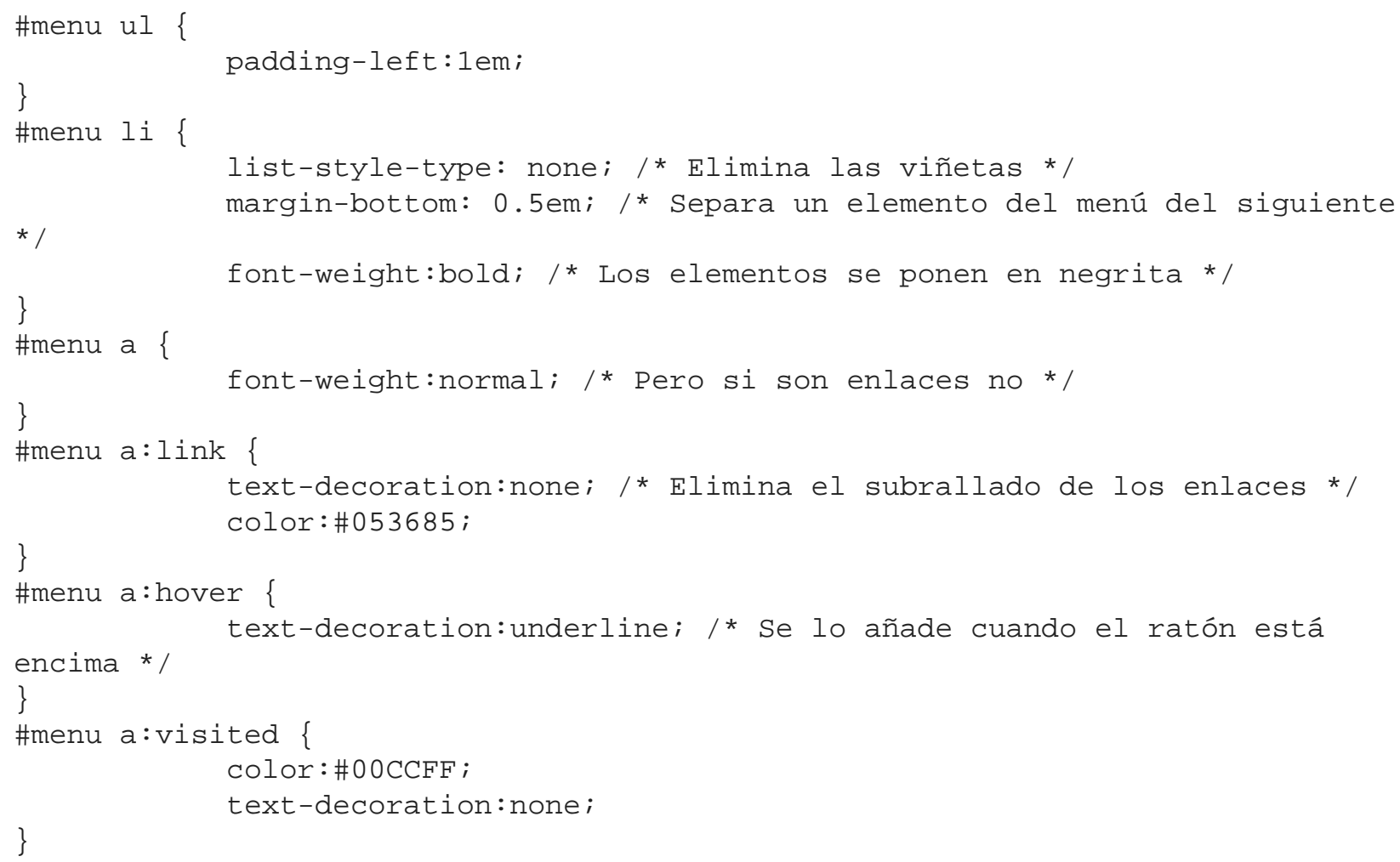

Antes de añadir las reglas, el menú es así:

- Inicio

- Ubicación

- Características

- Precios

- Disponibilidad

- Lugares de interés

- Contacto

Después de añadir las reglas, el menú queda así:

Inicio

Ubicación

Características

Precios

Disponibilidad

Lugares de interés Contacto 
Tutorial 3. Crear un sitio

\section{Desarrollo del tutorial: paso 16 de 18}

Y para dar por acabada la plantilla, ahora deberíamos definir las zonas editables. Dreamweaver ya ha marcado dos zonas editables.

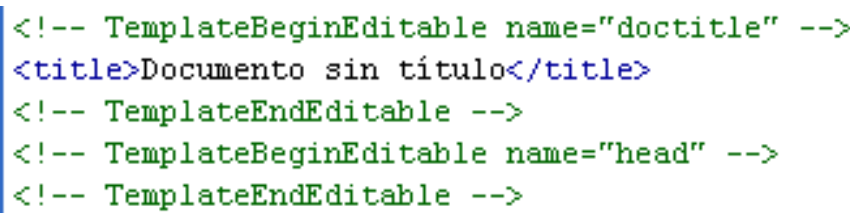

Deberíamos añadir al menos otras dos: una para la capa de contenido y otra para la capa del menú. Para añadir zonas editables, debemos, en vista de código, situar el cursor allí donde queramos hacer la zona editable e ir al menú y seleccionar Insertar-Objetos de plantilla-Región editable.

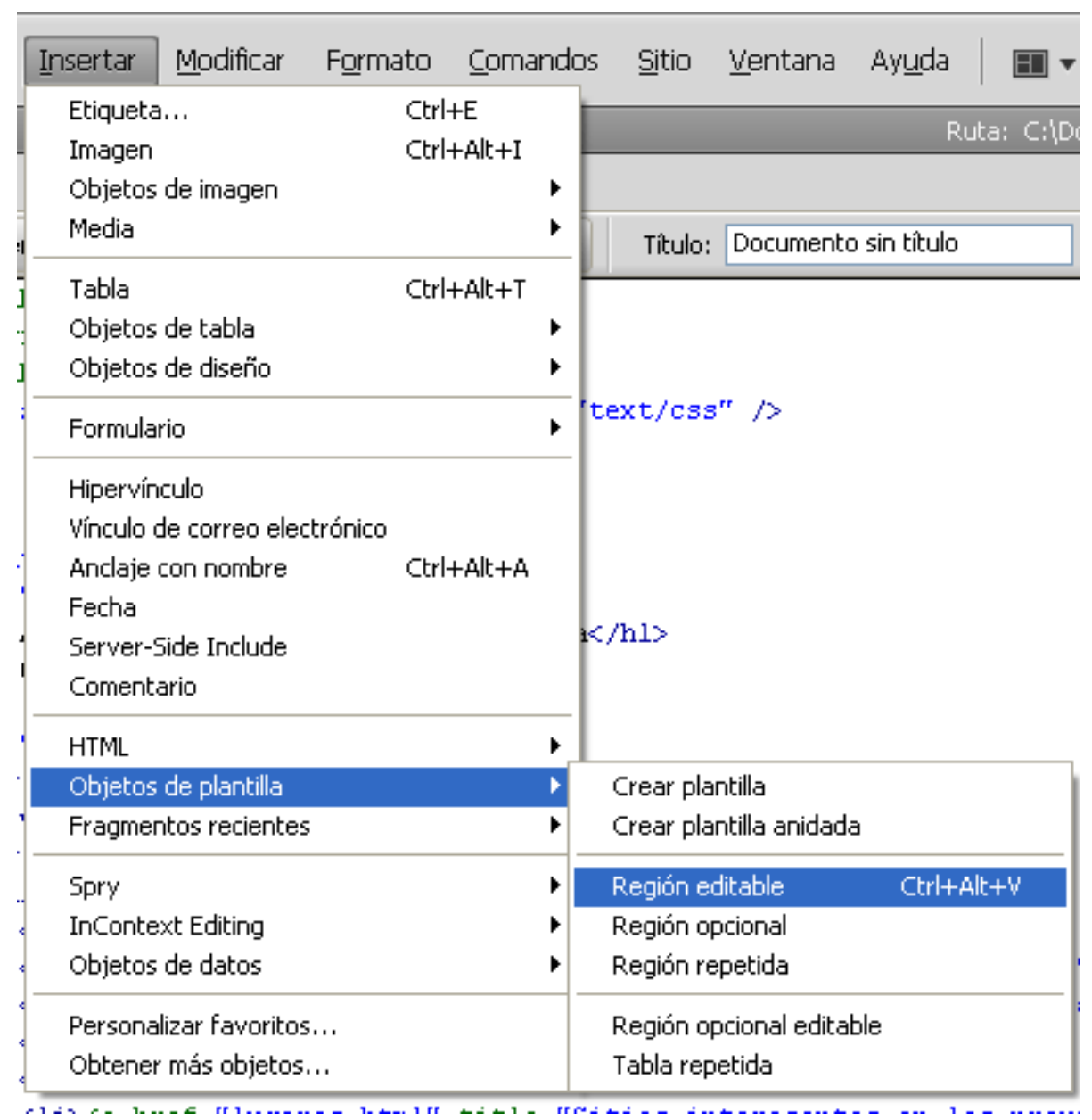


Tutorial 3. Crear un sitio

\section{Desarrollo del tutorial: paso 17 de 18}

Nos pedirá el nombre de esa región editable.

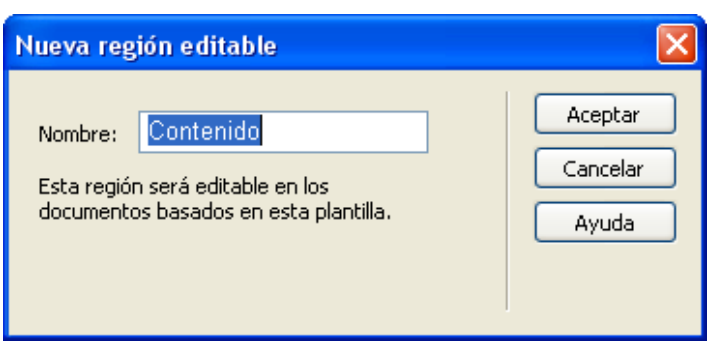

Y escribirá en el código el texto necesario para que esa zona pueda editarse cuando creemos una página a partir de la plantilla.

$\langle$ div id="contenido" $\rangle$

$<!--$ TemplateBeginEditable name="Contenido" -->Contenido $<!--$ TemplateEndEditable -->

Para la capa de menú, deberemos hacer lo mismo pero seleccionando antes todo el menú.

$\langle$ div id="menu"><!-- TemplateBeginEditable name="Menúr -->

$<u l>$

$<$ li $><a$ href="index.html" title="Iniciorr Inicio</a $></ 1 i>$

$<l i><a$ href="ubicacion.html" title="Situación de los apartamentos" $>$ Ubicación $</ a</ 1 i>$

$<l i><a$ href="caracteristicas.html" title="Características de los apartamentos" $>$ Caracteristicas $</ a\rangle</ 1 i\rangle$

$\langle 1 i>\langle a$ href $="$ precios.html" $>$ Precios $\langle/ a\rangle / 1 i\rangle$

$<$ li $><a$ href="disponibilidad.html" title="Apartamentos disponibles por fechas" $>$ Disponibilidad $/ a></ 1 i>$

$<$ li $><a$ href="lugares.html" title="Sitios interesantes en las proximidades" $>$ Lugares de interés $</ a></ 1\rangle$

$\langle$ li $>\langle a$ href="contato.html" title="Formulario de contactor" $>$ Contacto $\langle/ a\rangle\langle/ 1\rangle\rangle$ $</ u 1\rangle$

$<!--$ TemplateEndEditable $--></$ div $>$

Ya sólo nos queda guardar el documento y podremos usar la plantilla para hacer nuestra primera página web. 
Tutorial 3. Crear un sitio

\section{Desarrollo del tutorial: paso 18 de 18}

Para asentar los conceptos desarrollados en este tutorial, se recomienda hacer las siguientes actividades.

- Cread un nuevo sitio web, llamado museo.

- Cread una nueva plantilla para el sitio museo, con la siguiente estructura:

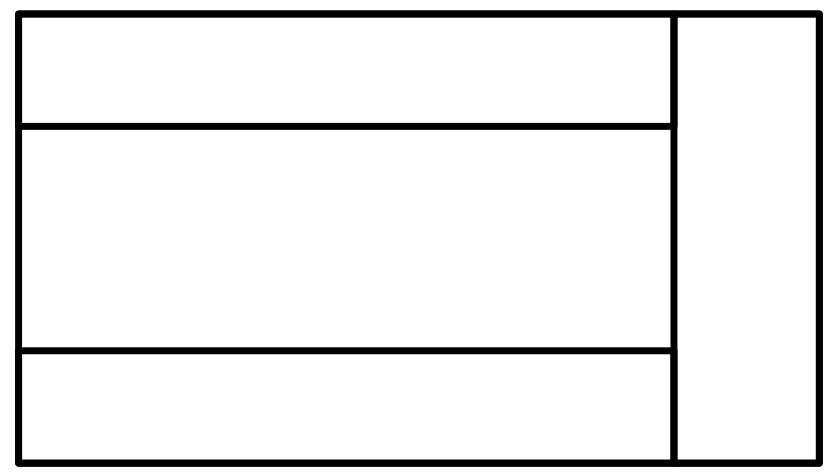

- Poned un título en la parte superior de la página.

- Poned una imagen en la parte superior de la capa de la derecha.

- Definid las zonas editables de la página.

- Guardad la plantilla. 
Tutorial 4. Añadir fotografías y enlaces a lugares de interés

\section{Desarrollo del tutorial: paso 1 de 13}

Con la plantilla que hemos creado en el tutorial anterior, vamos a hacer la primera página del sitio.

Empezaremos por la página de inicio. En el menú de Dreamweaver, seleccionamos Archivo-Nuevo... Aparecerá un cuadro de diálogo donde podremos seleccionar que queremos crear una página desde una plantilla, del sitio Alquiler y con la plantilla llamada plantilla. Dreamweaver muestra una previsualización de la plantilla.

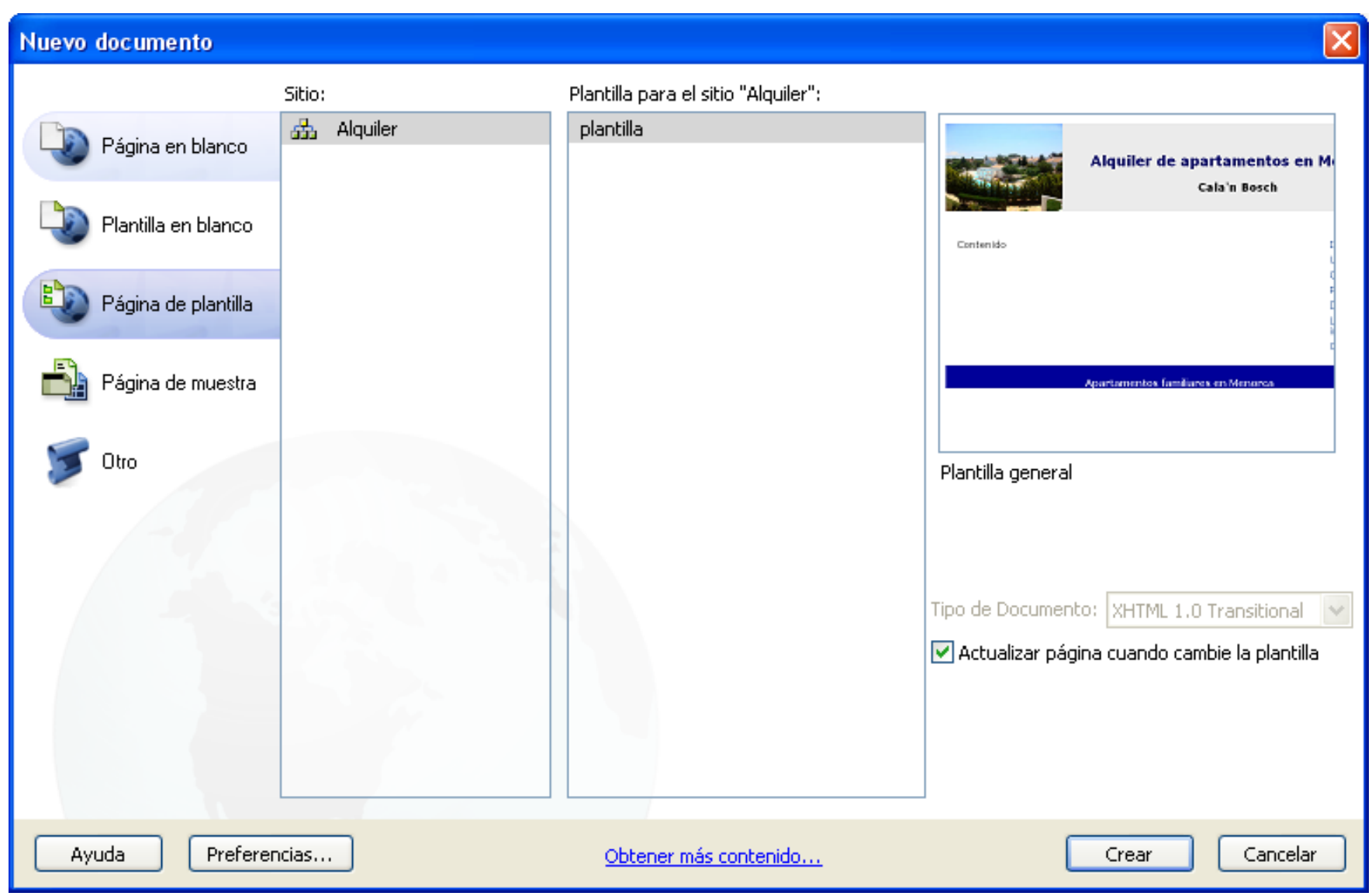


Tutorial 4. Añadir fotografías y enlaces a lugares de interés

\section{Desarrollo del tutorial: paso 2 de 13}

Una vez abierto el nuevo documento desde la plantilla, Dreamweaver se pone en vista de código, mostrando en gris claro todo el código "bloqueado".

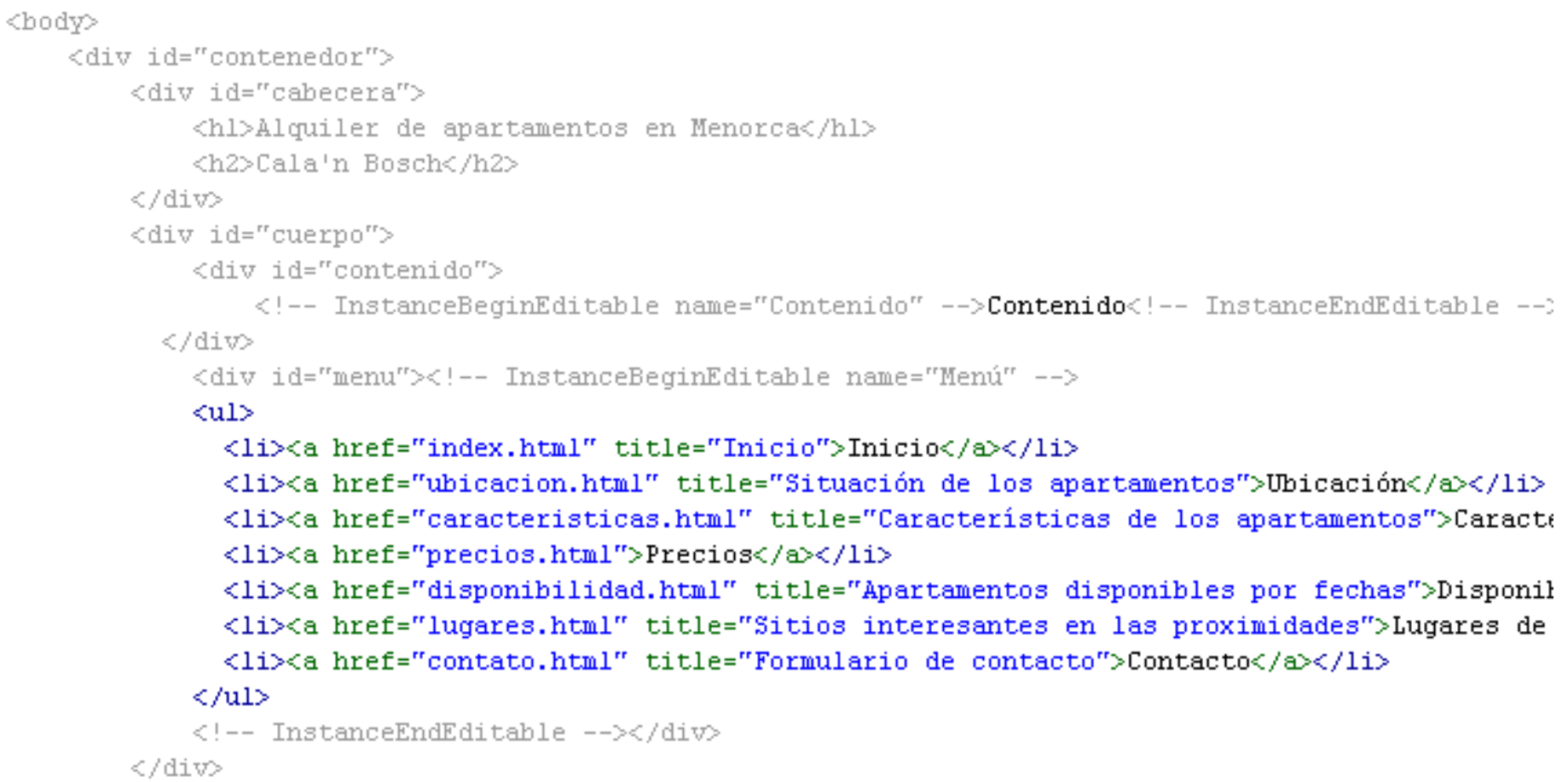


Tutorial 4. Añadir fotografías y enlaces a lugares de interés

\section{Desarrollo del tutorial: paso 3 de 13}

Creemos la página inicial. Esta página, cuyo nombre será index.html, tendrá un texto genérico. Introduciremos ese texto en el apartado de contenido y eliminaremos el enlace de la opción de menú Indice.

\section{Una vez introducido el texto,}

seleccionamos la palabra Inicio para borrar el enlace (aunque parezca un modo poco sofisticado, nos resulta útil para este tutorial).

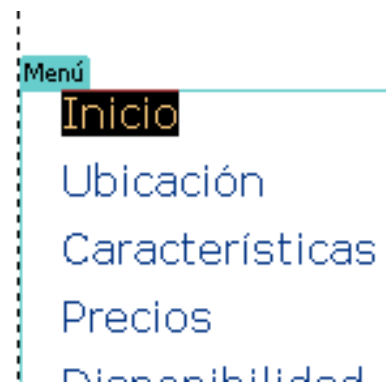

\section{Contenido \\ Apartamentos de alquiler en Cala'n Bosh en Menorca}

Apartamentos de entre 60 y 65 metros cuadrados con zona comunitaria ajardinada y tres piscinas.

Situados a 100 metros de la playa de Son Xoriguer, a 500 metros del puerto de Cala'n Bosch y a 6 lquilómetros de la ciudad de Ciutadella.

La zona comunitaria se compone de 700 metros cuadrados de jardines y tres piscinas.

Los apartamentos pueden ser en primera planta o en planta baja con acceso directo a la zona ajardinada.

Fácil aparcamiento en la zona.

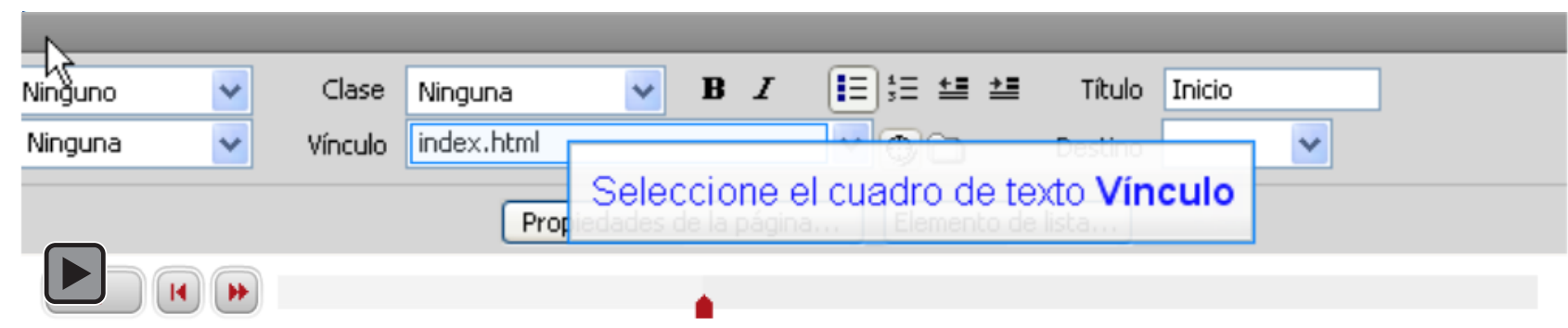


Tutorial 4. Añadir fotografías y enlaces a lugares de interés

\section{Desarrollo del tutorial: paso 4 de 13}

Al elaborar esta primera página, nos damos cuenta de un detalle: necesitamos diferenciar contenido y menú de alguna manera.

Para diferenciar el menú del contenido, modificaremos el fondo de la capa cuerpo. Podemos editar directamente el archivo CSS, o editarlo a través del cuadro de diálogo de edición de las reglas CSS de Dreamweaver.
Categoría

Tipo
Fondo

$$
\text { Background-color: }
$$

Background-image:

imgiffondo2.jpg

Background-repeat:

\section{Alquiler de apartamentos en Menorca}

\section{Cala'n Bosch}

El resultado es éste:

Inicio

Ubicación

Características

Precios

Disponibilidad

Lugares de interés

Contacto

La zona comunitaria se compone de 700 metros cuadrados de jardines y tres piscinas.

Ls apartamentos pueden ser en primera planta o en planta

baja con acceso directo a la zona ajardinada.

Fácil aparcamiento en la zona. 
Tutorial 4. Añadir fotografías y enlaces a lugares de interés

\section{Desarrollo del tutorial: paso 5 de 13}

Nos falta un paso antes de dar por acabada esta página inicial. El título de la página es, en estos momentos, "Documento sin título". Como título, le pondremos: "Alquiler de apartamentos en Menorca".

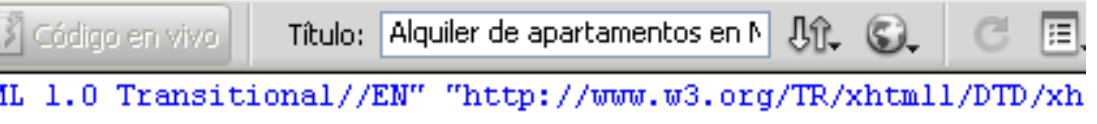
-..

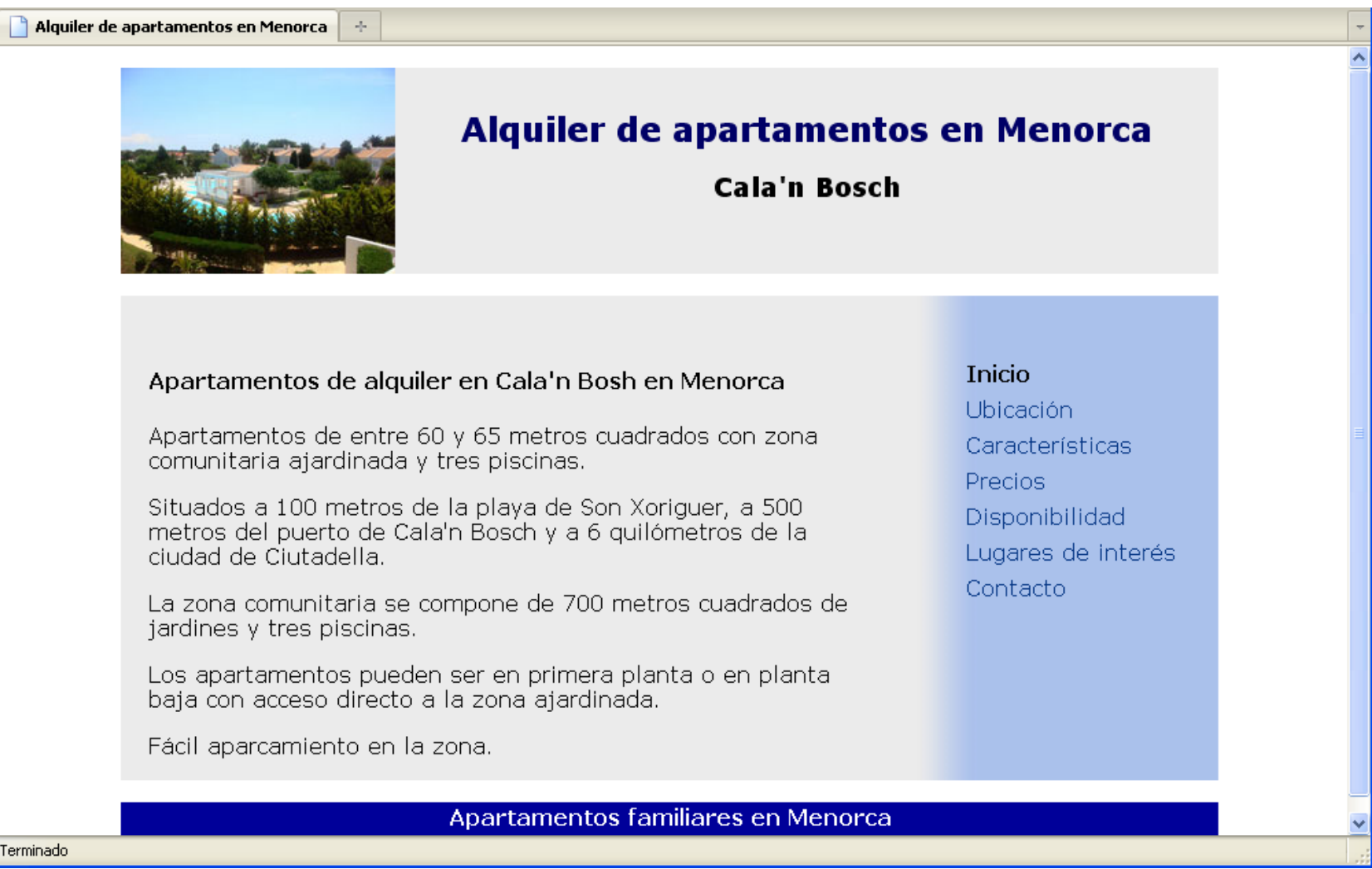

Una vez acabada la página inicial, lo guardamos todo (tanto la página HTML como el CSS), desde Archivo-Guardar todo Finamente, con F12 podemos ver una vista preliminar de nuestra página. 
Tutorial 4. Añadir fotografías y enlaces a lugares de interés

\section{Desarrollo del tutorial: paso 6 de 13}

Una vez acabada la página inicial, vamos a elaborar una nueva página de lugares de interés, que contendrá una relación de webs de sitios próximos. Pondremos en ella enlaces e imágenes relacionadas.

Tal y como hicimos para la primera página, crearemos un nuevo archivo a partir de la plantilla. Antes de empezar con el contenido de la página, cambiaremos su título por "Alquiler de apartamentos en Menorca-Lugares de interés" (sin las comillas) y quitaremos el enlace Lugares de Interés de la barra lateral.

Para cada lugar de interés pondremos un título (con la etiqueta h3), una imagen alineada a la derecha, un texto explicativo y una lista de enlaces donde encontrar más información.

Antes de empezar, modificaremos el archivo CSS añadiendo una regla específica para que las imágenes, en la capa contenido, queden alineadas a la izquierda y con el texto a la derecha.

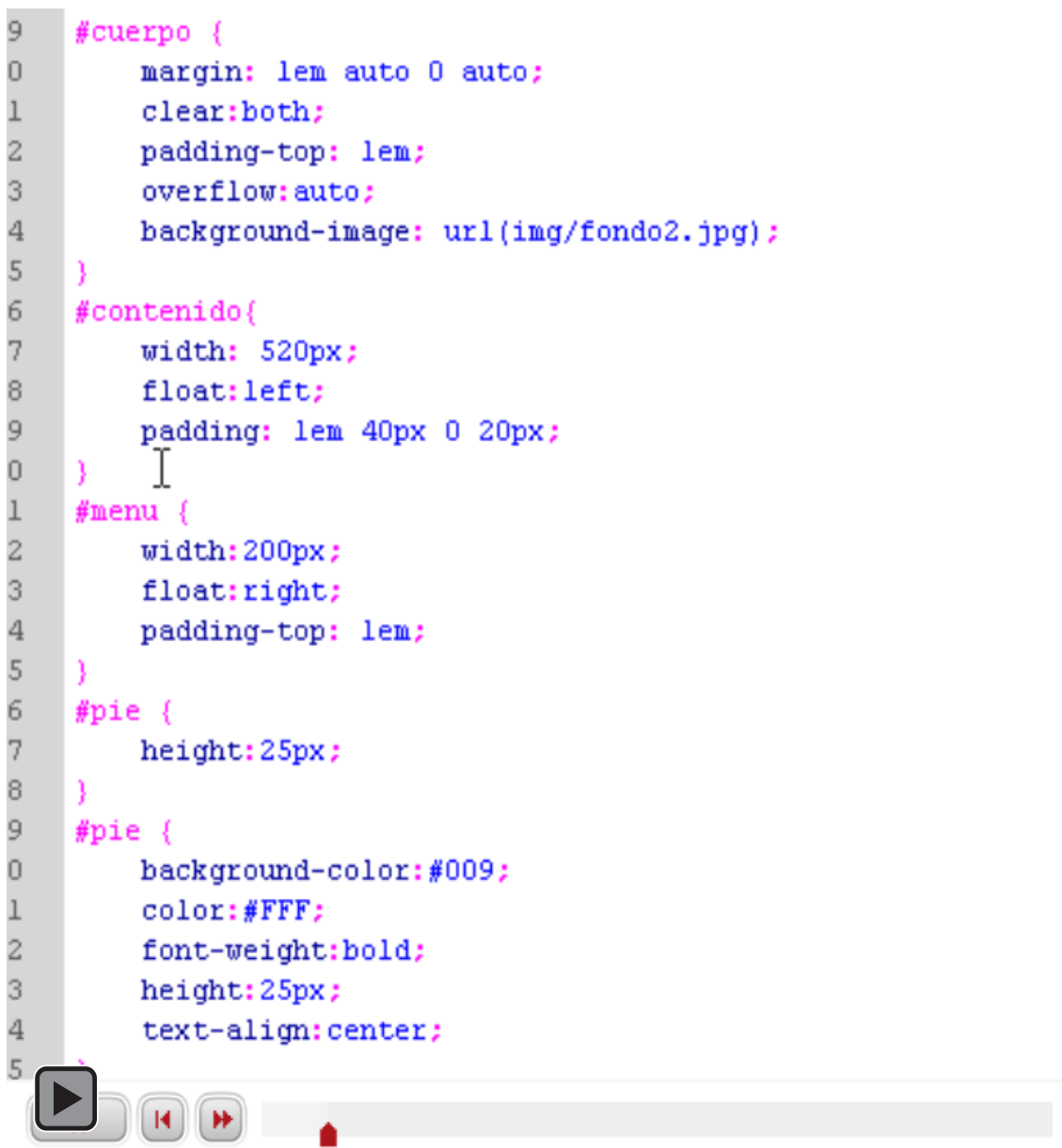


Tutorial 4. Añadir fotografías y enlaces a lugares de interés

\section{Desarrollo del tutorial: paso 7 de 13}

Vamos a añadir la información referente a la Naveta des Tudons

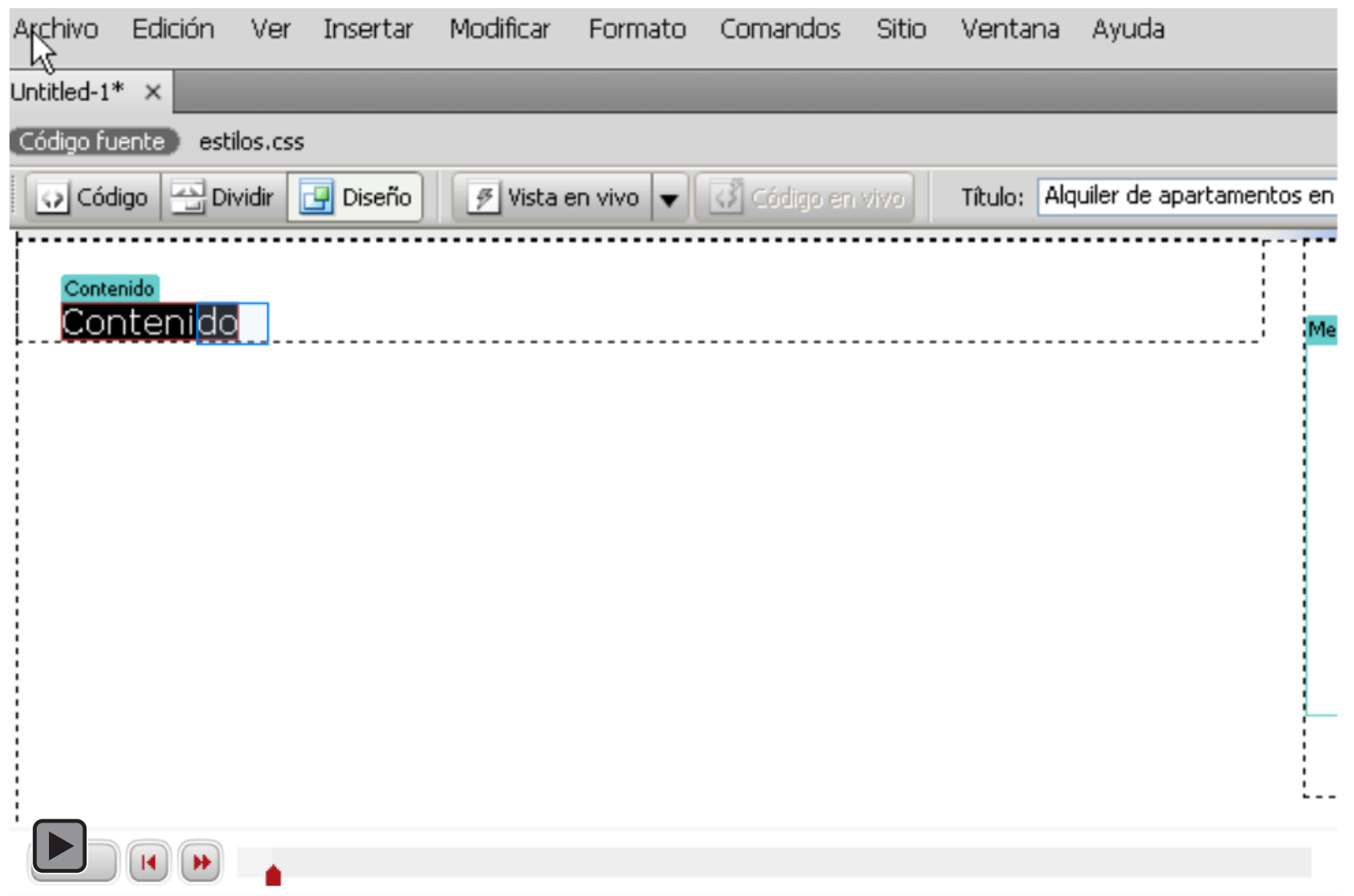

Deberíamos cambiar algunas cosas para mejorar la presentación... 
Tutorial 4. Añadir fotografías y enlaces a lugares de interés

Desarrollo del tutorial: paso 9 de 13

Nos falta asignar la clase texto a los párrafos escritos.

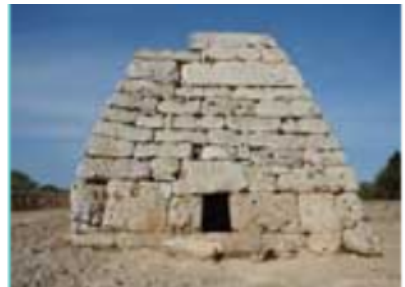

sin mortero.

La Naveta des Tudons es un monumento funeriario de unos 3.000 años de antigüedad. Está considerada como uno de los yacimientos arqueológicos más emblemáticos de Menorca. Tiene dos plantas y su construcción está hecha a base de piect pas perfectamente encajadas

Se encuentra cerca de Ciudadela, en el kilómetro 40 de la carretera que va de Ciudadela a Maó.

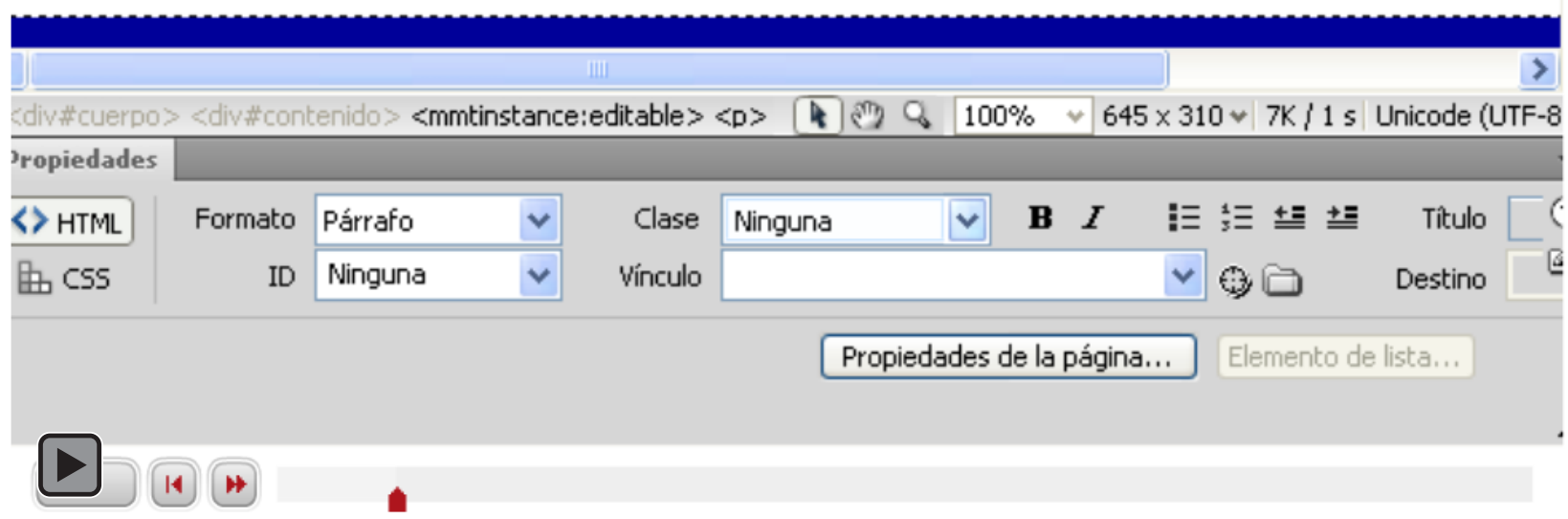


Tutorial 4. Añadir fotografías y enlaces a lugares de interés

\section{Desarrollo del tutorial: paso 10 de 13}

Añadimos el siguiente texto explicativo, con sus correspondientes enlaces:

Se puede encontrar más información en la wikipedia, en la página web

MenorcaWeb y en la Xarxa Menorca

Monumental (pdf)

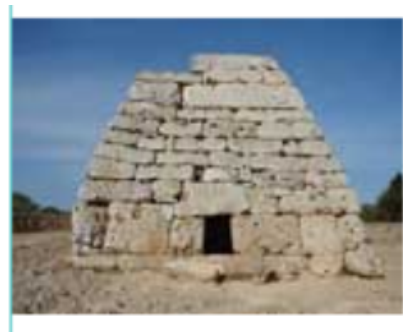

La Naveta des Tudons es un monumento funeriario de unos 3.000 años de antigüedad. Está considerada como uno de los yacimientos arqueológicos más emblemáticos de Menorca. Tiene dos plantas y su construcción está hecha a base de piedras perfectamente encajadas sin mortero.

Se encuentra cerca de Ciutadella, en el kilómetro 40 de la carretera que va de Ciudadela a Maó

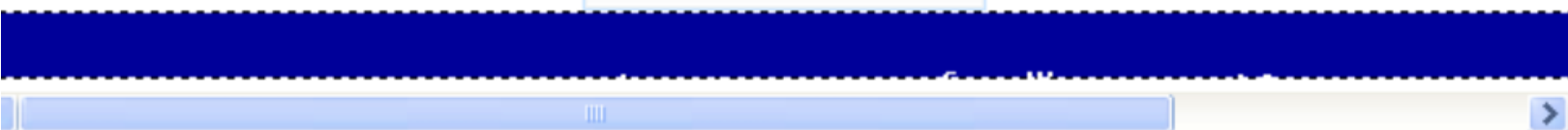

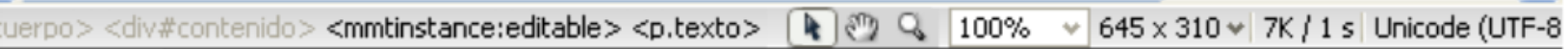
ropiedades

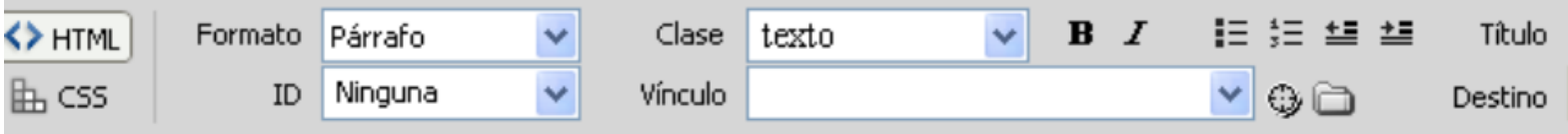

Los textos enlazan a:

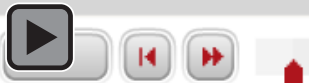

wikipedia: http://es.wikipedia.org/wiki/Naveta_des_Tudons 
Tutorial 4. Añadir fotografías y enlaces a lugares de interés

\section{Desarrollo del tutorial: paso 11 de 13}

Como la imagen de la Naveta des Tudons es muy pequeña, vamos a poner en ella un enlace para que se abra la misma imagen pero en un tamaño más grande.

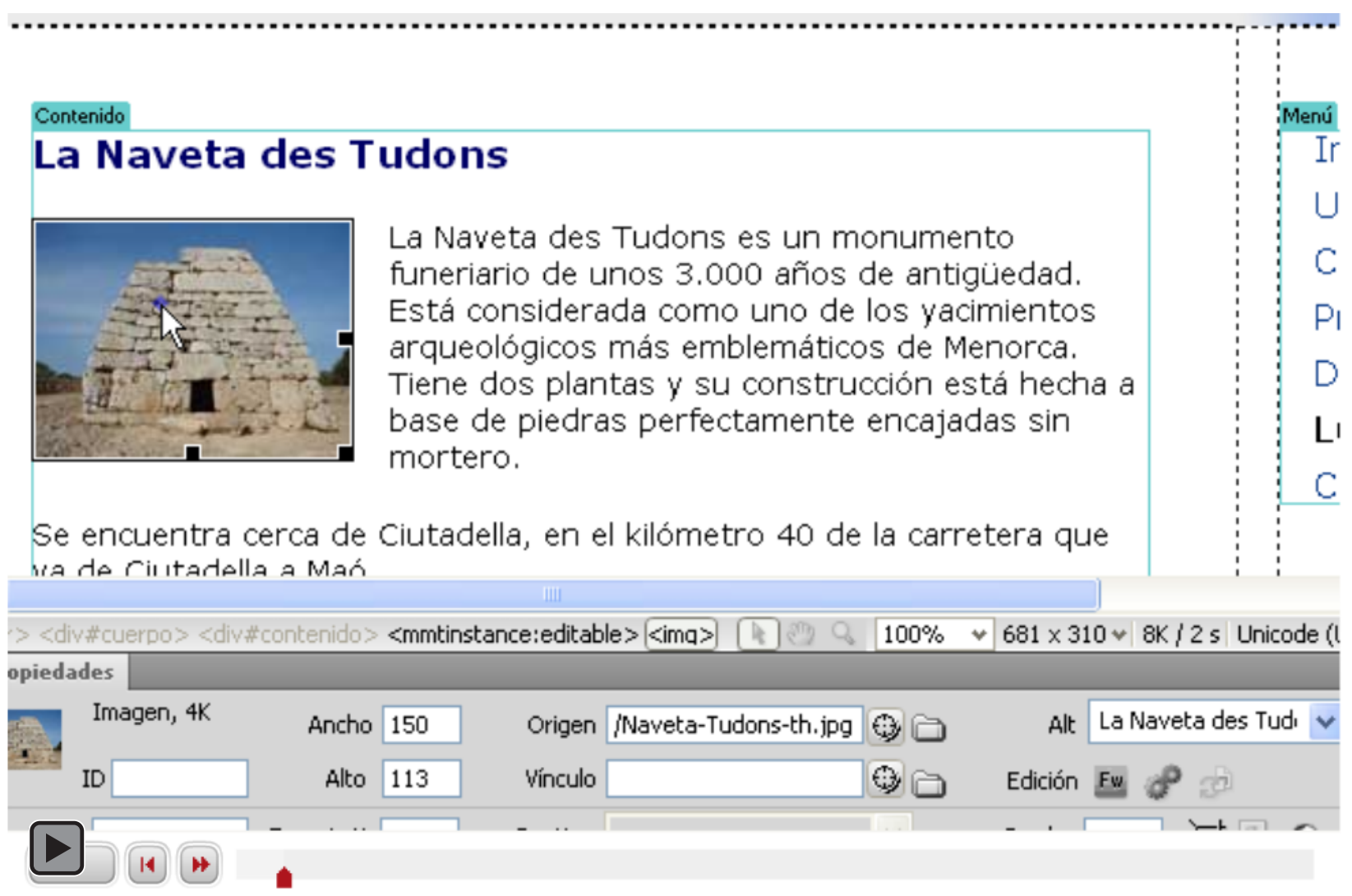


Tutorial 4. Añadir fotografías y enlaces a lugares de interés

Desarrollo del tutorial: paso 12 de 13

Siguiendo los mismos pasos, podemos añadir nuevos sitios de interés. Ahora la página queda así:

Alquiler de apartamentos en Menorca.

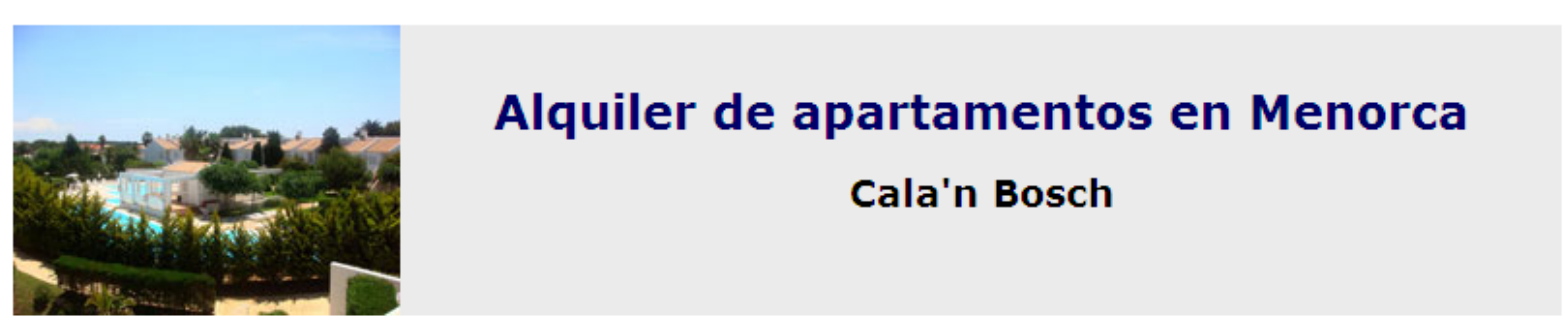

\section{La Naveta des Tudons}

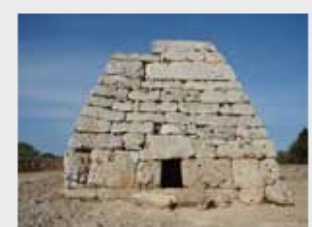

La Naveta des Tudons es un monumento funerario de unos 3.000 años de antigüedad.

Está considerada como uno de los yacimientos

arqueológicos más emblemáticos de Menorca.

Tiene dos plantas y su construcción está hecha a

base de piedras perfectamente encajadas sin

mortero.

Se encuentra cerca de Ciutadella, en el kilómetro 40 de la carretera que va de Ciutadella a Maó.

Se puede encontrar más información en la Wikipedia, en la página web MenorcaWeb y en la Xarxa Menorca Monumental (pdf).

\section{Platja de Macarella}

La platja de Macarella está considerada como una de las plavas más bonitas de Menorca. Se
Inicio

Ubicación

Características

Precios

Disponibilidad

Lugares de interés

Contacto 
Tutorial 4. Añadir fotografías y enlaces a lugares de interés

\section{Desarrollo del tutorial: paso 13 de 13}

Para asentar los conceptos desarrollados en este tutorial, se recomienda hacer la siguiente actividad.

Añadid un nuevo sitio de interés en la página realizada en este tutorial. Puede ser, por ejemplo, el puerto de la ciudad de Ciudadela. Se puede encontrar información sobre el puerto en la wikipedia ${ }^{1}$.

El nuevo sitio debe incluir:

- un título con el nombre del lugar,

- una fotografía, que debe subirse recortada al tamaño adecuado,

- al menos tres párrafos de información,

- uno o varios enlaces con la información relacionada.

1 http://es.wikipedia.org/wiki/Ciudadela_(España) 


\section{Tutorial 5. Catálogo de apartamentos}

\section{Desarrollo del tutorial: paso 1 de 16}

En la comunidad de vecinos existen cuatro tipos de apartamentos; cada apartamento tiene unas características determinadas, por lo que conviene comentarlas. Para hacer tal descripción, usaremos una lista de definición. Empezaremos por escribir el texto y después veremos cómo mejorar la presentación.

En primer lugar, debemos crear una nueva página y adaptarla a la opción del menú con la que se va a abrir. Los pasos serán lo siguientes:

- crear la página a partir de la plantilla,

- quitar el enlace de la opción de menú Características,

- cambiar el título de la página por Alquiler de apartamentos en Menorca-Características,

- guardar la página con el nombre caracteristicas.html.

El resultado será éste:

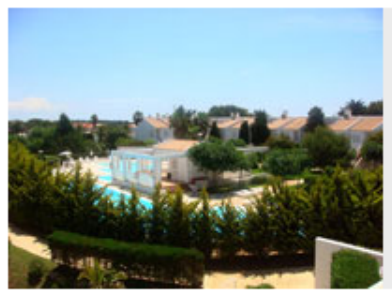

\section{Alquiler de apartamentos en Menorca}

Cala'n Bosch

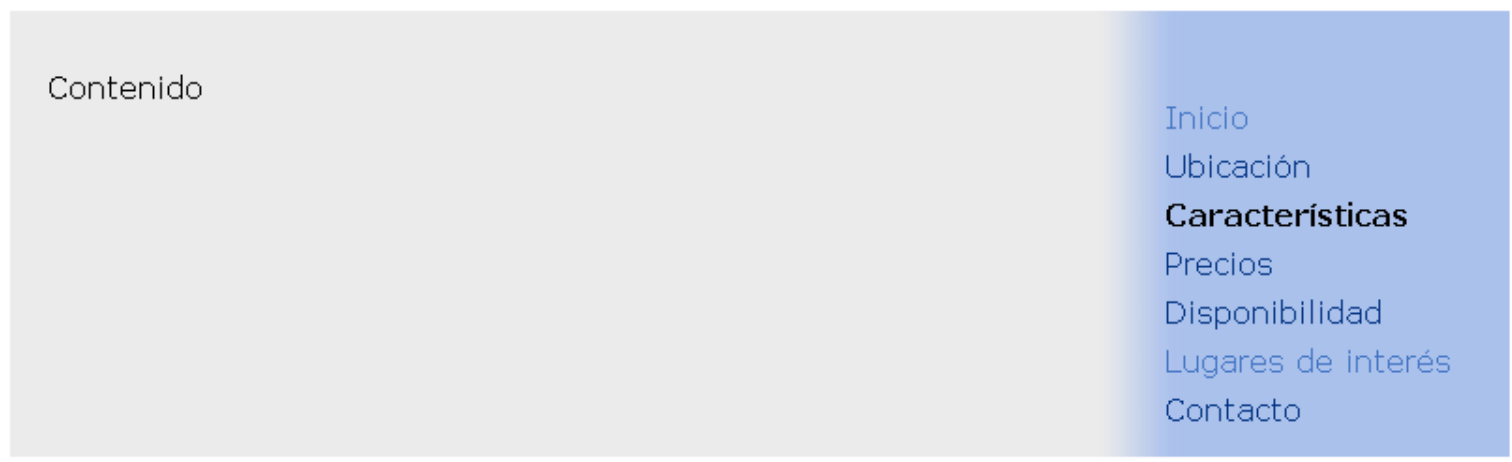


Tutorial 5. Catálogo de apartamentos

\section{Desarrollo del tutorial: paso 2 de 16}

Para crear la lista de definición, vamos al menú, Formato-Lista-Lista de definición.

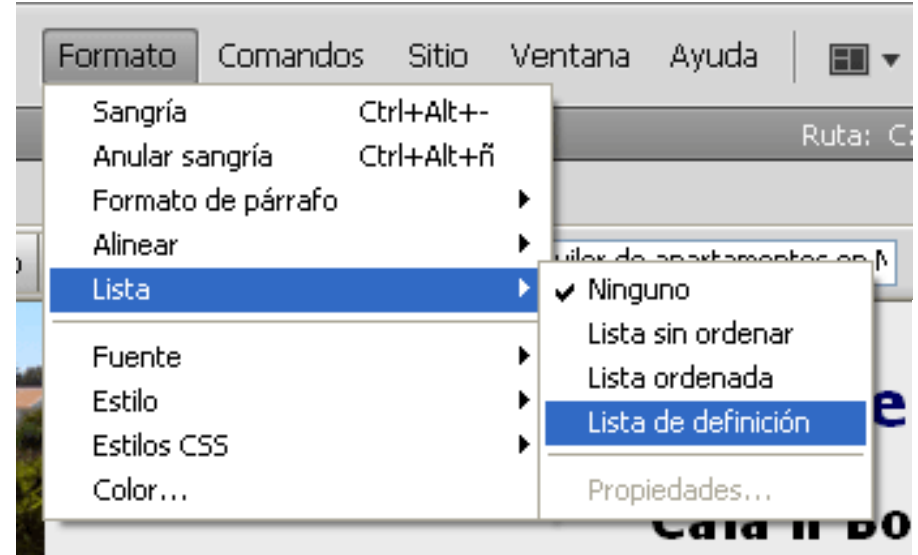

Una vez indicado que es una lista de definición, podemos escribir el texto.

Dreamweaver entenderá que lo primero que escribimos es un título y que cada vez que pulsemos la tecla Intro significará pasar de título a definición y al revés. Así, escribimos nuestro texto normalmente, y nos quedará esto:

\section{Contenido}

Apartamentos zona 1. Bajos

Apartamentos de 65 metros cuadrados, orientación este oeste y situados en planta baja. Tienen un jardín de 10 m2. Acceso directo al aparcamiento.

Apartamentos zona 1. Primer piso

Apartamentos de 60 metros cuadradok con una terraza de $5 \mathrm{~m} 2$. Tienen orientación este-oeste y sol todo el día. Acceso directo al aparcamiento.

Apartamentos zona 2. Bajos

Apartamentos de 65 metros cuadrados, orientación norte sur y situados en planta baja. Jardín de 10 metros

cuadrados con acceso directo a la zona comunitaria.

Apartamentos zona 2. Primer piso

Apartamentos de 60 metros cuadrados con una terraza

de $5 \mathrm{~m} 2$. Tienen orientación norte - sur y acceso directo a la zona comunitaria. 
Tutorial 5. Catálogo de apartamentos

Desarrollo del tutorial: paso 3 de 16

El resultado es poco vistoso. Modificando el archivo CSS podremos mejorarlo.

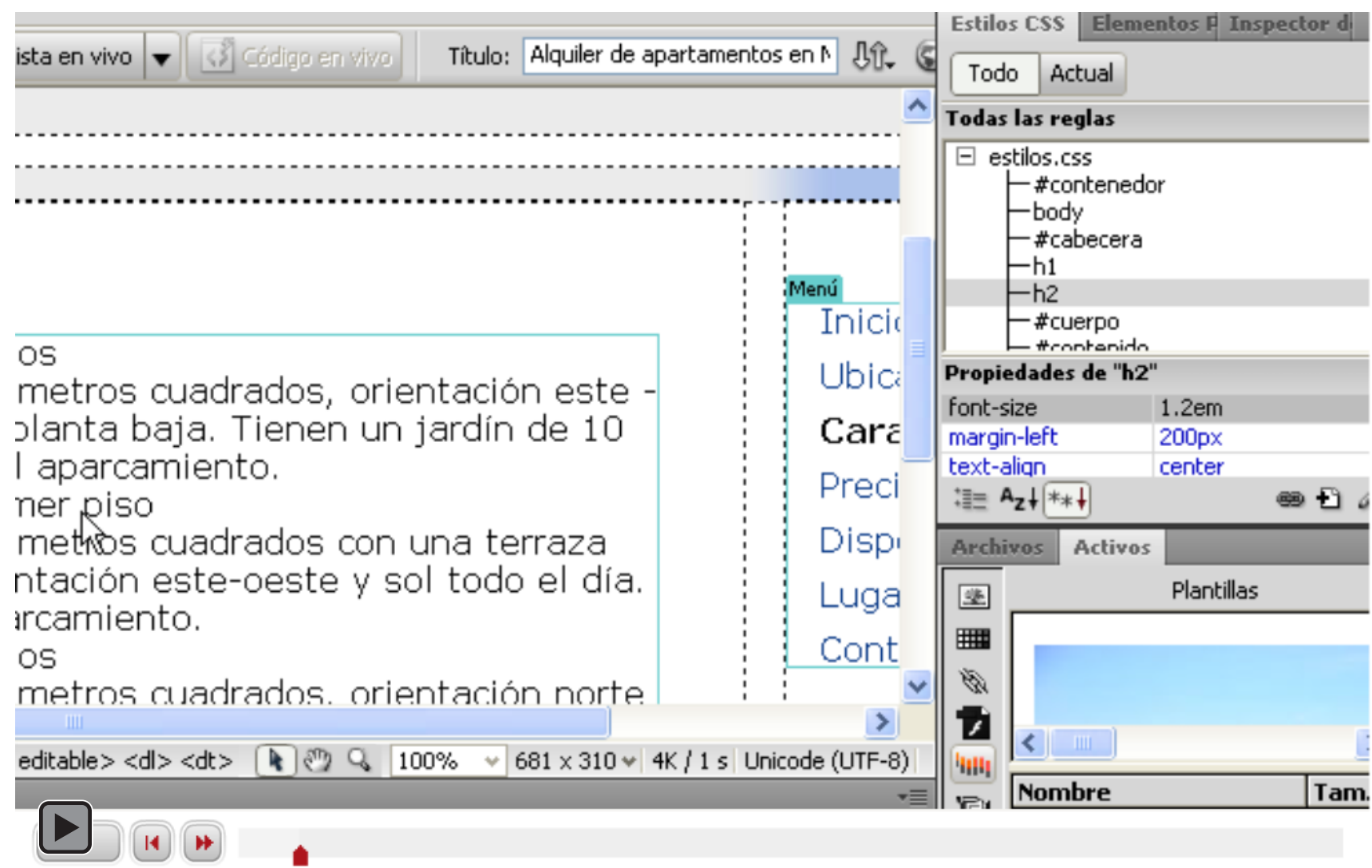


Tutorial 5. Catálogo de apartamentos

\section{Desarrollo del tutorial: paso 4 de 16}

Para cambiar el CSS que afecta a la definición, modificaremos directamente el archivo CSS incorporando la siguiente regla:

dd \{

margin-top: $0.5 \mathrm{em}$;

margin-bottom: $1 \mathrm{em}$;

font-size: $0.9 \mathrm{em}$;

\}

Apartamentos de 65 metros cuadrados, orie situados en planta baja. Jardín de 10 metros directo a la zona comunitaria.

$\mathrm{Si}$, una vez guardados los dos archivos, hacemos una vista preliminar, nos encontraremos con esto:

\section{Apartamentos zona 2. Primer piso}

Apartamentos de 60 metros cuadrados con Tienen orientación norte - sur y acceso direc comunitaria.

Vemos que aparece una barra azul no deseada debajo del último texto. Esto se debe a que Dreamweaver ha añadido un <dt $>$ al final del texto. Deberemos quitarlo desde la vista de código:

<dd Apartamentos de $60 \mathrm{II}$

aitaria. $\langle/$ dd $\rangle$

$<\mathrm{dt}>\&$ nbsp $;</ \mathrm{dt}>$

$\langle/ \mathrm{d} l\rangle$

$<!--$ InstanceEndEditable --> 


\section{Tutorial 5. Catálogo de apartamentos}

\section{Desarrollo del tutorial: paso 5 de 16}

Dado que la lista de definición se refiere a las características de los apartamentos, vamos a poner un título que lo diga.

Pero tenemos un problema. Dreamweaver no nos permitirá, en vista de diseño, salir de la lista de definición para llegar al principio del texto. Para ver claramente el problema, seleccionamos la vista Dividir y, desde la visualización de diseño intentamos llevar el cursor fuera de la lista de definición.

En la imagen de la izquierda tenemos la vista Dividir, en la que se observa en la parte inferior el diseño y en la parte superior el código. En el código, vemos el cursor al principio de la A de Apartamentos. Para poder poner el título, debemos mover el cursor en la vista de código.

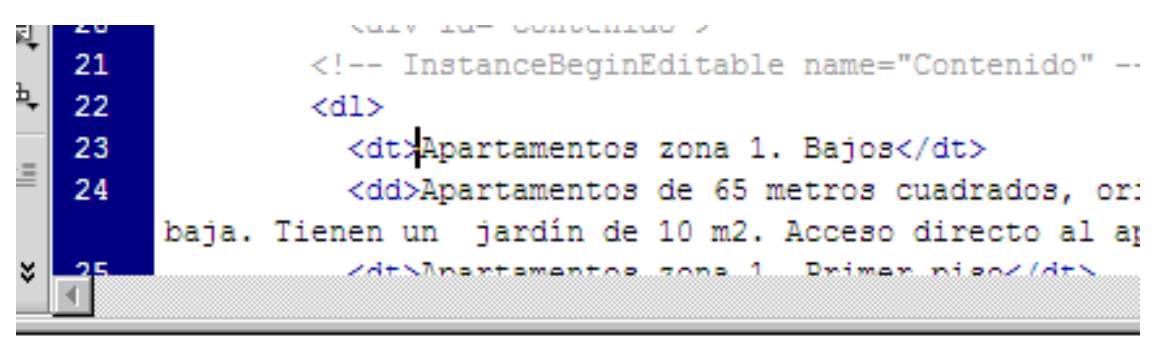

\section{Apartenido}

Apartamentos de 65 metros cuadrados, orientación situados en planta baja. Tienen un jardín de $10 \mathrm{~m} 2$. al aparcamiento.

\section{Apartamentos zona 1. Primer piso}

\section{Contenido}

\section{Características de los apartamentos}

\section{Apartamentos zona 1. Bajos}

Apartamentos de 65 metros cuadrados, orientación este situados en planta baja. Tienen un jardín de $10 \mathrm{~m} 2$. Acc al aparcamiento.
Para poder poner el título, deberemos situar el cursor delante de la etiqueta $<$ dl $>$ directamente desde la vista de código.

Una vez allí, tan solo queda escribir el texto "Características de los apartamentos" y aplicarle la etiqueta h3. 
Tutorial 5. Catálogo de apartamentos

\section{Desarrollo del tutorial: paso 6 de 16}

El siguiente paso será añadir las características de la zona comunitaria. Empezaremos por poner el título: "Características de la zona comunitaria", y a continuación las detallaremos.

Para esta lista, usaremos una lista no ordenada a la que cambiaremos las viñetas mediante CSS.

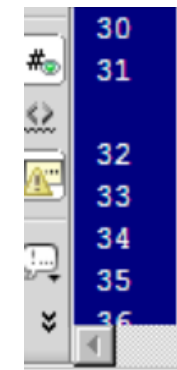

〈dt>Apartamentos zona 2. Primer piso</dt>

<dd>Apartamentos de 60 metros cuadrados con una terraza de $5 \mathrm{~m} 2$. orientación norte - sur y acceso directo a la zona comunitaria.</dd $>$

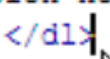

\section{Apartamentos zona 2. Primer piso}

Apartamentos de 60 metros cuadrados con una terraza de $5 \mathrm{~m} 2$.

Tienen orientación norte - sur y acceso directo a la zona

comunitaria.

$$
\text { Pulse la tecla Enter }
$$

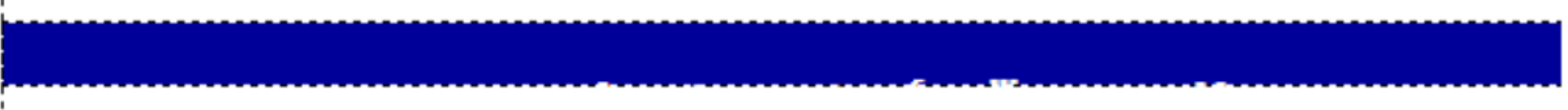

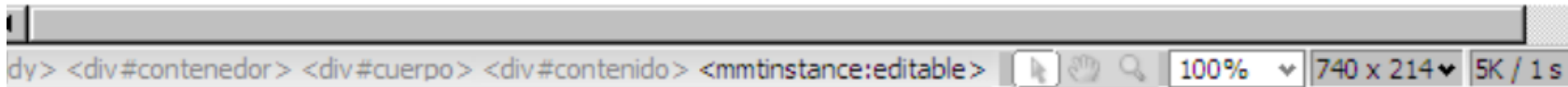
Propiedades

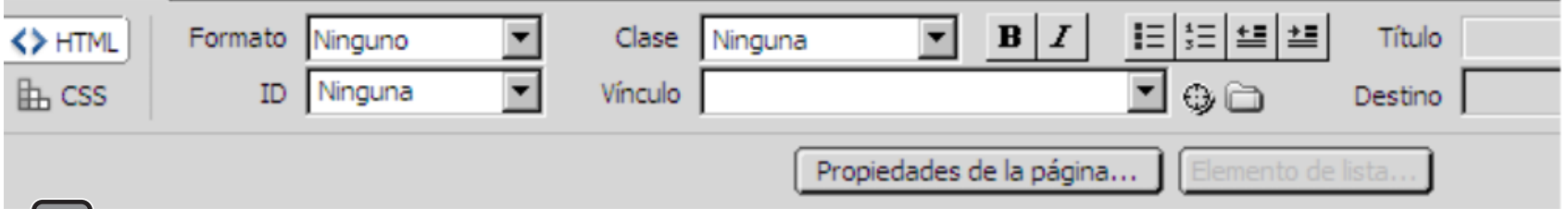

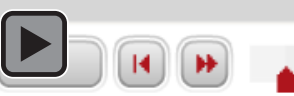

Interactivo 
Tutorial 5. Catálogo de apartamentos

\section{Desarrollo del tutorial: paso 7 de 16}

Vamos a cambiar la viñeta y el tamaño del texto de la lista, de manera que quede mejor con el conjunto de la página. Para ello, crearemos una nueva regla en el archivo CSS:

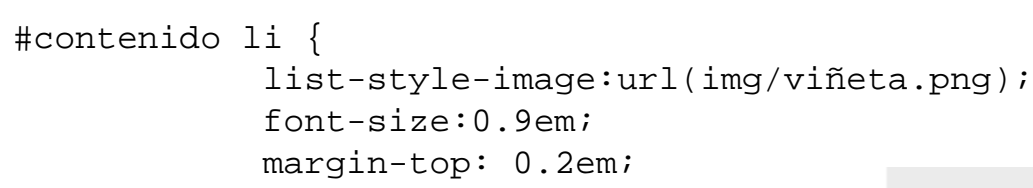

\section{Características de la zona comunitaria}

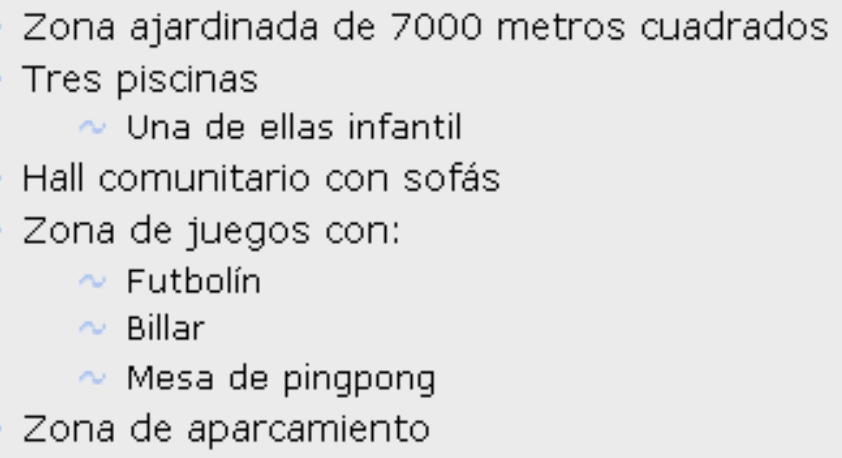




\section{Tutorial 5. Catálogo de apartamentos}

\section{Desarrollo del tutorial: paso 8 de 16}

Hasta ahora no hemos comprobado si nuestra plantilla es accesible o si respeta los estándares. Así que, antes de continuar, abramos la plantilla y hagamos las comprobaciones necesarias.

Cerramos el archivo caracteristicas.html (guardando los cambios si es necesario) y abrimos la plantilla.

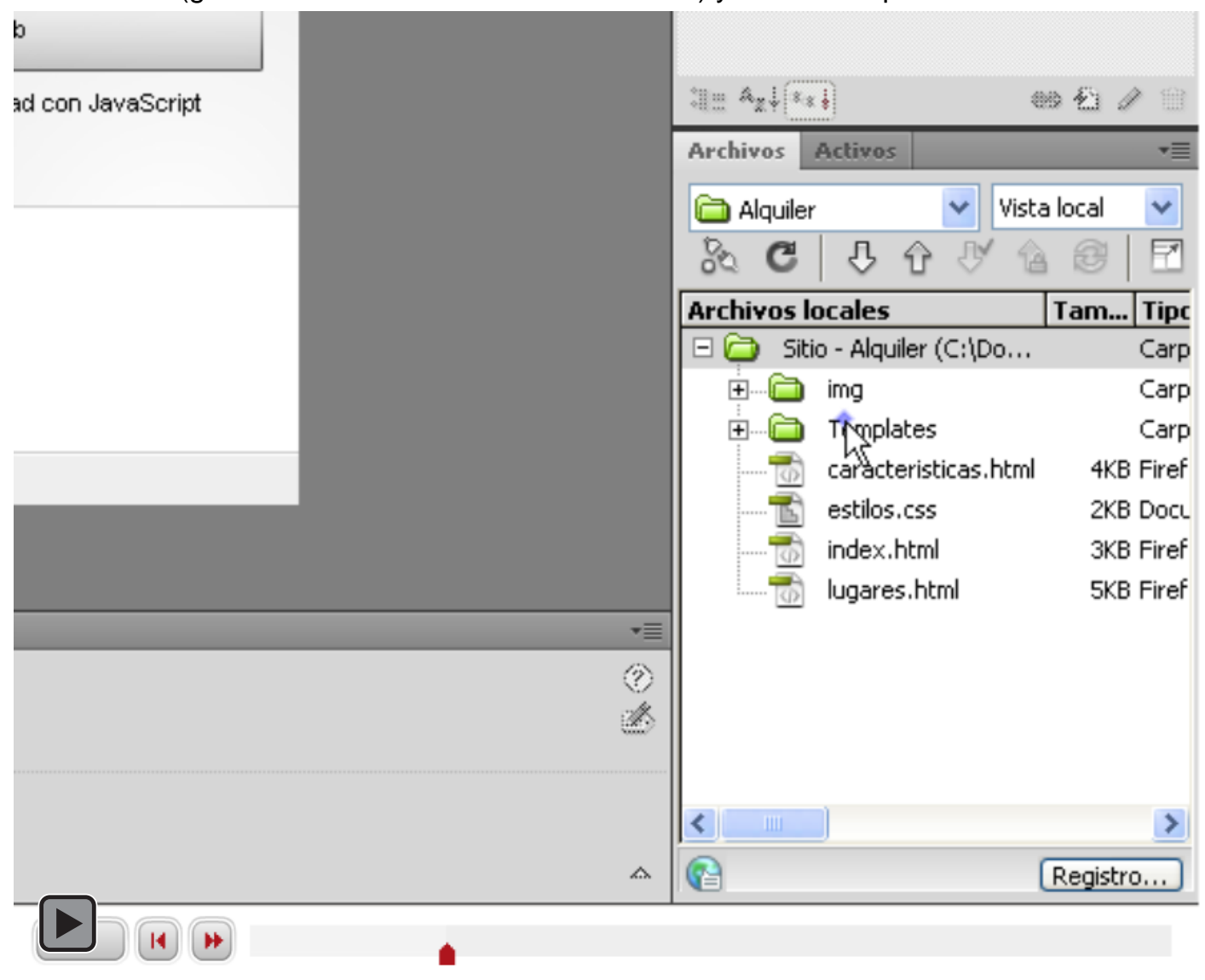




\section{Tutorial 5. Catálogo de apartamentos}

\section{Desarrollo del tutorial: paso 9 de 16}

Para comprobar tanto si nuestra plantilla se ajusta a los estándares como si es accesible, tenemos sendos botones en la barra de herramientas.

Usaremos el botón de la izquierda para validar el código fuente de la página y el CSS, mientras que el de la derecha nos permitirá validar la accesibilidad y la compatibilidad de nuestro código con diferentes navegadores. Estos son los navegadores que Dreamweaver comprueba por defecto.

Si comprobamos la compatibilidad con navegadores, con la configuración por defecto de Dreamweaver, veremos que no detecta ningún problema.
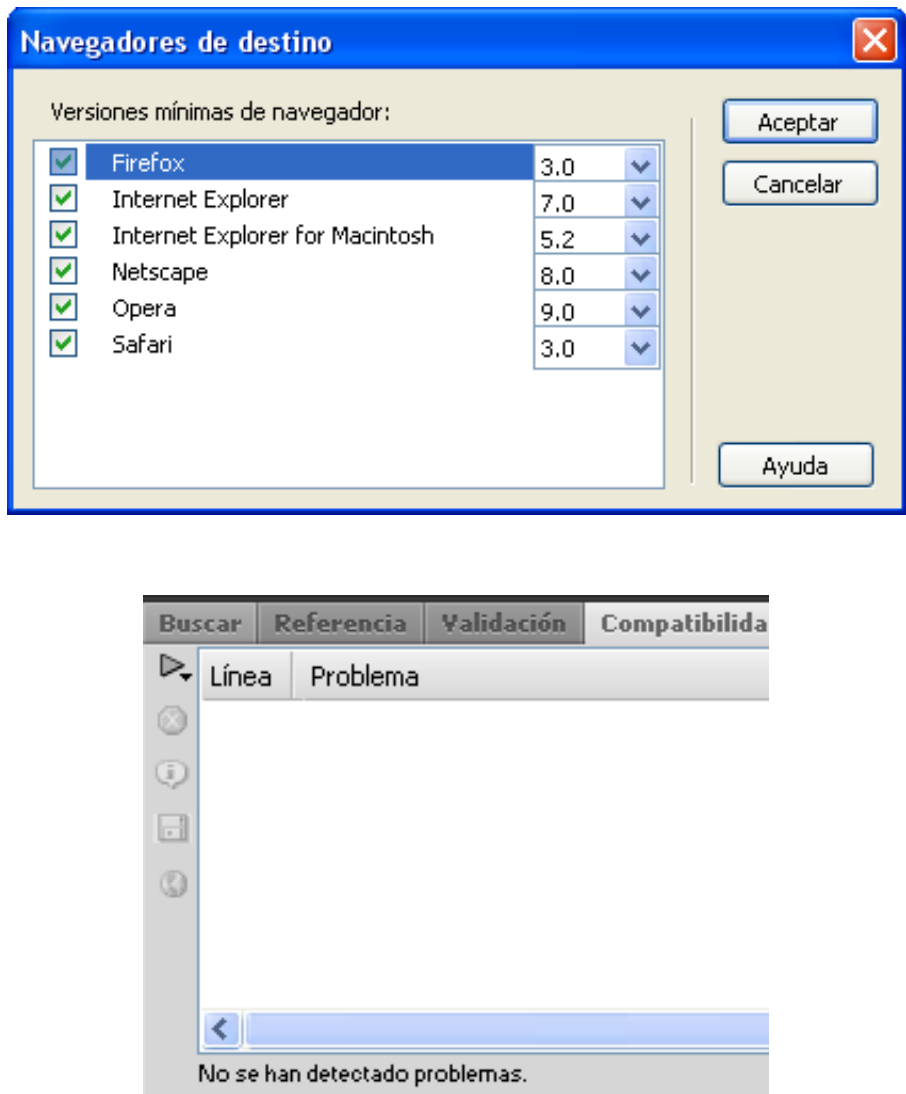
Tutorial 5. Catálogo de apartamentos

\section{Desarrollo del tutorial: paso 10 de 16}

También podemos validar la página.

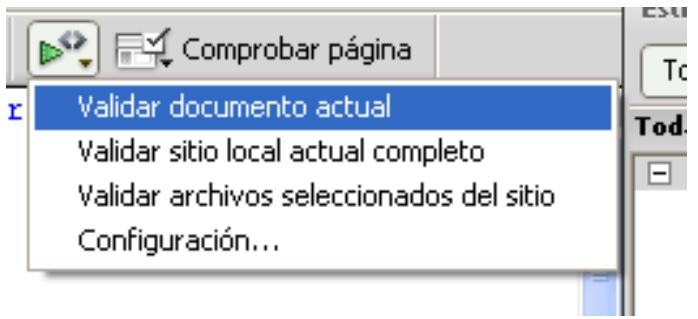

De nuevo, tampoco detecta ningún problema.

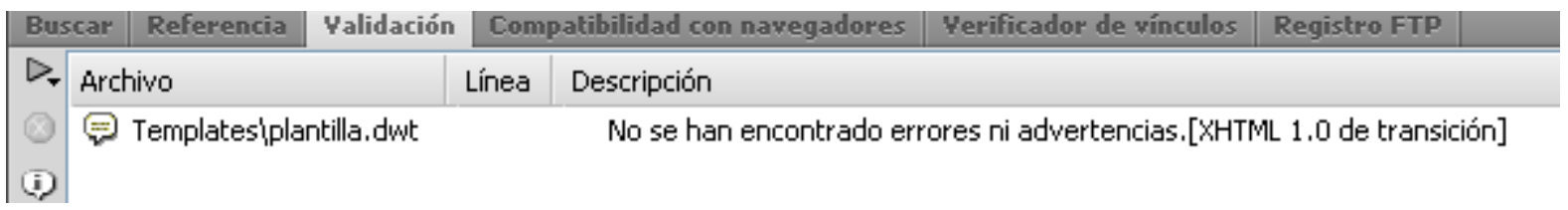

Dado que hemos hecho la página con Dreamweaver prácticamente sin editar el código y Dreamweaver genera código válido, es poco sorprendente. 


\section{Tutorial 5. Catálogo de apartamentos}

\section{Desarrollo del tutorial: paso 11 de 16}

Hemos visto que el código de nuestra plantilla es válido y que no da problema con casi ningún navegador. Veamos ahora si existen problemas de accesibilidad.

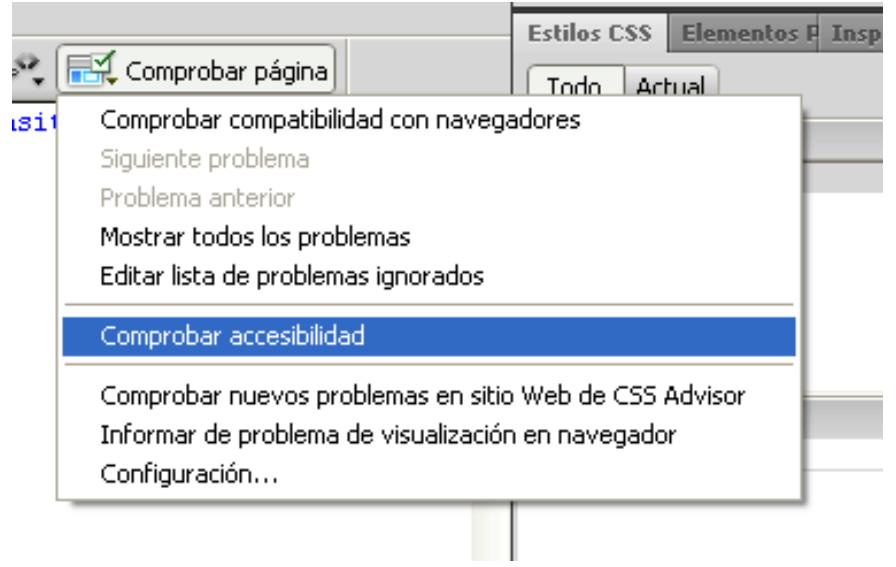

Y aquí aparece un error.

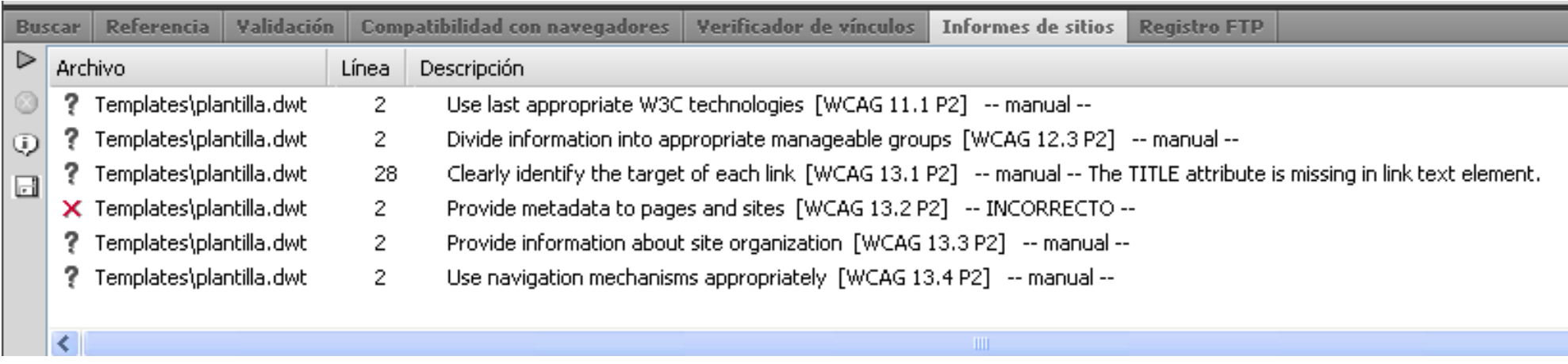

Dreamweaver nos indica qué pautas de accesibilidad debemos comprobar a mano (con un interrogante) y en qué pautas tenemos un error. El error que nos marca en este caso, revisado con otras herramientas, resulta no serlo, pero nos ayuda a darnos cuenta de que no hemos añadido etiquetas <meta>, que pueden servirnos para ayudar a los buscadores a localizar nuestra página. Vamos a añadir alguna de estas etiquetas. 
Tutorial 5. Catálogo de apartamentos

Desarrollo del tutorial: paso 12 de 16

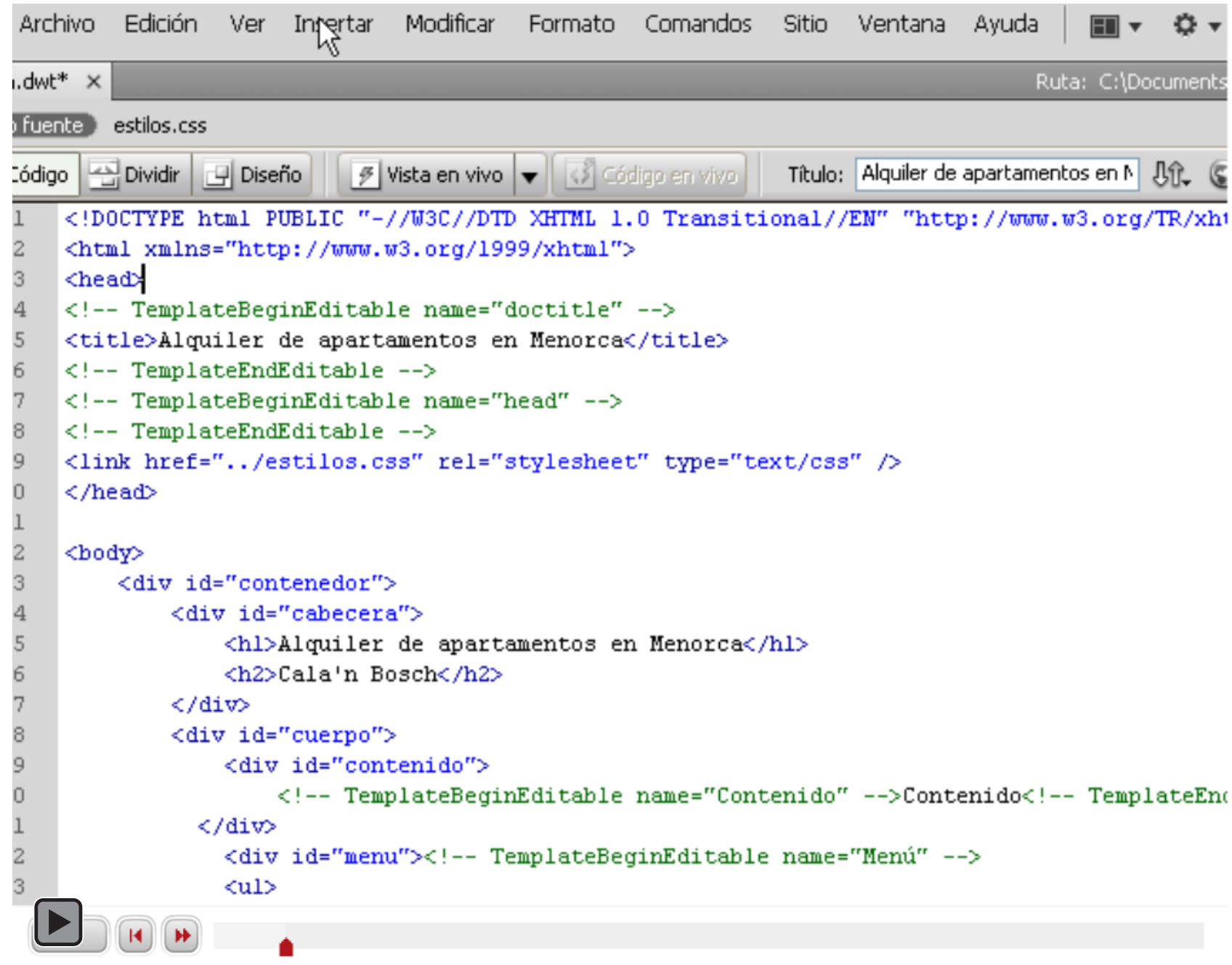


Tutorial 5. Catálogo de apartamentos

\section{Desarrollo del tutorial: paso 13 de 16}

Hemos añadido las etiquetas meta fuera de la zona editable. Al hacerlo así, cuando guardemos la plantilla, Dreamweaver actualizará todos los archivos de ese sitio.

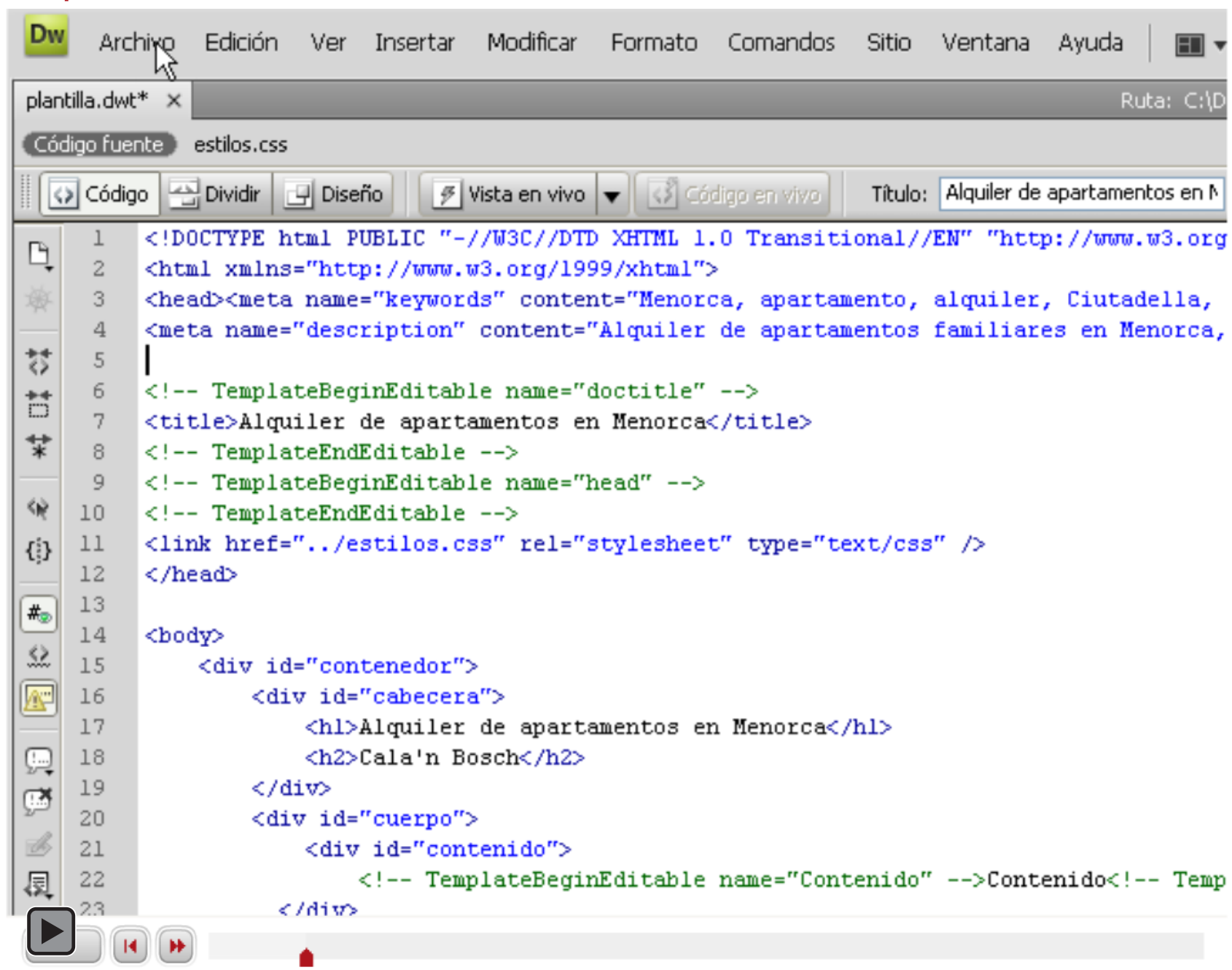




\section{Tutorial 5. Catálogo de apartamentos}

\section{Desarrollo del tutorial: paso 14 de 16}

En esta página destaca mucho visualmente que el menú es corto en comparación con el contenido. Aunque eso no es un problema, hemos pensado que podía quedar bien una imagen en la parte inferior del menú.

Como será una imagen tan solo de presentación, deberemos ponerla en el CSS. A priori, parece sencillo con Dreamweaver. En la plantilla, editamos la regla CSS del identificador menú.

Modificamos la regla según estas características.

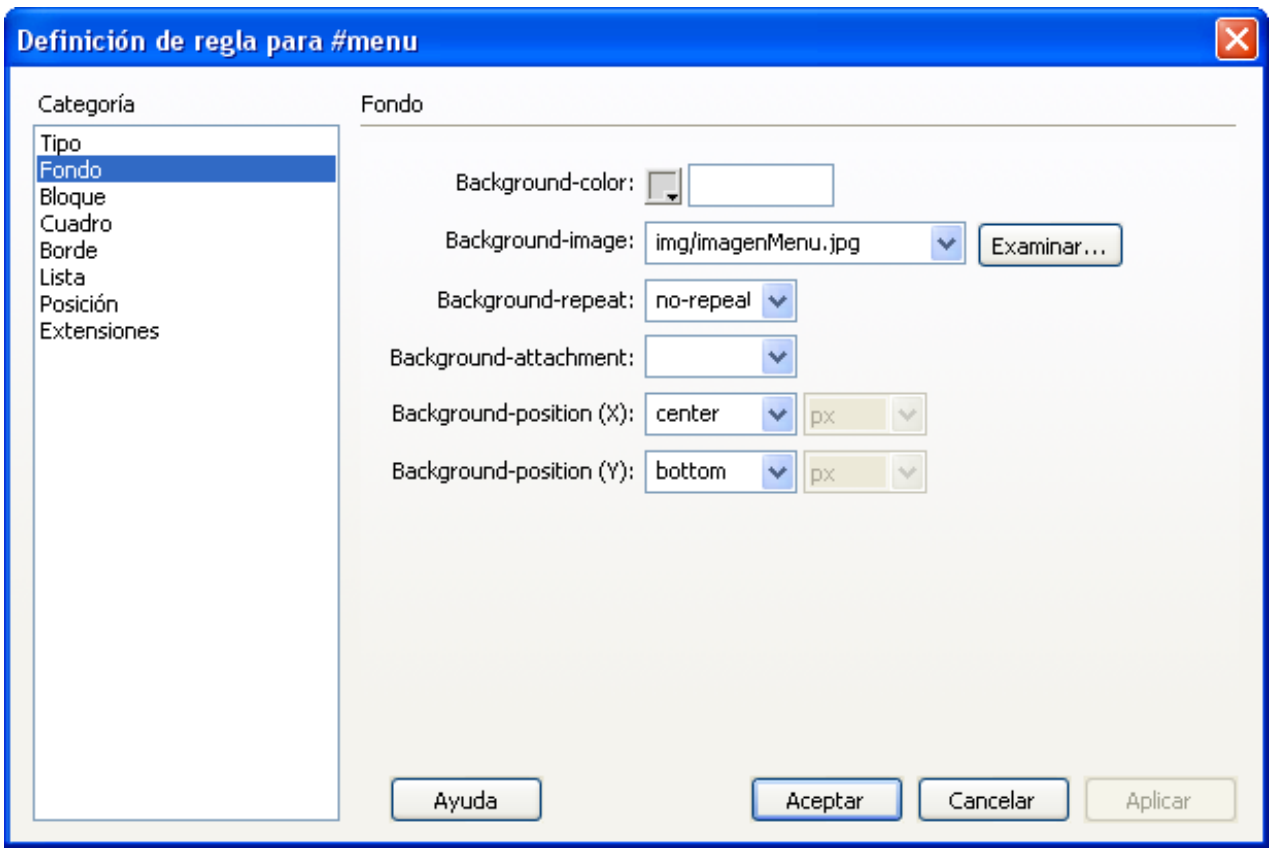

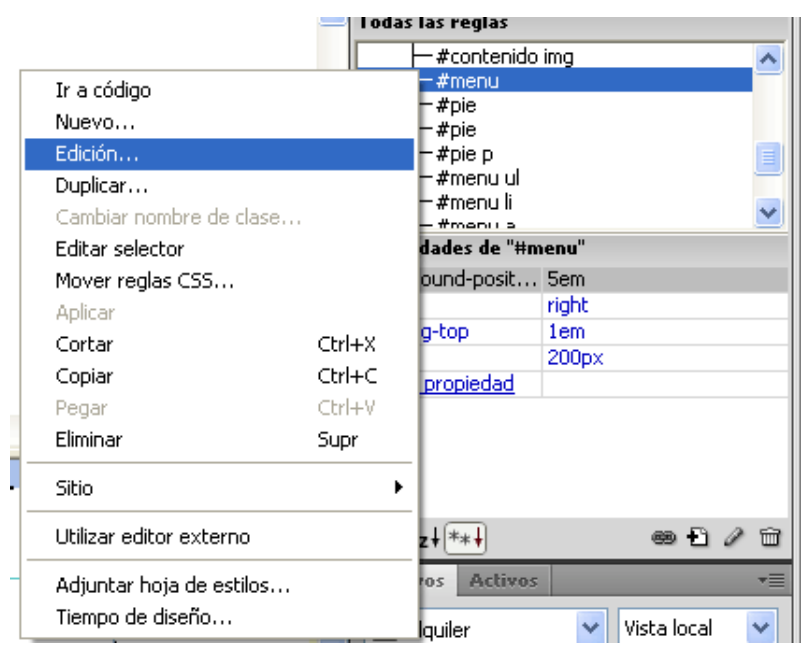

A pesar de que Dreamweaver nos ofrece dos Background-position, en realidad lo gestiona como uno sólo, al que incorpora las opciones que indicamos. 


\section{Tutorial 5. Catálogo de apartamentos}

\section{Desarrollo del tutorial: paso 15 de 16}

Aunque parezca que con esto ya está, en realidad nos falta dar un paso más.

Si accedemos a la presentación preliminar de la plantilla, veremos que la imagen queda en el centro del menú. Esto se debe al tamaño de la capa donde se encuentra, y tiene fácil solución: height:20em.

\section{El resultado es éste:}

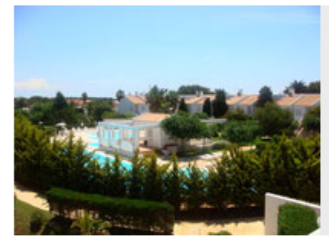

\section{Alquiler de apartamentos en Menorca}

\section{Cala'n Bosch}

\section{Características de los apartamentos}

\section{Apartamentos zona 1. Bajos}

Apartamentos de 65 metros cuadrados, orientación este - oeste y situados en planta baja. Tienen un jardín de $10 \mathrm{~m} 2$. Acceso directo al aparcamiento.

Apartamentos zona 1. Primer piso

Apartamentos de 60 metros cuadrados con una terraza de $5 \mathrm{~m} 2$ Tienen orientación este-oeste y sol todo el día. Acceso directo al aparcamiento.

Apartamentos zona 2. Bajos

Apartamentos de 65 metros cuadrados, orientación norte sur y

situados en planta baja. Jardín de 10 metros cuadrados con acceso directo a la zona comunitaria.

Apartamentos zona 2. Primer piso

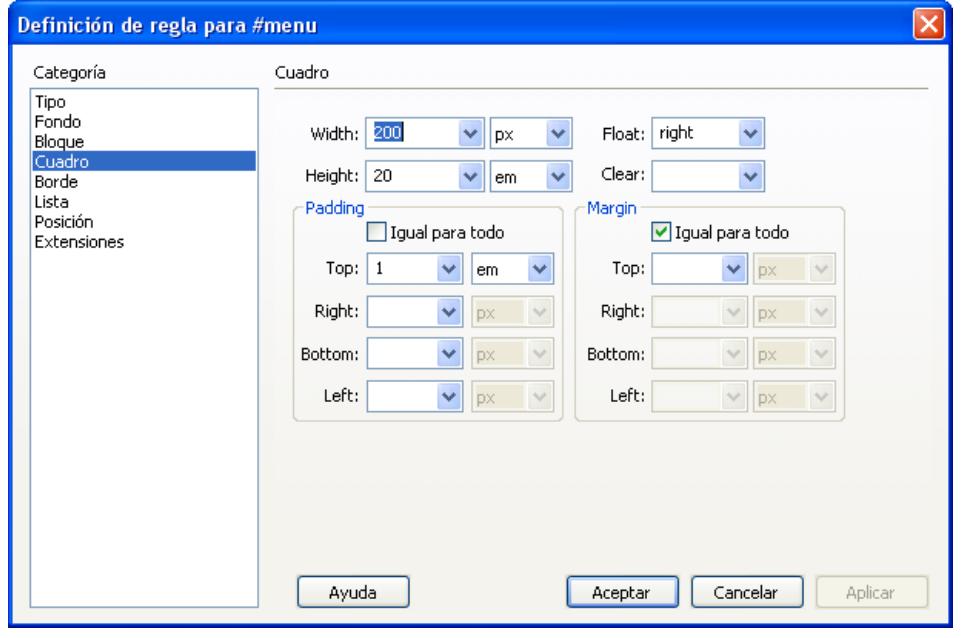

¿Es necesario guardar la plantilla y actualizar las páginas ya confeccionadas?

No: al modificar el archivo CSS, no es necesario ni guardar la plantilla ni actualizar las páginas. 
Tutorial 5. Catálogo de apartamentos

\section{Desarrollo del tutorial: paso 16 de 16}

Para asentar los conceptos desarrollados en este tutorial, se recomienda realizar la siguiente actividad.

- Comprobad si son válidas todas las páginas web que hemos hecho hasta ahora.

- Añadid un nuevo apartado (debajo de las características de la zona comunitaria) titulado

"Características de la zona de aparcamiento", con dos apartados (como si de los apartamentos se tratase):

\section{- Zona exterior}

- Acceso directo a los apartamentos de la zona 1. Descubierto. Capacidad para 20 vehículos sin límite de altura.

- Zona interior

- Acceso directo a los apartamentos de la zona 1. Cubierto. Capacidad para 10 vehículos. Altura máxima 1,80 metros.

$\sim$ Zona de aparcamiento

\section{Características de la zona de aparcamiento}

\section{Zona exterior}

Acceso directo a los apartamentos de la zona 1. Descubierto. Capacidad para 20 vehículos sin límite de altura.

\section{Zona interior}

Acceso directo a los apartamentos de la zona 1. Cubierto. Capacidad para 10 vehículos. Altura máxima 1,80 metros.| 


\section{Tutorial 6. Temporadas y precios}

\section{Desarrollo del tutorial: paso 1 de 12}

Para establecer la lista de precios, la mejor opción será una tabla. En las columnas pondremos el tipo de apartamento y en las filas, la temporada. Los datos que debemos representar en la página web deberán ser éstos:

\begin{tabular}{|l|l|l|l|l|}
\hline & \multicolumn{2}{|c|}{ Zona 1 } & \multicolumn{2}{c|}{ Zona 2 } \\
\hline Temporada & \multicolumn{1}{|c|}{ Bajo } & \multicolumn{1}{c|}{ Piso } & \multicolumn{1}{c|}{ Bajo } & \multicolumn{1}{c|}{ Piso } \\
\hline Alta & $145,00 €$ & $160,00 €$ & $145,00 €$ & $160,00 €$ \\
\hline Media - Alta & $100,00 €$ & $110,00 €$ & $100,00 €$ & $110,00 €$ \\
\hline Media - Baja & $80,00 €$ & $85,00 €$ & $75,00 €$ & $80,00 €$ \\
\hline Baja & $60,00 €$ & $65,00 €$ & $50,00 €$ & $55,00 €$ \\
\hline
\end{tabular}

Son precios por noche de estancia, así que habrá que hacer algunas aclaraciones:

- El precio es por noche.

- La hora de entrada son las 17:00 y la de salida las 12:00

- Las semanas completas tienen un $5 \%$ de descuento y los meses completos un $10 \%$.

- No se incluye el IVA (7\%).

Además, necesitaremos especificar las temporadas.

\begin{tabular}{|l|l|}
\hline Alta & Del 15/07 al 31/08 \\
\hline Media - Alta & Del 15/06 al 14/07 y del 1/09 al 15/09 \\
\hline Media - Baja & Del 1/05 al 14/06 y del 16/09 al 15/10 \\
\hline Baja & Del 1/03 al 31/04 (excepto Semana Santa) y del 16/10 al 15/11 \\
\hline No disponible & Del 16/11 al 29/02 \\
\hline
\end{tabular}

Y deberemos añadir que Semana Santa se considera temporada Media-Alta. 


\section{Tutorial 6. Temporadas y precios}

\section{Desarrollo del tutorial: paso 2 de 12}

Pongamos la información en nuestra página web. Los pasos que debemos seguir son:

1.Crear una nueva página a partir de la plantilla.

2.Cambiar el título de la página: Ahora debe ser Alquiler de apartamentos en Menorca - Temporadas y precios.

3.En el menú, quitarle el enlace a Precios.

4.Guardar la página con el nombre de precios.html

Ahora, desde el menú Insertar-Tabla, crearemos una tabla de seis filas y cinco columnas.

En el apartado Texto, que se corresponde con la etiqueta $<$ caption>, escribimos Tabla de precios según tipo de apartamento y temporada. En el apartado Resumen, que se corresponde con el atributo summary, describimos cómo es la tabla: "Las dos primeras filas son de título, el resto tienen los datos de las temporadas. En las columnas se encuentran los 4 tipos de apartamentos".

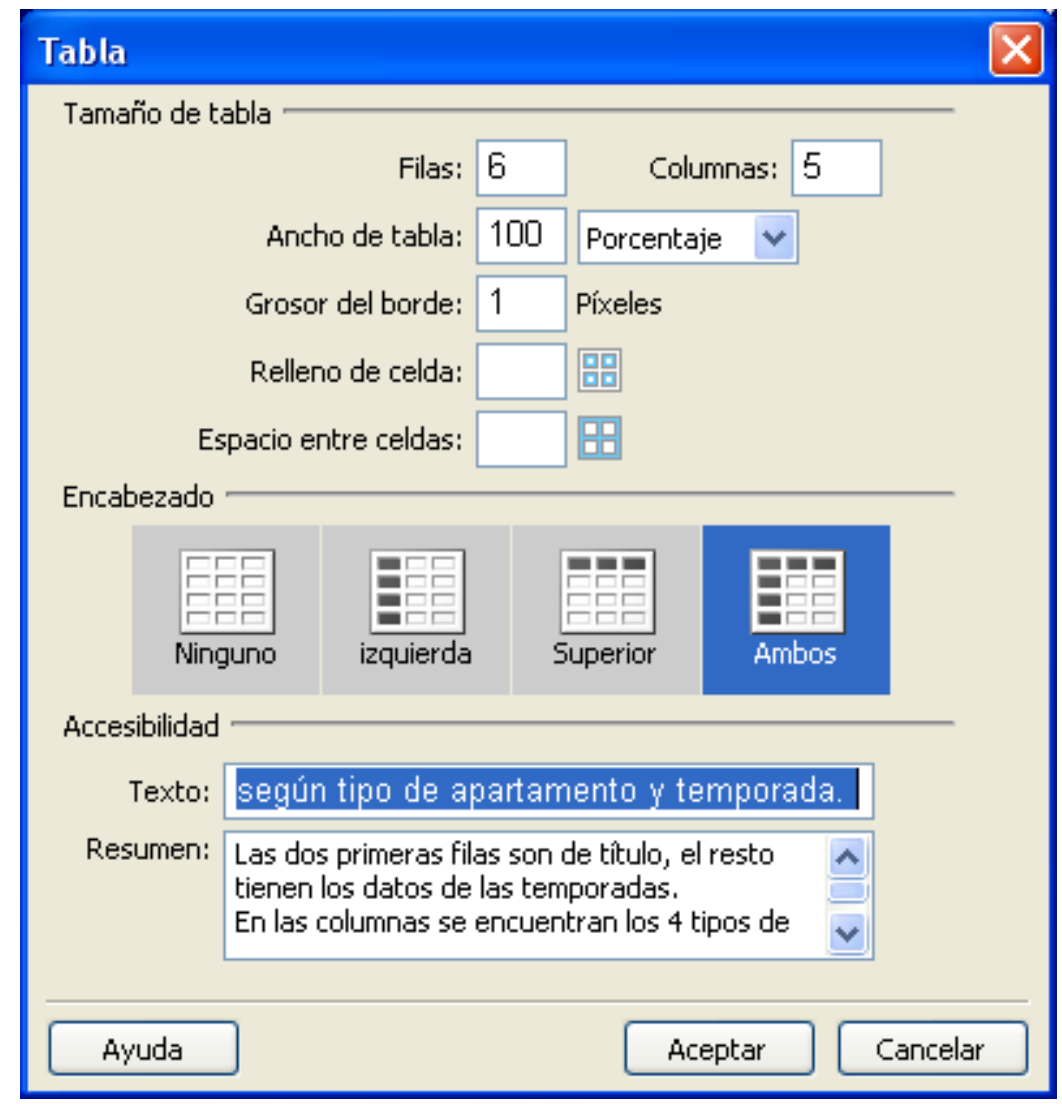




\section{Tutorial 6. Temporadas y precios}

\section{Desarrollo del tutorial: paso 3 de 12}

El siguiente paso será agrupar las celdas que nos interese. Por otra parte, también querremos que la segunda fila sea considerada como encabezado. Ambas cosas las haremos desde la vista de diseño.

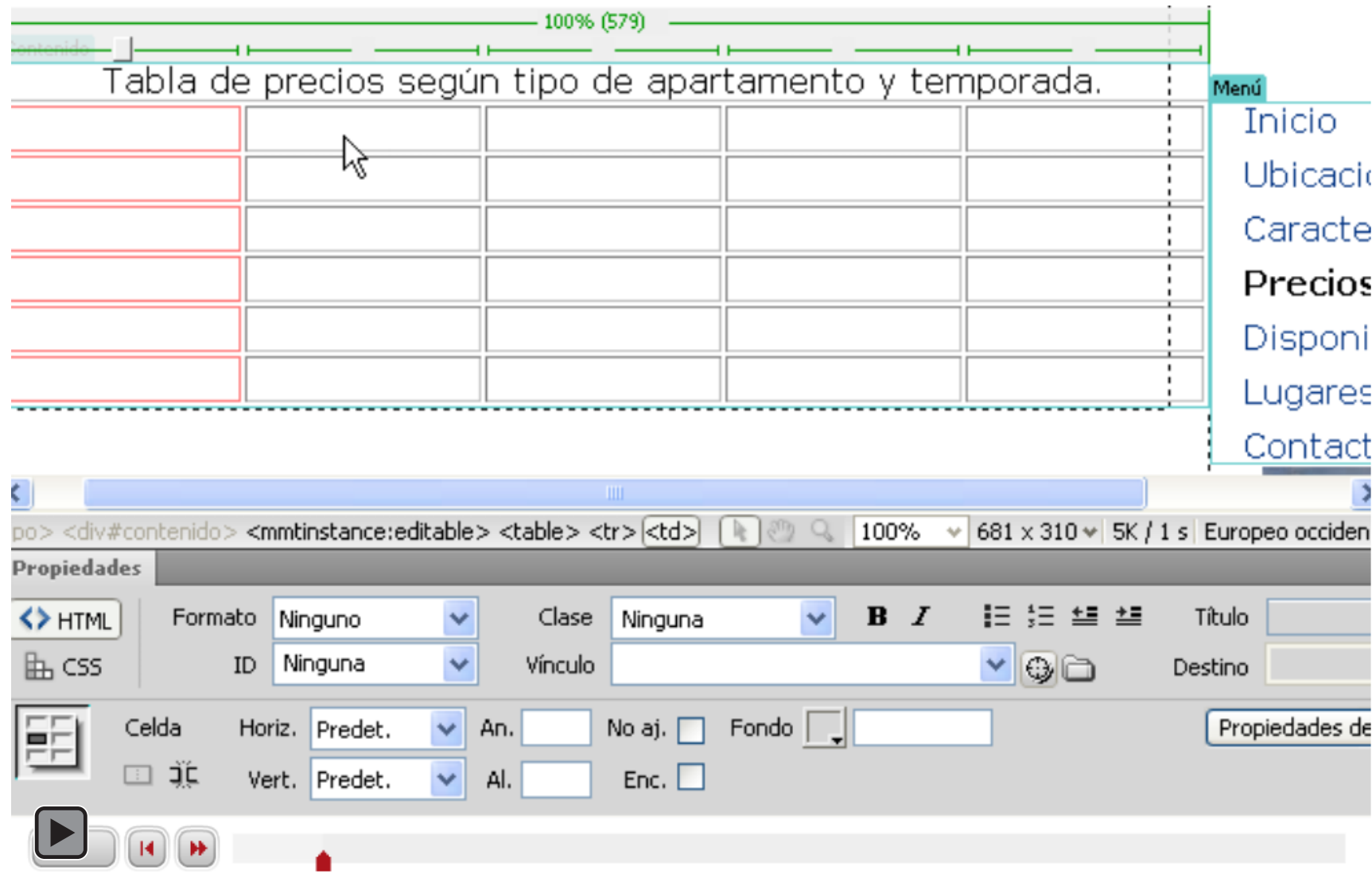




\section{Tutorial 6. Temporadas y precios}

\section{Desarrollo del tutorial: paso 4 de 12}

Ahora vamos a rellenar las dos primeras filas. El resultado será éste:

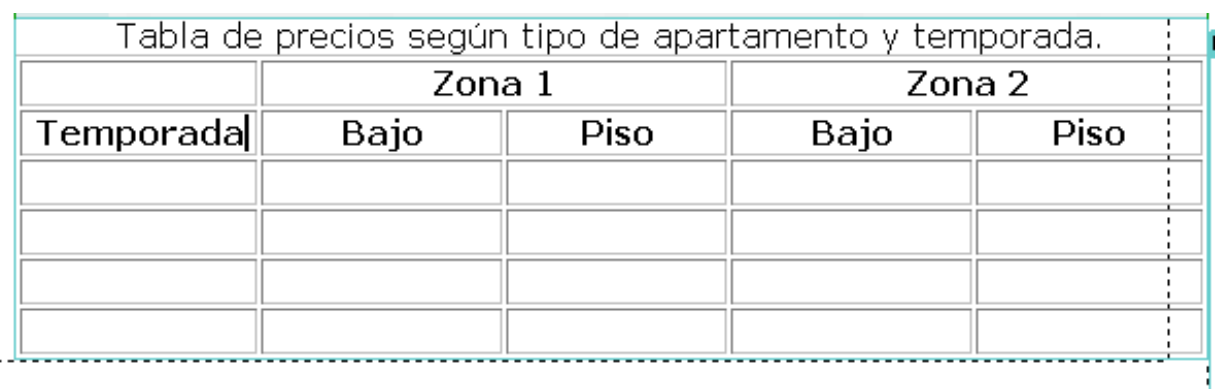

A continuación debemos indicar que Zona 1 y Zona 2 agrupan columnas. Eso no podemos hacerlo con

Dreamweaver y, por tanto, deberemos hacerlo desde la vista de código.

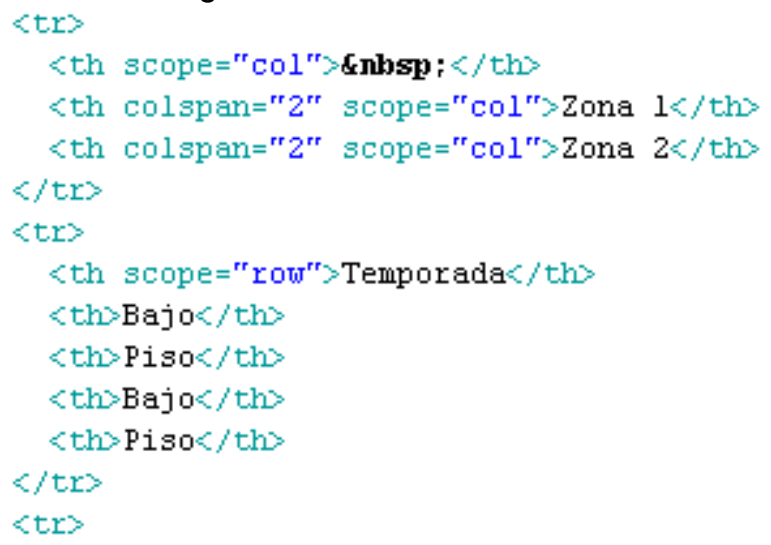

Aprovecharemos para cambiar también el ámbito del encabezado Temporada.

El código después de modificarlo quedará así:

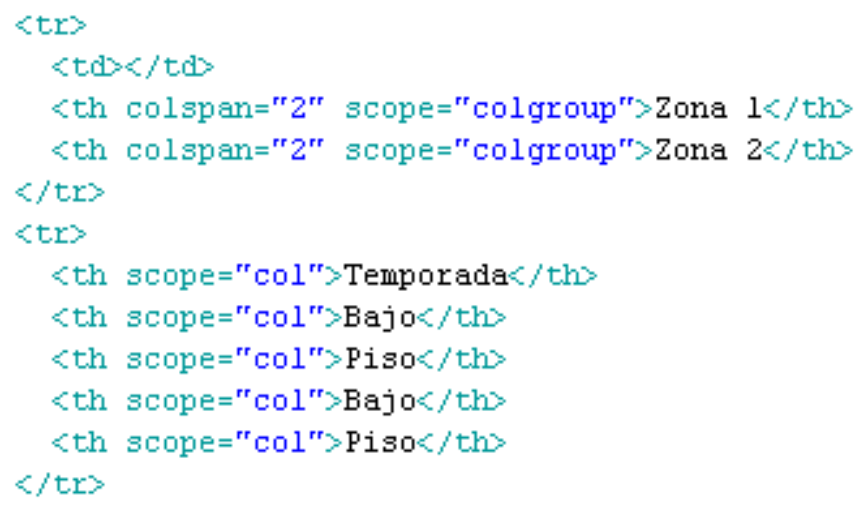




\section{Tutorial 6. Temporadas y precios}

\section{Desarrollo del tutorial: paso 5 de 12}

Rellenamos el resto de datos, guardamos y vamos a la vista preliminar. El resultado no es demasiado atractivo.

Tabla de precios según tipo de apartamento y temporada.

\begin{tabular}{|c|c|c||c|c|}
\hline \multicolumn{1}{|c|}{} & \multicolumn{2}{c|}{ Zona 1 } & \multicolumn{2}{c|}{ Zona 2 } \\
\hline \hline Temporada & Bajo & Piso & Bajo & Piso \\
\hline \hline Alta & $145 €$ & $160 €$ & $145 €$ & $160 €$ \\
\hline \hline Media - Alta & $100 €$ & $110 €$ & $100 €$ & $110 €$ \\
\hline \hline Media - Baja & $80 €$ & $85 €$ & $75 €$ & $80 €$ \\
\hline \hline Baja & $60 €$ & $65 €$ & $50 €$ & $55 €$ \\
\hline \hline
\end{tabular}

Para arreglarlo deberemos modificar el CSS. Tenemos dos opciones. Podríamos añadir las reglas que nos interesan dentro del archivo CSS general del sitio; pero también podríamos crear un nuevo archivo CSS sólo para esta página. Dado que no tendremos tablas en ninguna otra página, no parece mala idea hacerlo así.

Para crear un nuevo archivo CSS, actuamos igual que si quisiéramos crear una nueva regla, indicando que queremos guardarla en un Nuevo archivo de hoja de estilos.

\begin{tabular}{|c|c|c|c|}
\hline \multicolumn{4}{|c|}{ Nueva regla CSS } \\
\hline \multirow{2}{*}{\multicolumn{3}{|c|}{$\begin{array}{l}\text { Tipo de selector: } \\
\text { Elija un tipo de selector contextual para la regla CSS. }\end{array}$}} & Aceptar \\
\hline & & & \\
\hline \multicolumn{2}{|l|}{ Etiqueta (redefine un elemento HTML) } & & \\
\hline \multicolumn{4}{|c|}{ Nombre del selector: } \\
\hline \multicolumn{4}{|c|}{ Elija o introduzca un nombre para el selector. } \\
\hline \multicolumn{2}{|l|}{ table } & $\checkmark$ & \\
\hline \multicolumn{2}{|c|}{$\begin{array}{l}\text { Este nombre de selector aplicará la regla a } \\
\text { todos los elementos 〈table>. }\end{array}$} & 스 & \\
\hline$<$ & & & \\
\hline Menos especifico & Más especifico & & \\
\hline \multicolumn{4}{|c|}{ Definición de regla: } \\
\hline \multicolumn{4}{|c|}{ Elija dónde se va a definir la regla. } \\
\hline (Nuevo archivo de hoja de estilos) & $\checkmark$ & & Ayuda \\
\hline
\end{tabular}


Tutorial 6. Temporadas y precios

Desarrollo del tutorial: paso 6 de 12

Las reglas CSS que hemos creados son éstas:

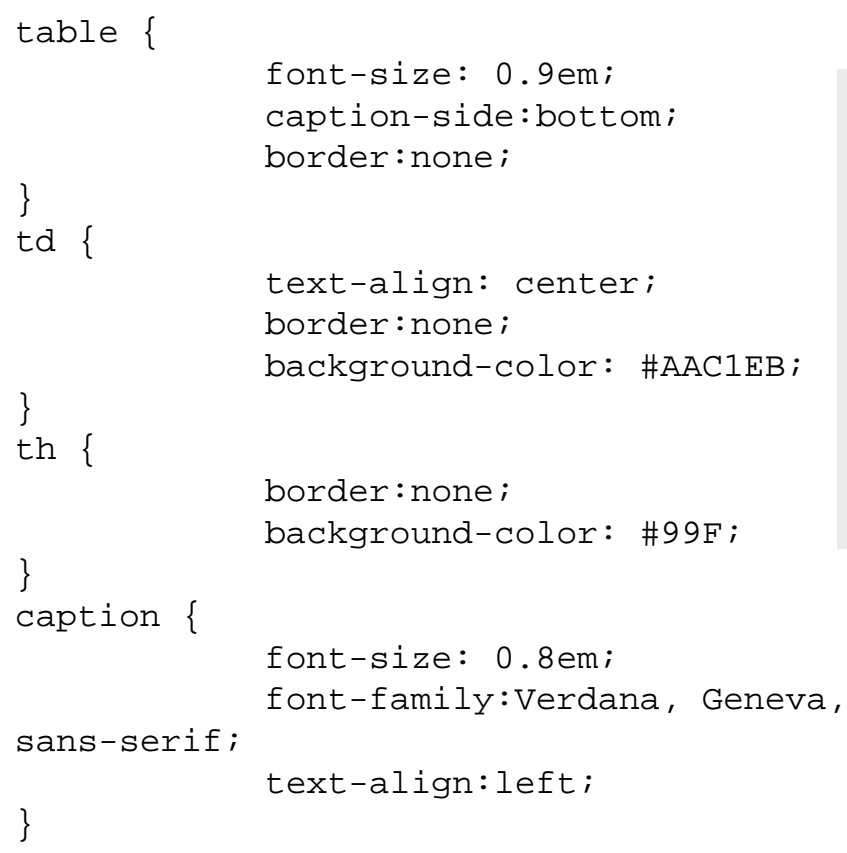

Estas reglas CSS generan la tabla que vemos en la imagen. 
Tutorial 6. Temporadas y precios

\section{Desarrollo del tutorial: paso 7 de 12}

Para mejorar la tabla y que no se vea la celda superior izquierda, añadiremos una nueva regla en el CSS y le pondremos una clase a esa celda.

Así, el código de la página quedará de esta manera:

$\langle\mathrm{tr}\rangle$

$<$ td class="nadarr $></$ t $>$

$<$ th colspan $={ }^{r r} 2^{r r}$ scope $={ }^{r r}$ colgroup ${ }^{r}>$ Zona $1</$ th $>$

$<$ th colspan="r ${ }^{r r}$ scope $={ }^{r}$ colgrouprr $>$ Zona $2</$ th $>$
Y la regla CSS será ésta:

. nada \{

background-color:\#ebebeb;

\}

El resultado es el siguiente:

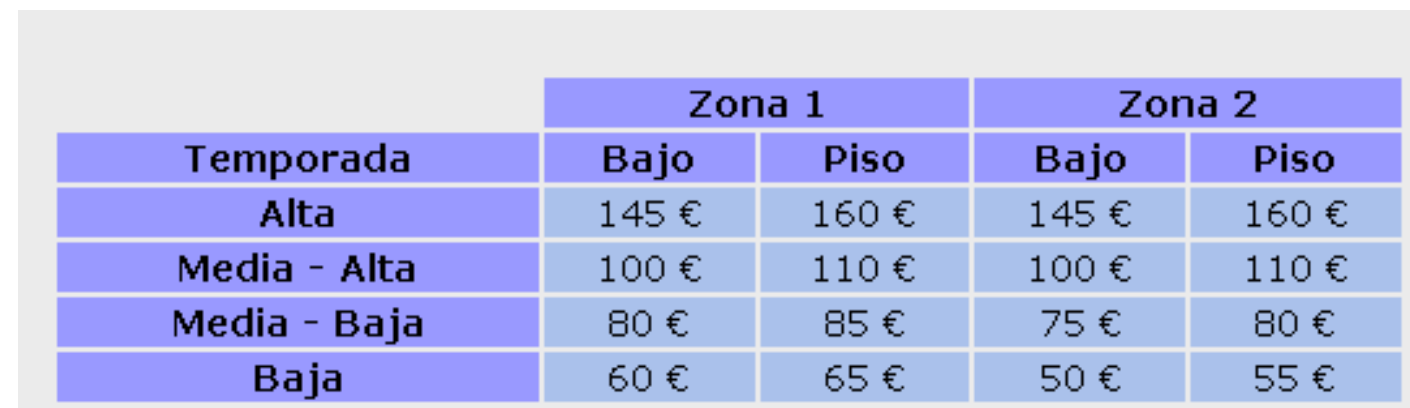

Tabla de precios según tipo de apartamento y temporada. 


\section{Tutorial 6. Temporadas y precios}

\section{Desarrollo del tutorial: paso 8 de 12}

Añadiremos ahora la lista de aclaraciones. En la vista de diseño escribiremos el siguiente texto:

Nota:

1. El precio es por noche.

2. La hora de entrada son las 17:00 y la de salida las 12:00.

3. Las semanas completas tienen un $5 \%$ de descuento y los meses completos un $10 \%$

4. No se incluye el IVA (7\%).

Pero, aunque hemos definido una lista ordenada, el resultado no es el esperado.
Nota:

El precio es por noche.

La hora de entrada son las 17:00 y la de salida las 12:00

Las semanas completas tienen un $5 \%$ de descuento y los meses completos un $10 \%$.

No se incluye el IVA (7\%)
El resultado se debe a una regla que pusimos en el archivo CSS estilos.css:

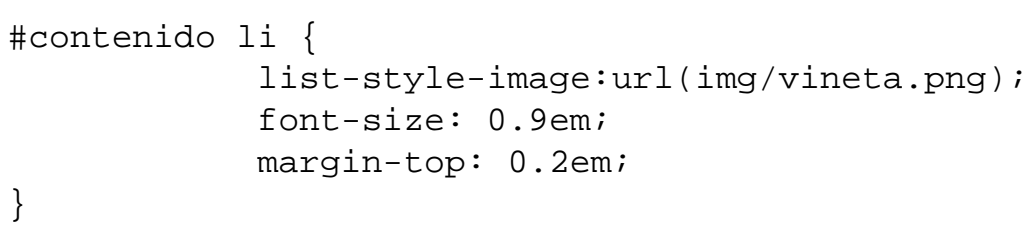

Tal y como está definida, esta regla afecta a todos los elementos de cualquier lista. Para que afecte sólo a las listas no ordenadas la cambiaremos un poco:

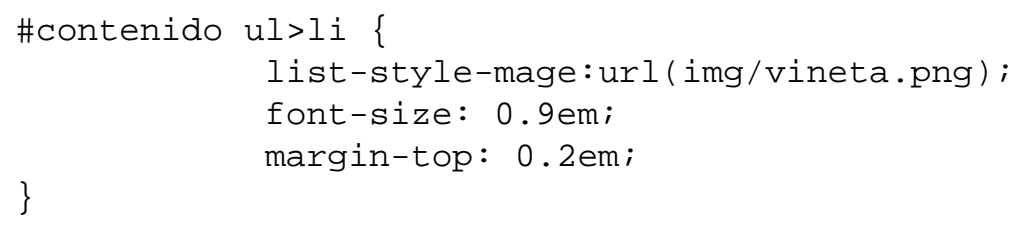

El añadir el $u l>l i$ hace que esa regla afecte sólo a los elementos de las listas no ordenadas.

Podríamos haber añadido la regla con ul li, sin embargo, esto haría que la viñeta se asignase también a listas ordenadas que estuvieran dentro de una lista no ordenada. 


\section{Tutorial 6. Temporadas y precios}

\section{Desarrollo del tutorial: paso 9 de 12}

Ahora la lista está así:

Nota:

1. El precio es por noche.

2. La hora de entrada son las 17:00 y la de salida las 12:00

3. Las semanas completas tienen un $5 \%$ de descuento y los meses completos un $10 \%$.

4. No se incluye el IVA $(7 \%)$

Falla el tamaño de la letra y la separación entre elementos de la lista. Para solucionarlo podemos añadir una nueva regla al archivo estilos.css:

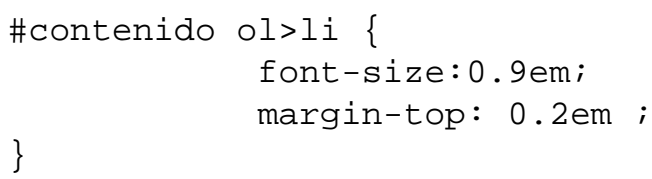

Sin embargo, estamos repitiendo ítems que también teníamos definidos en la regla \#contenido ul>li.
Podemos simplificar nuestro CSS substituyendo las reglas \#contenido ul>li y \#contenido ol>li por:

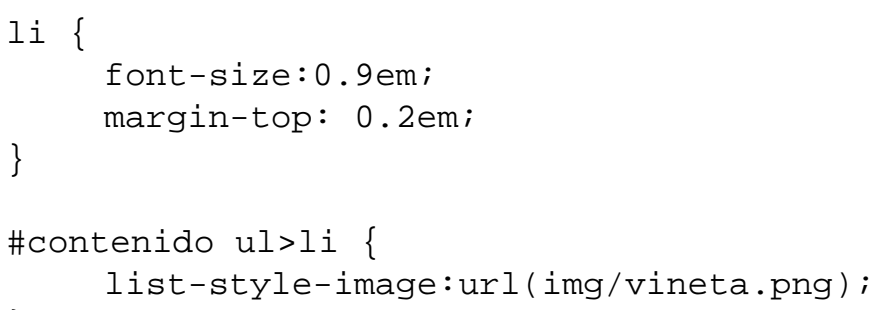


Tutorial 6. Temporadas y precios

\section{Desarrollo del tutorial: paso 10 de 12}

Finalmente, añadiremos la segunda tabla directamente desde la vista de diseño de Dreamweaver, de la siguiente manera:

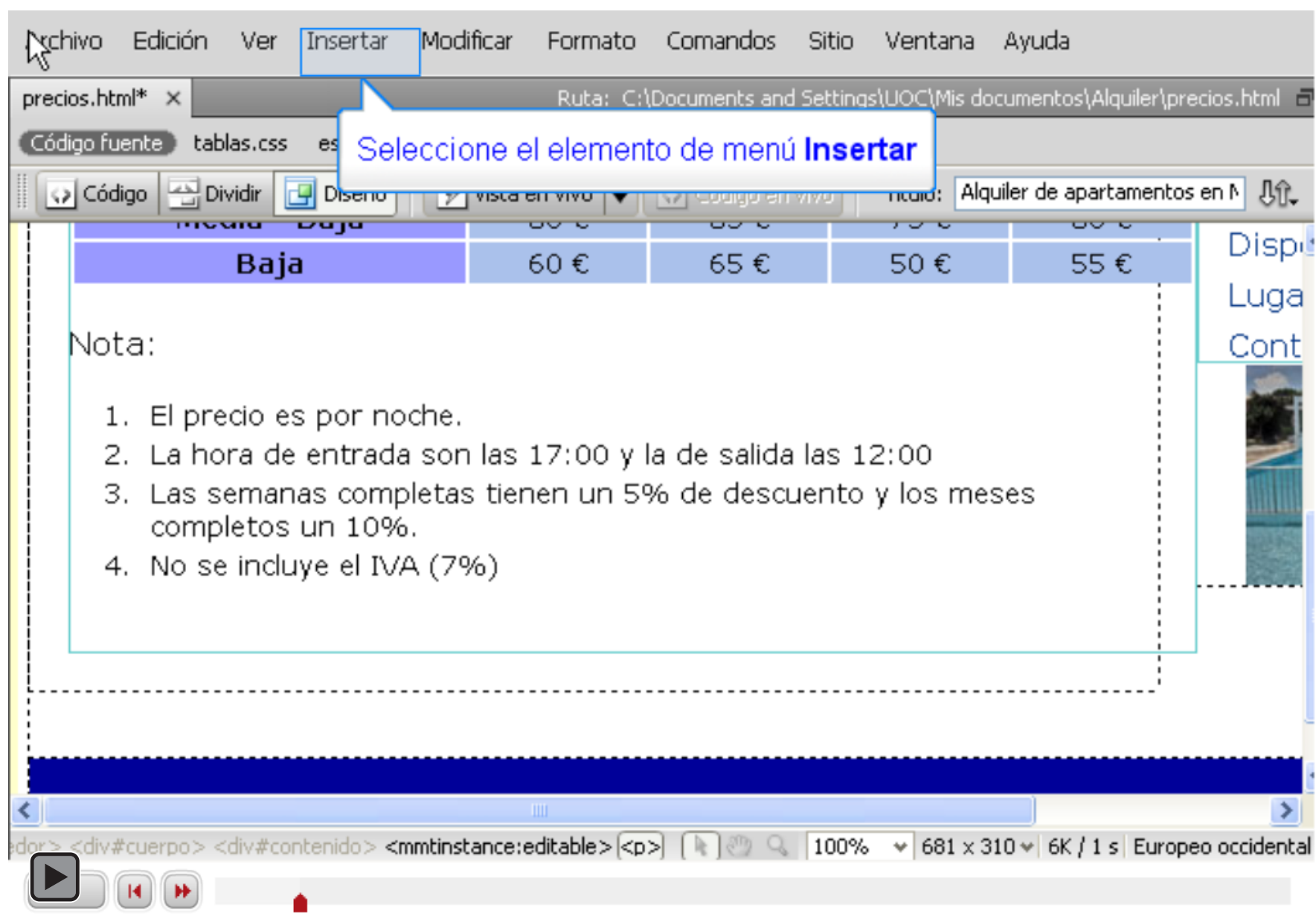

Interactivo 
Tutorial 6. Temporadas y precios

\section{Desarrollo del tutorial: paso 11 de 12}

Rellenamos la tabla con los datos que vimos en el primer paso de este tutorial y obtenemos el siguiente resultado:

\begin{tabular}{|c|c|c|c|c|}
\hline & \multicolumn{2}{|c|}{ Zona 1 } & \multicolumn{2}{c|}{ Zona 2} \\
\hline Temporada & Bajo & Piso & Bajo & Piso \\
\hline Alta & $145 €$ & $160 €$ & $145 €$ & $160 €$ \\
\hline Media - Alta & $100 €$ & $110 €$ & $100 €$ & $110 €$ \\
\hline Media - Baja & $80 €$ & $85 €$ & $75 €$ & $80 €$ \\
\hline Baja & $60 €$ & $65 €$ & $50 €$ & $55 €$ \\
\hline
\end{tabular}

Tabla de precios según tipo de apartamento y temporada.

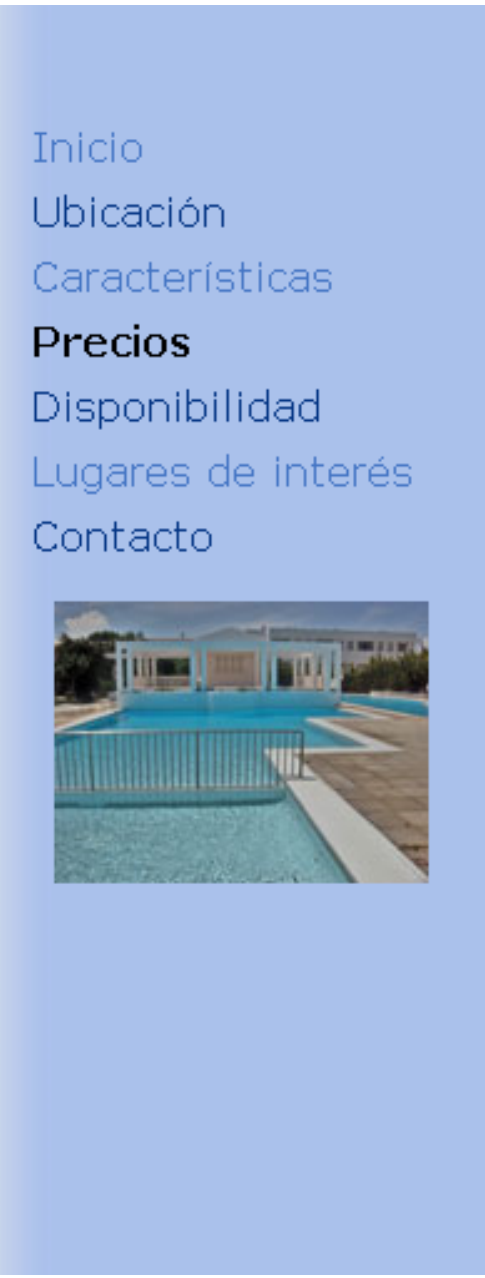

1. El precio es por noche.

2. La hora de entrada son las 17:00 y la de salida las 12:00

3. Las semanas completas tienen un $5 \%$ de descuento y los meses completos un $10 \%$.

4. No se incluye el IVA (7\%)

\begin{tabular}{|c|c|}
\hline $\begin{array}{c}\text { Temporada } \\
\text { Alta }\end{array}$ & Del $15 / 07$ al $31 / 07$ y durante la Semana Santa \\
\hline Media - Alta & Del $15 / 06$ al $14 / 07$ y del $1 / 09$ al $15 / 09$ \\
\hline Media - Baja & Del $1 / 05$ al $14 / 06$ y del $16 / 09$ al $15 / 10$ \\
\hline Baja & Del $1 / 03$ al $31 / 04$ (excepto Semana Santa) y del $16 / 10$ al \\
$15 / 11$
\end{tabular}


Tutorial 6. Temporadas y precios

\section{Desarrollo del tutorial: paso 12 de 12}

Para asentar los conceptos desarrollados en este tutorial, se recomienda realizar la siguiente actividad.

Hay una página que no vamos a desarrollar en esta guía: la página de disponibilidad. La actividad propuesta consiste en crear dicha página. Para ello se deberá hacer una tabla como la de la imagen. Además, para remarcar los apartamentos ocupados, se creará una nueva clase que, aplicada a la celda, cambie el fondo a rojo, el color del texto a blanco y aplique negrita al texto.

En este caso, es muy importante que el código sea lo más limpio posible, dado que el objetivo es que en un futuro los datos se extraigan de una base de datos con PHP, y cualquier complicación en el código repercutirá en la programación.

\begin{tabular}{|c|c|c|c|c|c|}
\hline & \multicolumn{2}{|c|}{ Zona $\mathbf{3}$} & \multicolumn{2}{c|}{ Zona $\mathbf{2}$} \\
\hline Mes (año 2010) & Bajo & Piso & Bajo & Piso \\
\hline Marzo & Sí & Sí & Sí & Sí \\
\hline Abril & Sí & Sí & Sí & Sí \\
\hline Mayo & Sí & Sí & Sí & Sí \\
\hline Junio & Sí & Sí & Sí & Sí \\
\hline Julio & Sí & Sí & Sí & No \\
\hline Agosto & Sí & No & No & No \\
\hline Septiembre & Sí & Sí & Sí & Sí \\
\hline Octubre & Sí & Sí & Sí & Sí \\
\hline
\end{tabular}

Inicio

Ubicación

Características

Precios

Disponibilidad

Lugares de interés

Contacto

Disponibilidad de apartamentos por zonas 


\section{Tutorial 7. Crear una página de contacto}

\section{Desarrollo del tutorial: paso 1 de 14}

Para crear una página de contacto, vamos a crear un formulario donde pediremos al usuario que rellene seis datos:

- su nombre,

- su dirección de correo electrónico,

- su teléfono,

- el apartamento que le interesa,

- la época en que le interesa el alquiler,

- comentarios.

Lo primero que haremos es crear una nueva página a partir de la plantilla. Recordamos los pasos:

- En el menú de Dreamweaver seleccionamos, Archivo-Nuevo-Página de plantilla-Alquiler-Crear.

- Cambiamos el título de la página, añadiendo al final - Página de contacto.

- En el menú de la página borramos el enlace de Contacto.

- Guardamos poniéndole a la página el nombre de contacto.html
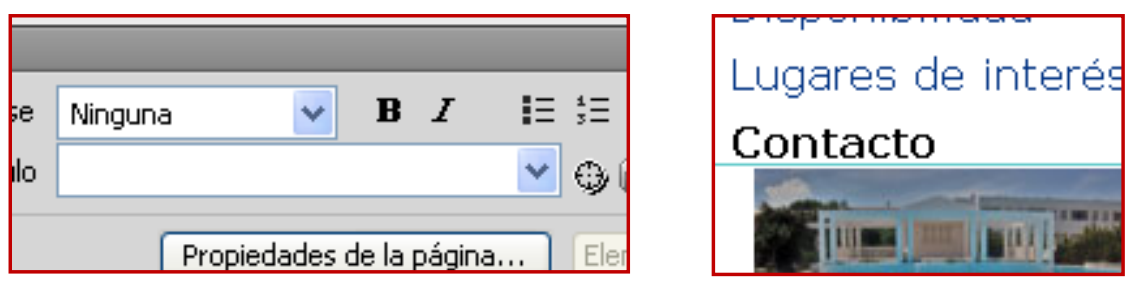

Borramos el enlace de "Contacto"

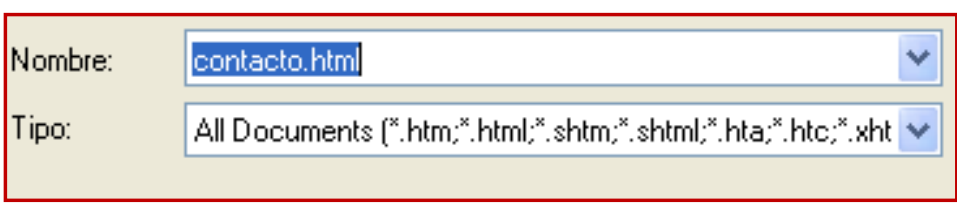

Guardamos con el nombre contacto.html 
Tutorial 7. Crear una página de contacto

Desarrollo del tutorial: paso 2 de 14

Añadimos un titular $(<\mathrm{h} 3>)$ y un texto explicativo que quedarán así:

\section{Contacto}

Para ponerse en contacto con nosotros, por favor rellene este cuestionario.

Contactaremos con usted tan pronto como nos sea posible.

$Y$ ya podemos añadir los tres primeros campos.

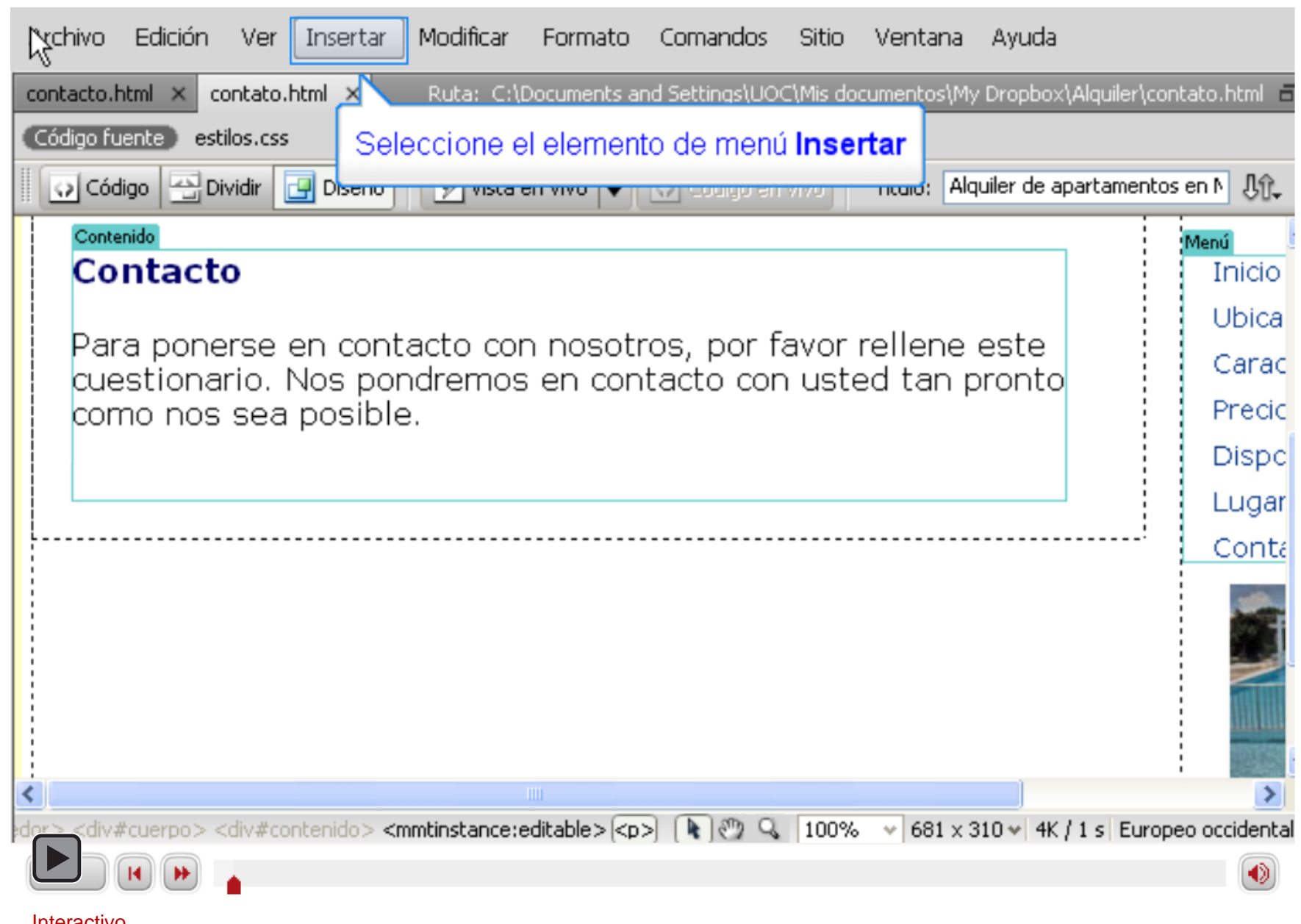




\section{Tutorial 7. Crear una página de contacto}

\section{Desarrollo del tutorial: paso 3 de 14}

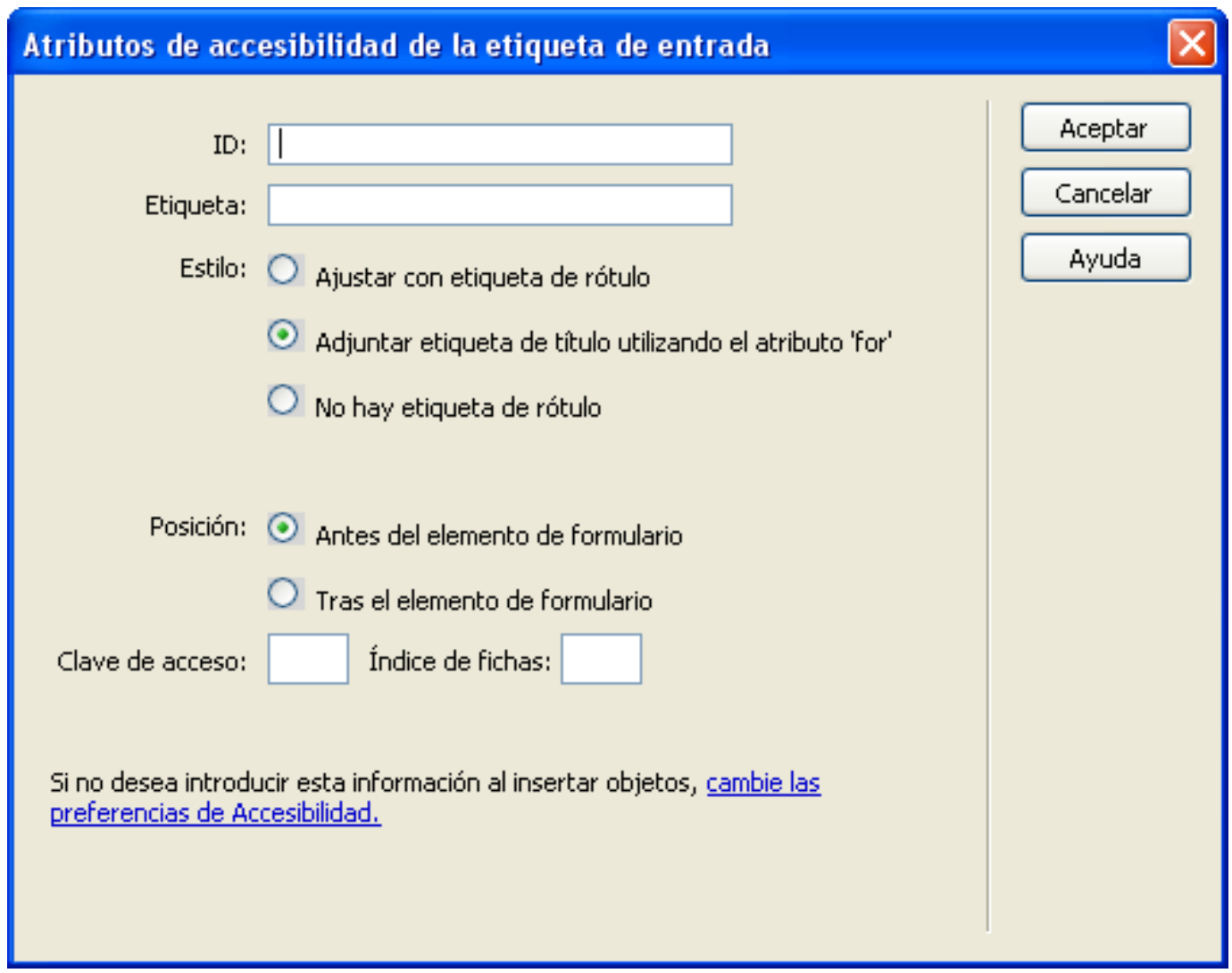

Hemos visto que, al crear los campos de texto, Dreamweaver nos presenta un cuadro de diálogo donde se nos piden los siguientes datos:

- Identificador.

- Etiqueta: texto que aparecerá acompañando al campo de texto.

- Estilo: cómo debe ponerse la etiqueta.

- Posición: dónde se pondrá la etiqueta.

- Clave de acceso: tecla de acceso rápido para acceder directamente al campo.

- Índice de fichas: orden en que se visitarán los campos cuando se navegue con el tabulador.

Guardamos la página y previsualizamos en el navegador. Lo siguiente será cambiar los tamaños de los campos de nombre y correo electrónico, para que sean algo más grandes y hacer más pequeño el campo teléfono. 
Tutorial 7. Crear una página de contacto

\section{Desarrollo del tutorial: paso 4 de 14}

\section{Contacto}

Para ponerse en contacto con nosotros, por favor rellene este cuestionario. Nos pondremos en contacto con usted tan pronto como nos sea posible.

Nombre:

Correo electrónico:

Teléfono:

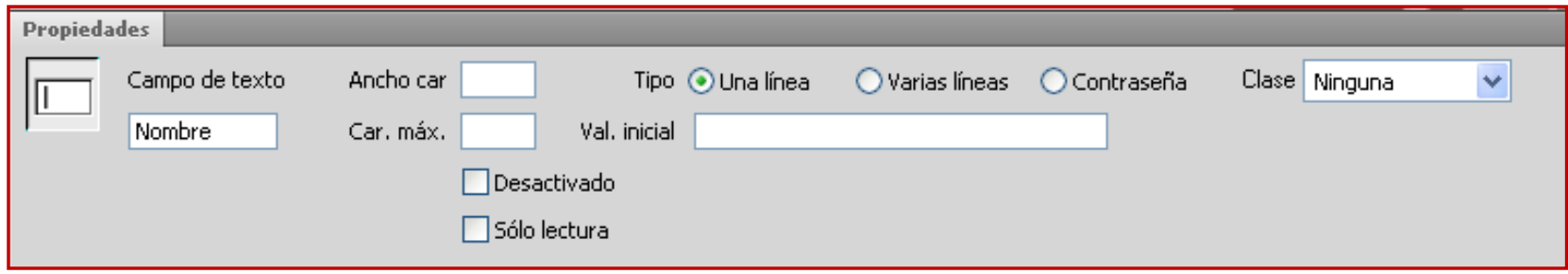

En nuestro caso, vamos a modificar el ancho de caracteres de los tres campos. Pondremos treinta en los campos de nombre y correo electrónico y quince en el campo de teléfono.

Ahora nuestro formulario se ve así:
Nombre:

Correo electrónico:

Teléfono:
Para modificar los tamaños de los campos de entrada, deberemos, desde la vista de diseño, seleccionar el campo que queremos modificar. En la barra de propiedades aparecerán las propiedades de ese campo, donde podremos modificar:

- el número de caracteres que se visualizarán (Ancho car),

- el número máximo de caracteres que se podrán escribir en el campo (Car. máx.),

- el tipo de campo de texto,

- el valor inicial que tendrá el campo,

- si está activado o desactivado,

- si sólo es de lectura,

- Si se le aplica alguna clase. 
Tutorial 7. Crear una página de contacto

Desarrollo del tutorial: paso 5 de 14

Vamos a añadir ahora el campo "Tipo de apartamento que le interesa". Este campo tendrá cuatro valores posibles:

- zona 1 bajo

- zona 1 piso

- zona 2 bajo

- zona 2 piso

Nos interesa que el usuario pueda escoger más de una opción. Podríamos hacerlo con una lista desplegable, pero queda más claro con un grupo de casillas de verificación.

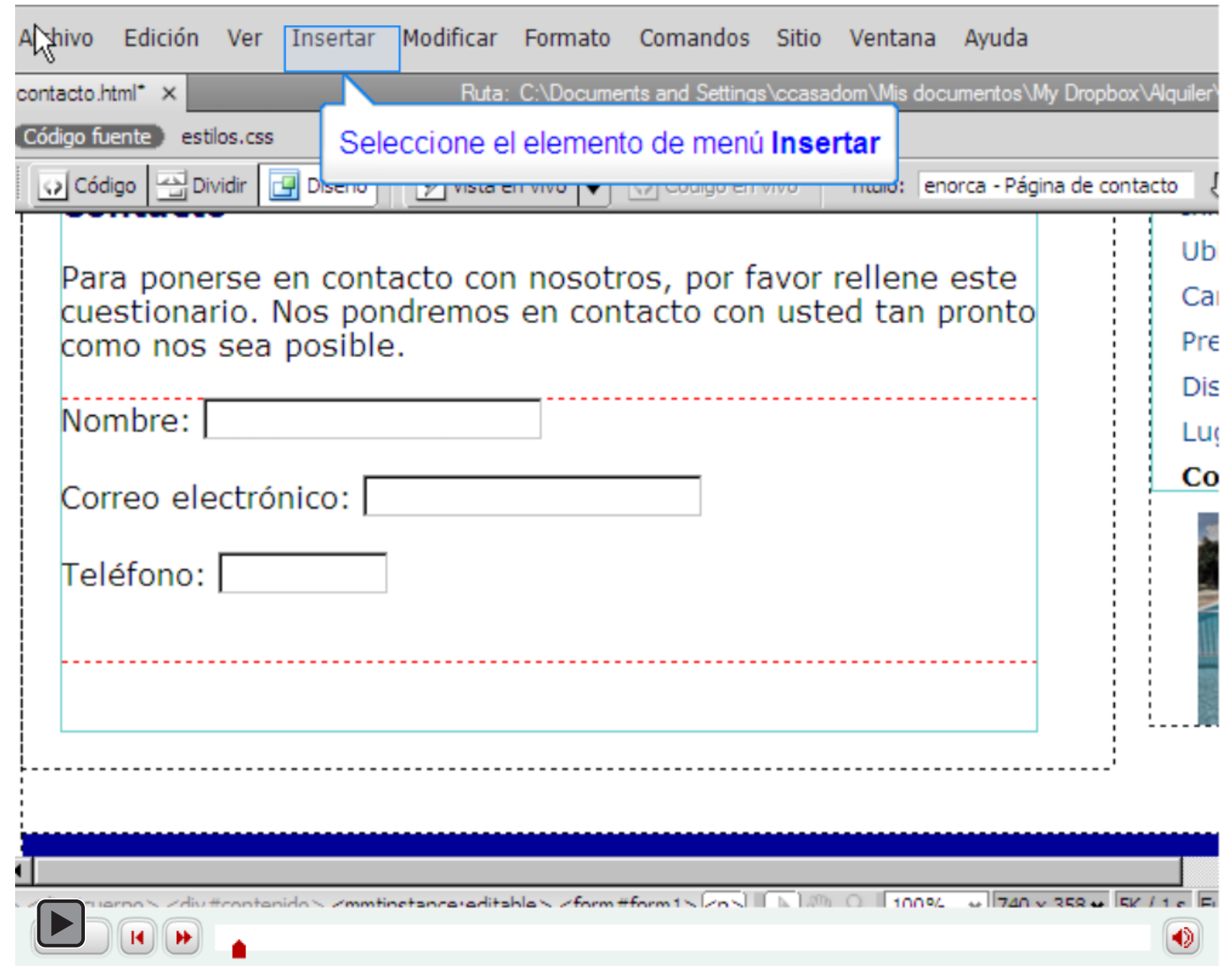

Interactivo 
Tutorial 7. Crear una página de contacto

\section{Desarrollo del tutorial: paso 6 de 14}

Para la temporada, haremos una lista desplegable donde el usuario podrá escoger una de las siguientes posibilidades:

- Julio-Agosto

- Mayo-Junio

- Septiembre-Octubre

- Otra temporada

Por defecto, dejaremos seleccionado Julio-Agosto, pues es la época con más peticiones.

El Índice de fichas es el orden en que se pasará de elemento a elemento cuando se use la tecla de tabulación.

En este caso, asignaremos como Índice de fichas el número ocho, porque, aunque no pudimos hacer lo mismo con las casillas de verificación, lo haremos más adelante.

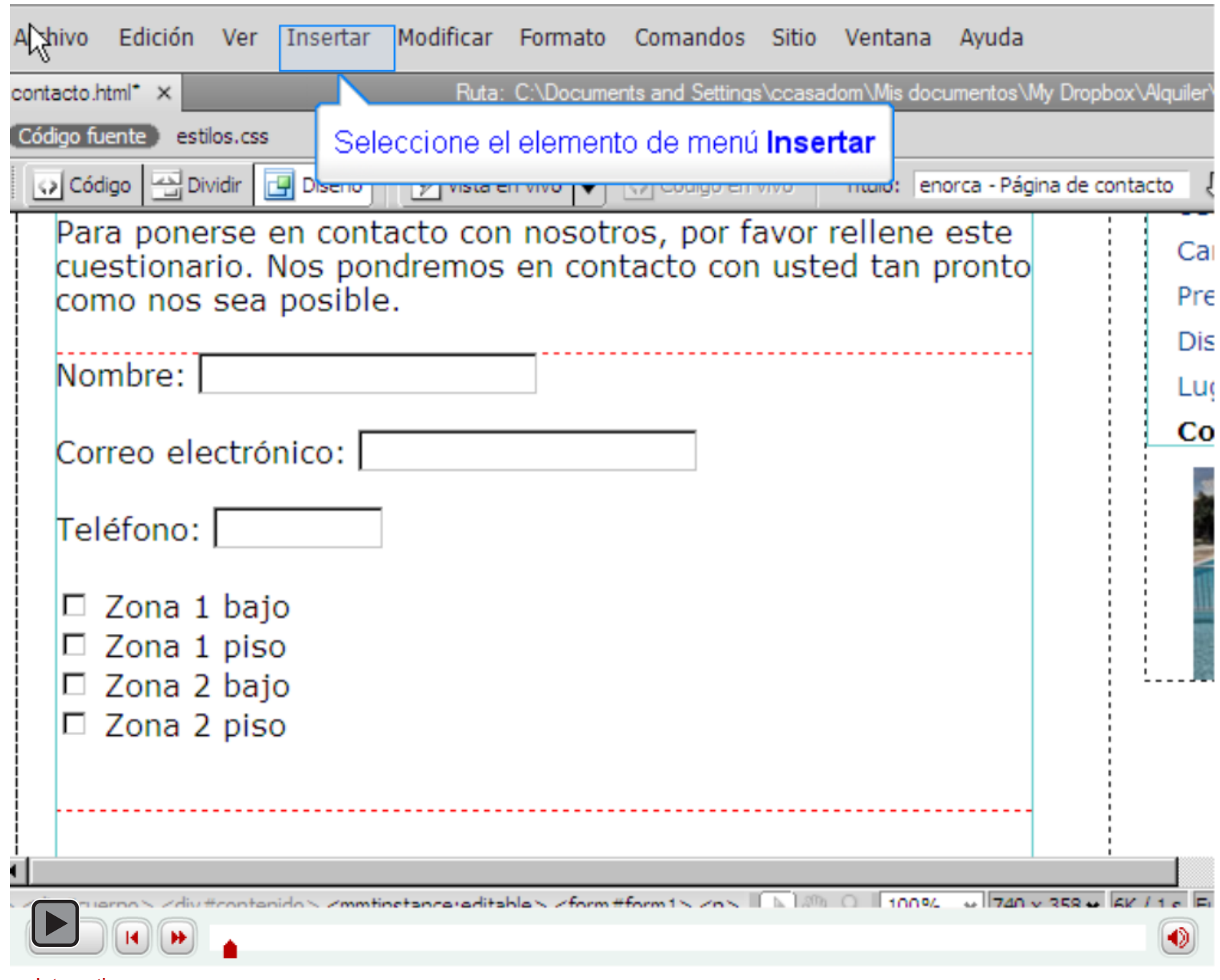

Interactivo 
Tutorial 7. Crear una página de contacto

\section{Desarrollo del tutorial: paso 7 de 14}

Nos faltan un par de elementos para poder tener acabado el formulario de contacto: un campo de comentarios y un botón de envío.

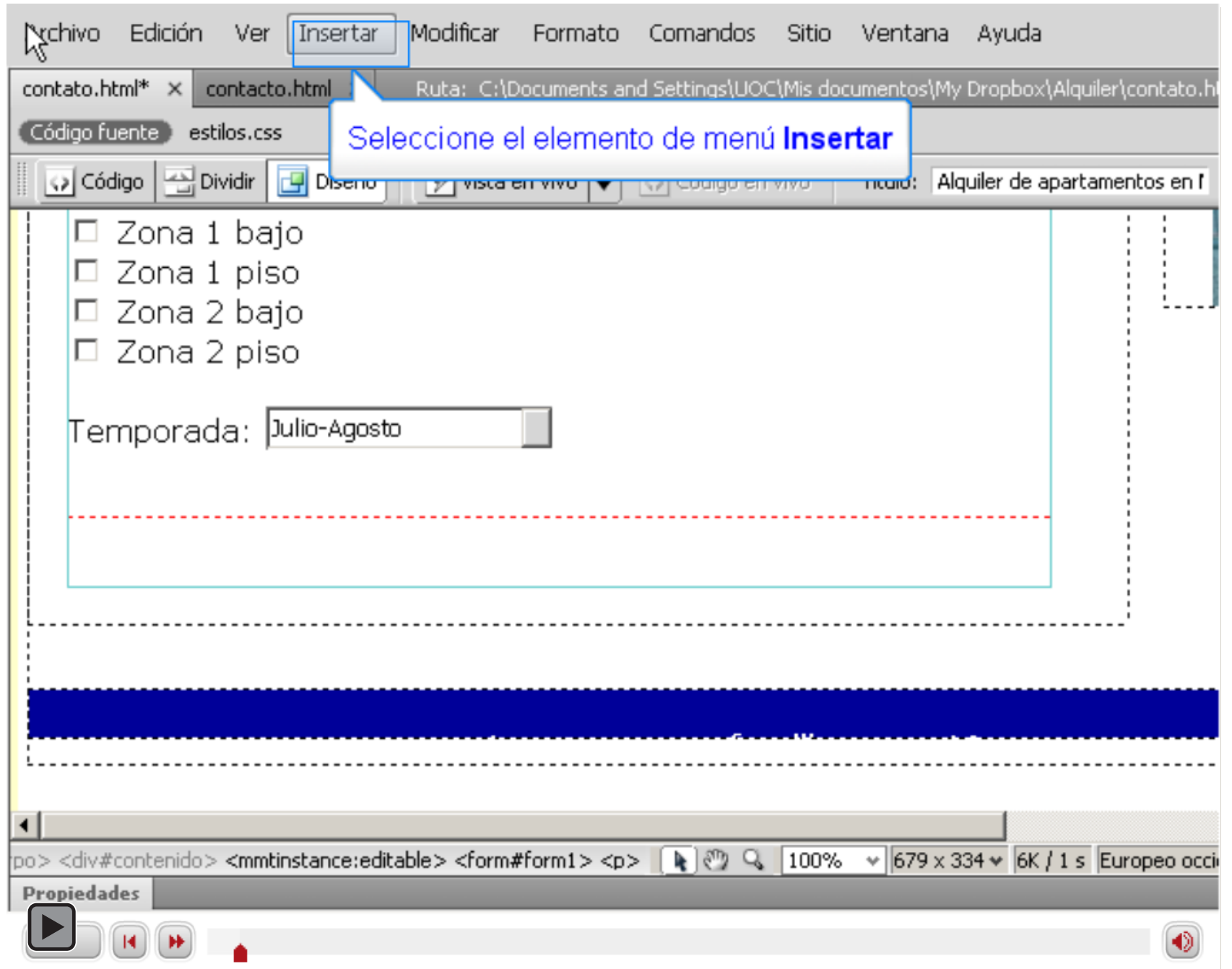




\section{Tutorial 7. Crear una página de contacto}

\section{Desarrollo del tutorial: paso 8 de 14}

Una vez acabado el formulario, deberemos indicar qué hay que hacer con los datos que rellene el usuario.

Acercamos el ratón a la línea roja delimitadora del formulario $y$ haciendo clic en ella, en la ventana de propiedades tenemos la posibilidad de modificar el funcionamiento del formulario.

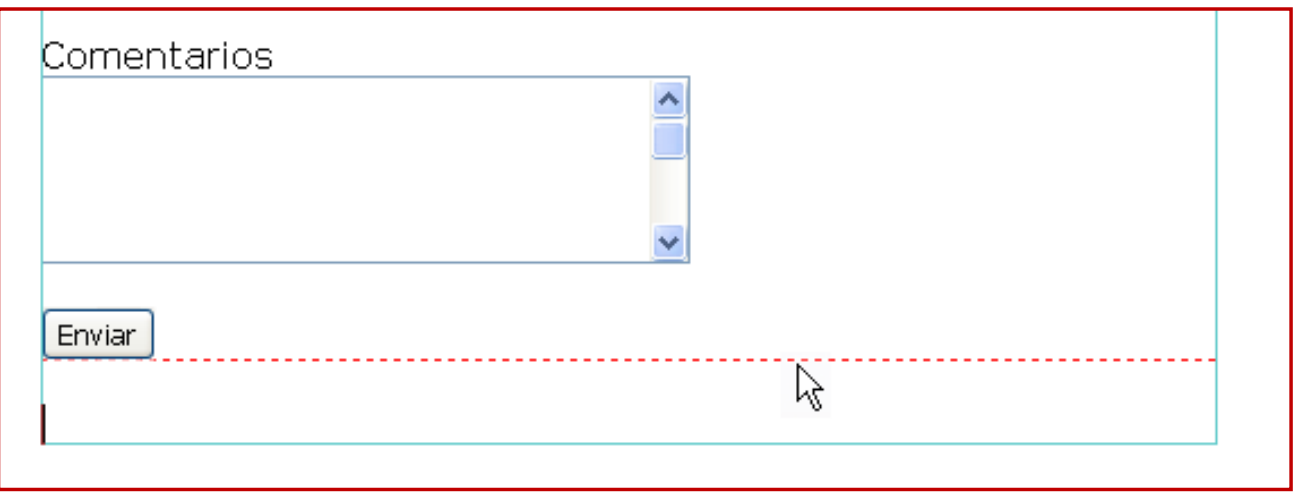

\begin{tabular}{|c|c|c|c|c|c|c|c|c|c|}
\hline \multicolumn{10}{|c|}{ Propiedades } \\
\hline & form1 & Método & POST & $\checkmark$ & Tipo de codificación: & $\checkmark$ & Clase & & $\checkmark$ \\
\hline
\end{tabular}

En Acción podríamos poner:

\section{mailto:direccion@correo.electronico}

con lo que se abriría el programa de correo electrónico del usuario indicando en la dirección del destinatario la dirección que hayamos puesto.

También podríamos poner la dirección de una página web. En ese caso, cuando el usuario pulsase el botón de enviar, se abriría la página seleccionada, a la que se le enviarían los datos introducidos por el usuario, mediante el método (POST o GET) indicado. Además, en el apartado Dest. se puede seleccionar si la página web debe abrirse en la misma ventana del navegador, en otra nueva, o lo que corresponda. 


\section{Tutorial 7. Crear una página de contacto}

\section{Desarrollo del tutorial: paso 9 de 14}

Así es como aparece nuestro formulario cuando previsualizamos en el navegador.

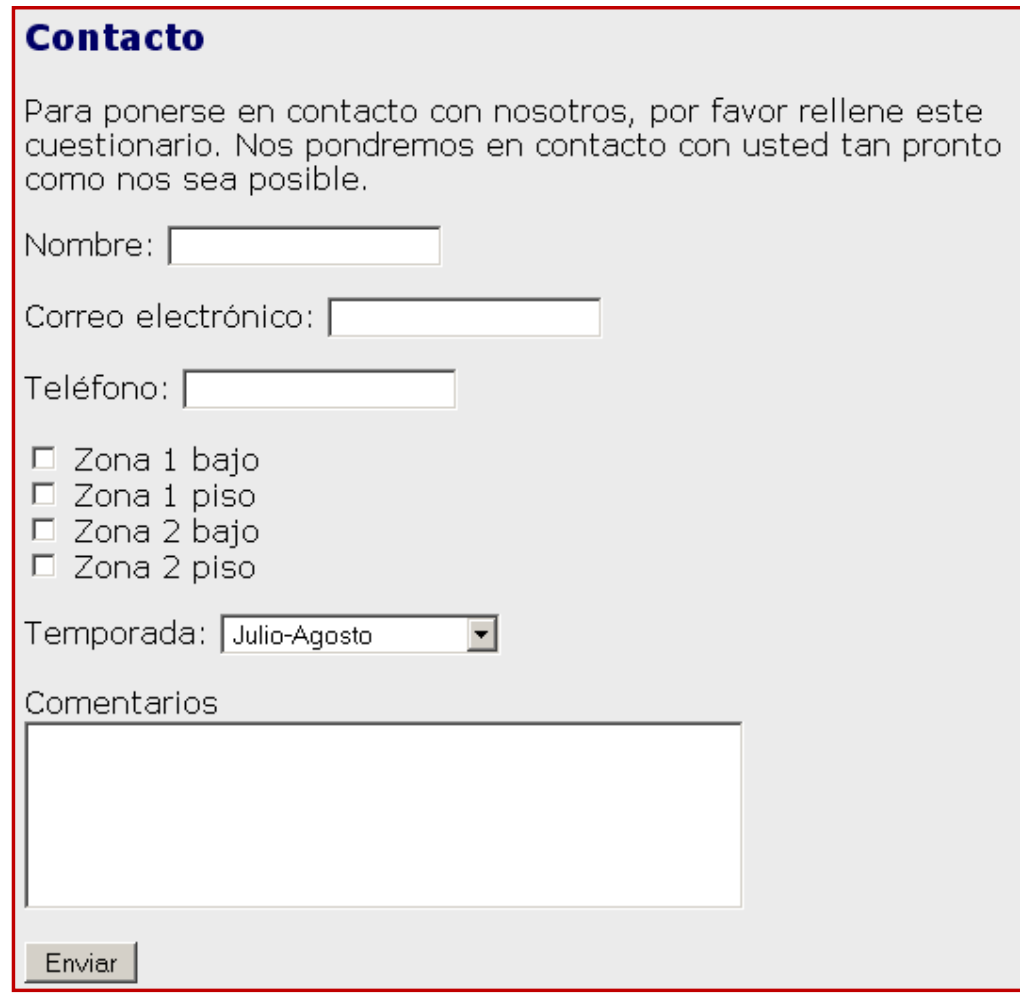

Ahora ya está listo. Sin embargo, vamos a mejorar la presentación.
Lo primero que haremos será agrupar las cuatro casillas de verificación dentro de un <fieldset>. Para ello, en la vista de diseño seleccionaremos las cuatro casillas de verificación. Después, en el menú, iremos a Insertar-Formulario-Juego de campos.

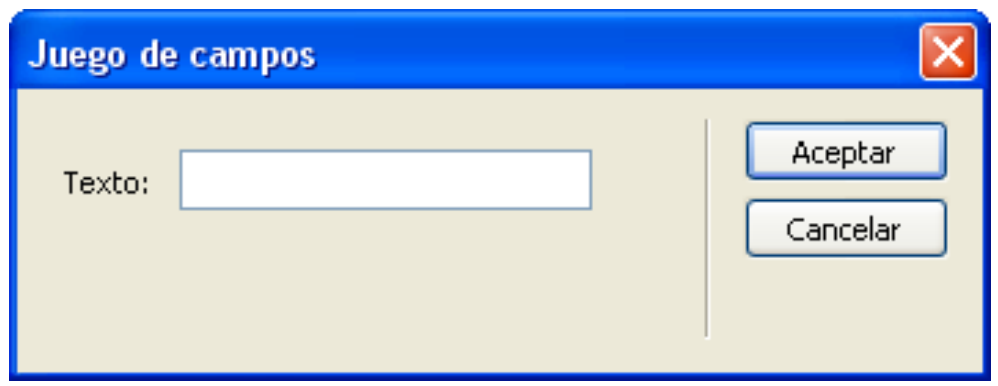

En ese momento nos pide el texto bajo el que se agruparán las casillas de verificación. Pondremos: Tipo de apartamento preferido.

Si previsualizamos, el resultado es éste:

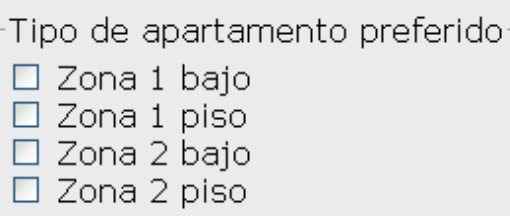




\section{Tutorial 7. Crear una página de contacto}

\section{Desarrollo del tutorial: paso 10 de 14}

Vamos ahora a poner los tipos de apartamento en dos columnas: los de la zona 1 en la columna de la izquierda y los de la zona 2 en la columna de la derecha.

Lo haremos desde la vista de código. Eliminaremos la etiqueta de párrafo que engloba a cada una de las casillas de verificación y pondremos dos etiquetas < div>; cada una de ellas engloban a las casillas de una zona. Además, a cada etiqueta <div> le asignaremos un identificador: casillas 1 a la que engloba a las dos casillas de la zona 1 y casillas2 a la que engloba las casillas de la zona 2.

El resultado, en vista de código, será éste:

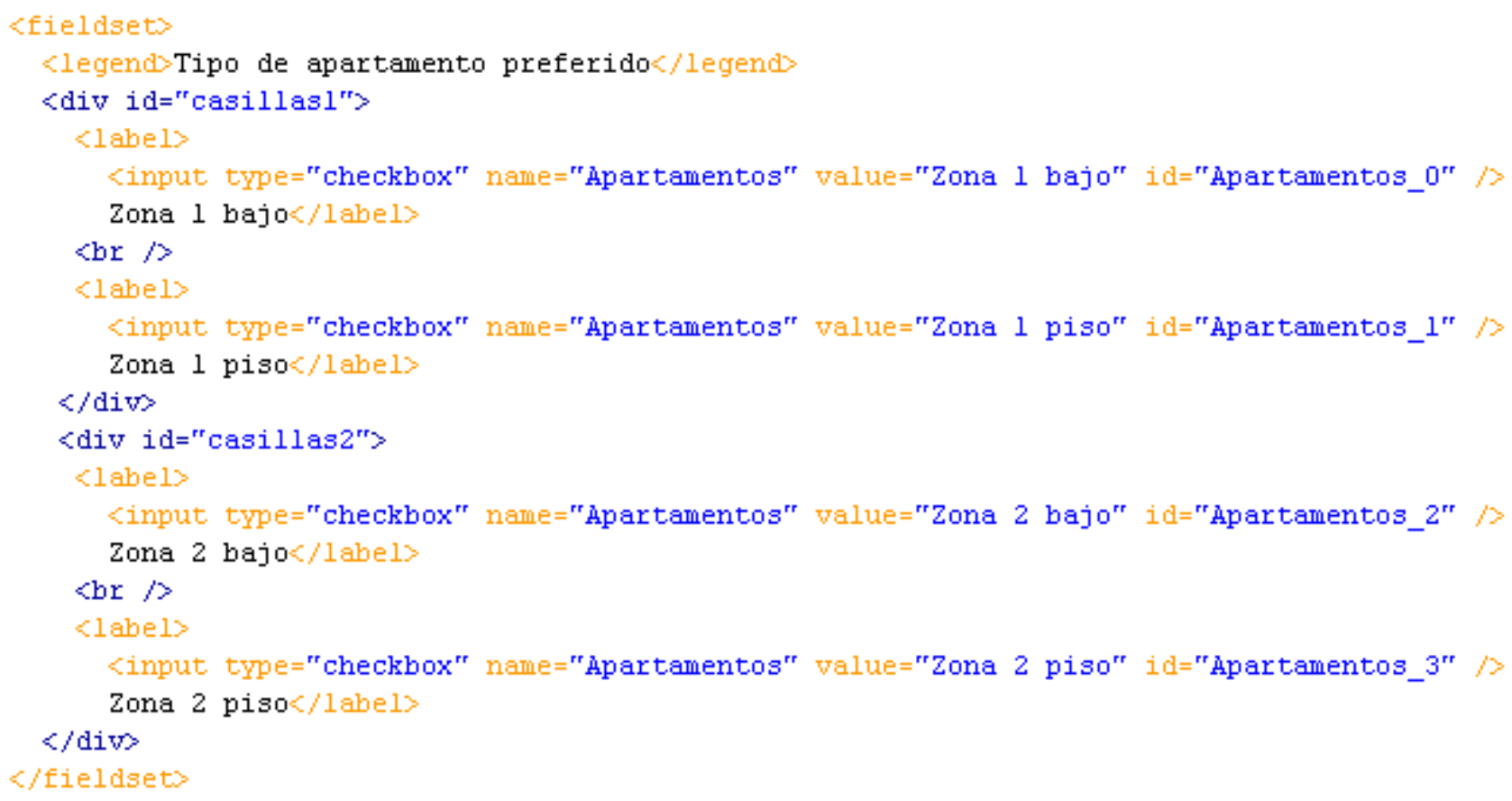




\section{Tutorial 7. Crear una página de contacto}

\section{Desarrollo del tutorial: paso 11 de 14}

Deberemos crear sendas reglas CSS para hacer que los dos < div> queden uno al lado del otro. Igual que hicimos con las tablas, vamos a crear una nueva hoja de estilos a la que llamaremos formulario.css, donde guardaremos las reglas que usaremos para esta página.

Para crear el nuevo archivo CSS, haremos una nueva regla CSS y en el cuadro de diálogo seleccionaremos Nuevo archivo de hoja de estilos.

Esta regla la definiremos en la categoría cuadro. Allí pondremos 45\% en Width i left en Float.

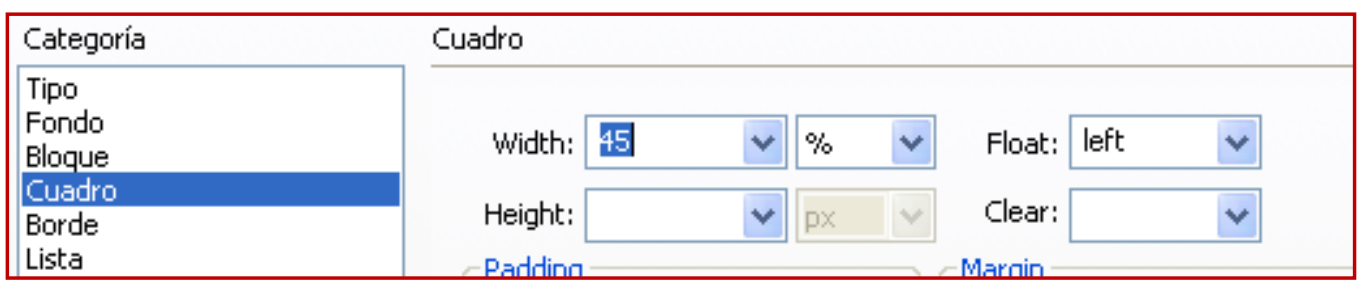

\section{Nueva regla CSS}

Tipo de selector:

Elija un tipo de selector contextual para la regla CSS.

ID (sólo es aplicable a un elemento HTML)

Cancelar

Nombre del selector:

Elija o introduzca un nombre para el selector.

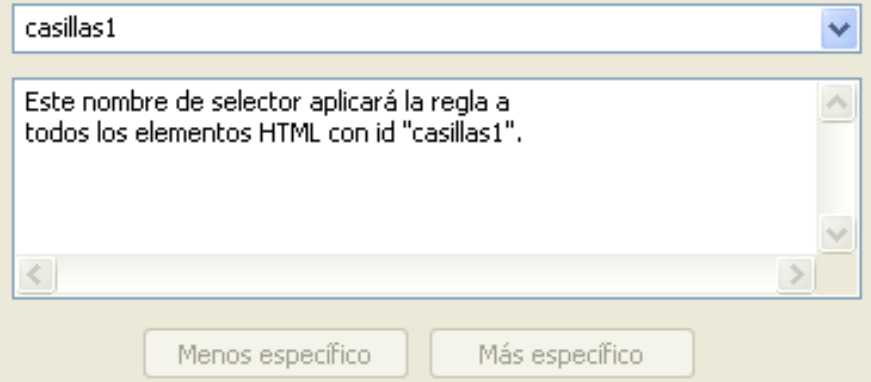

Definición de regla:

Elija dónde se va a definir la regla.

(Nuevo archivo de hoja de estilos) 


\section{Tutorial 7. Crear una página de contacto}

\section{Desarrollo del tutorial: paso 12 de 14}

Éste es el aspecto que tienen ahora las casillas de verificación de nuestro formulario.

Para los campos de nombre, correo electrónico y teléfono, vamos a hacer que los campos de texto queden alineados por la izquierda. Para ello, debemos hacer tres cosas:.

1. Crear una capa (con la etiqueta $<$ div $>$ ) que englobe los tres campos. Le pondremos como identificador campostext.

2. Crear una regla CSS para las etiquetas <label> de esa capa, para que floten a la izquierda y tengan un tamaño del $35 \%$ de la capa.

3. Crear una regla CSS para esa capa, para darle una altura de 8em y una anchura del $100 \%$.

Además, para mejorar la presentación, daremos un tamaño de 50 al campo nombre.

En las imágenes se puede ver el código resultante y las reglas CSS introducidas.

\begin{tabular}{|ll|}
\hline Teléfono: & \\
& \\
\hline Tipo de apartamento preferido \\
$\square$ Zona 1 bajo & $\square$ Zona 2 bajo \\
$\square$ Zona 1 piso & $\square$ Zona 2 piso \\
\hline & \\
Temporada: Otras & $\checkmark$ \\
\hline
\end{tabular}

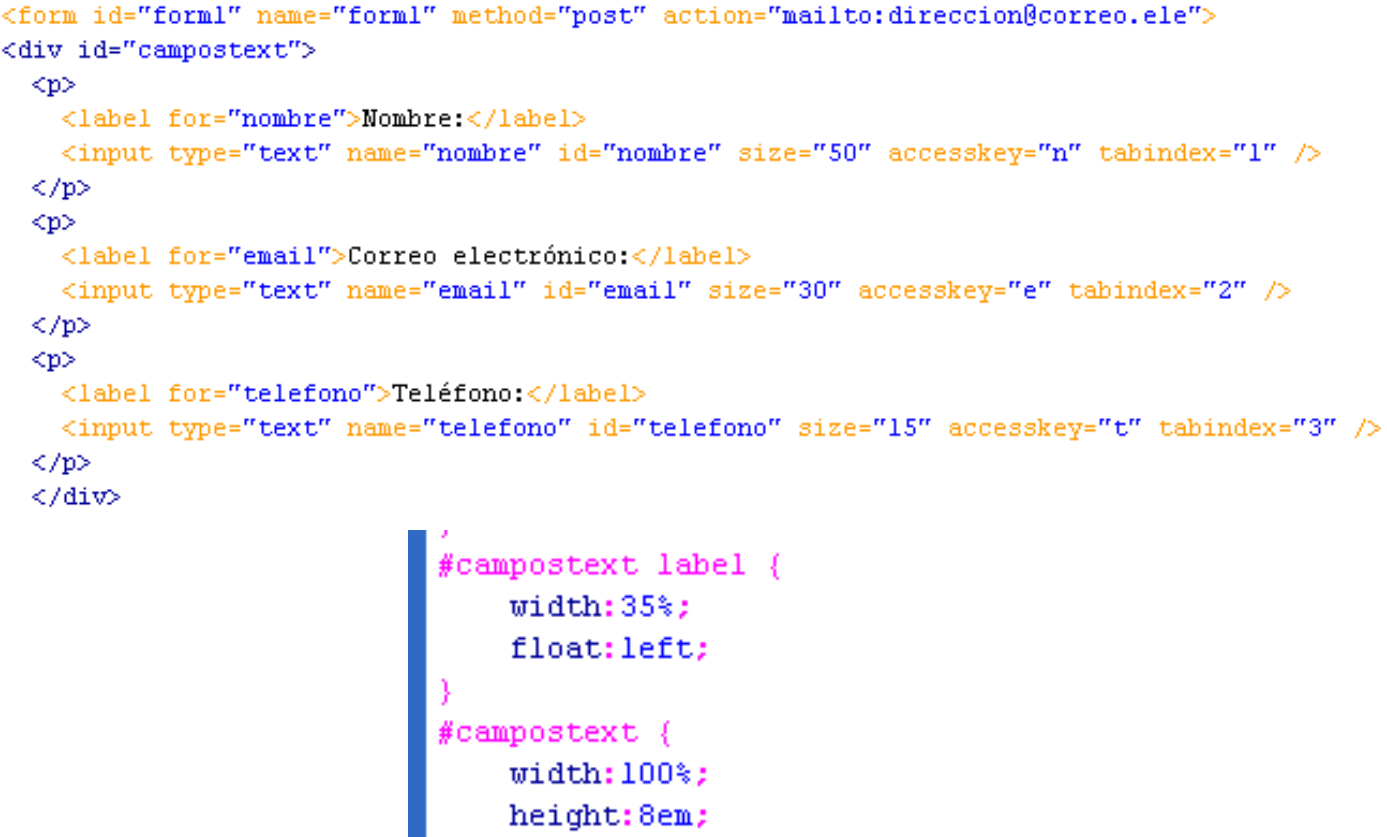




\section{Tutorial 7. Crear una página de contacto}

\section{Desarrollo del tutorial: paso 13 de 14}

Vamos a mejorar la accesibilidad de nuestro formulario. Hemos tenido en cuenta la accesibilidad siempre que Dreamweaver nos lo ha permitido, pero en las casillas de verificación no hemos podido asignar orden de tabulación (Índice de fichas según Dreamweaver). Tal como está ahora, si cambiamos de campo usando el tabulador, nos saltaremos las casillas de verificación. Por tanto, en vista de código, vamos a añadir los correspondientes atributos tabindex.




Tutorial 7. Crear una página de contacto

Desarrollo del tutorial: paso 14 de 14

Actividades complementarias:

- Utilizad la herramienta de Validar formato para validar el código XHTML de nuestra página. Aparecerá un error.

Solucionadlo.

- Añadid un nuevo campo:

- ¿Qué cambios hay que hacer en el código de los demás campos para que todo siga funcionando correctamente?

- ¿Y en el CSS?

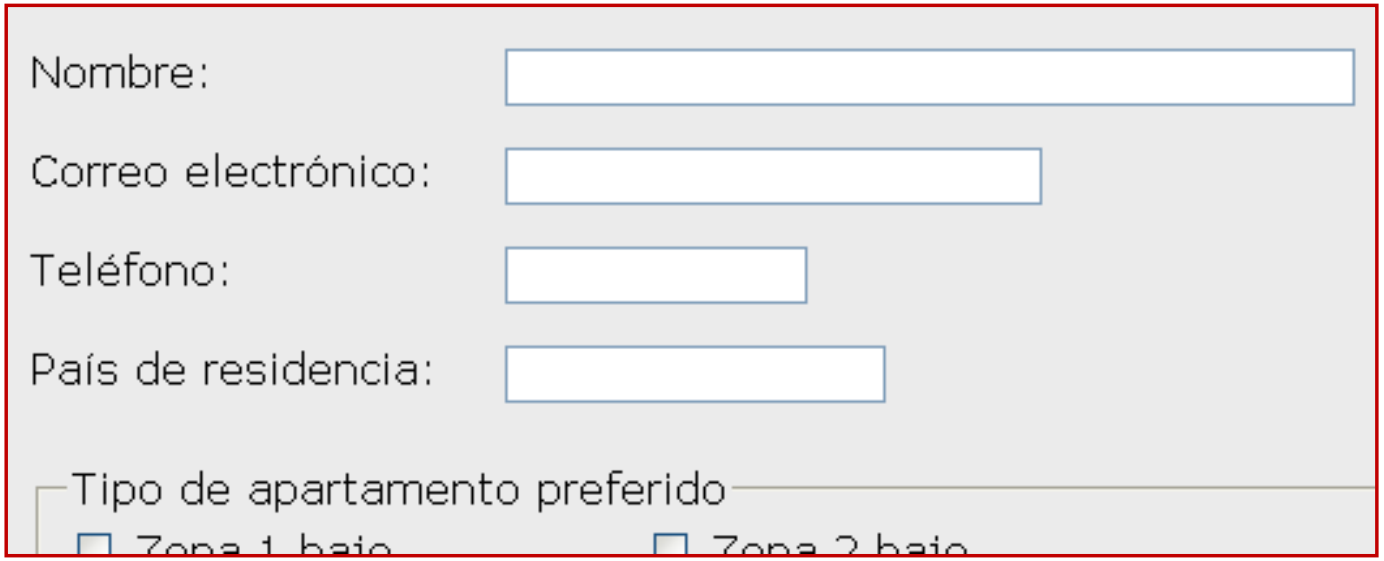

